\title{
Aluminum Spent Fuel Performance in Dry Storage Task 4 Aluminum Oxide Sampling of ATR Dry-Stored Fuel
}

Phil Winston, Task Lead Scott Middlemas TGA Alexander Winston, Sample Prep and SEM Analysis Jeff Aguiar, TEM/STEM Analysis Xiang Liu TEM Data Acquisition Kevin Tolman XRD

May 2020

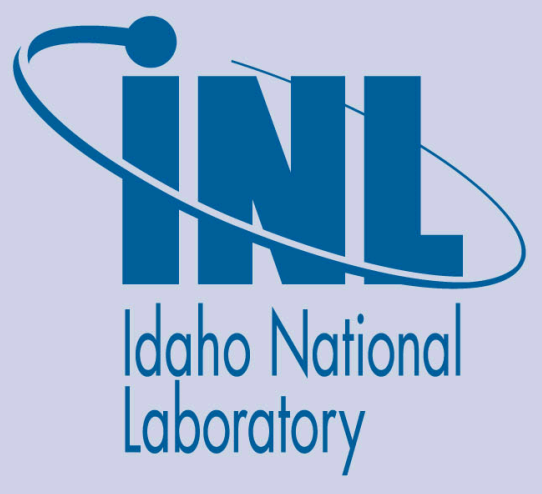

The INL is a U.S. Department of Energy National Laboratory operated by Battelle Energy Alliance 


\section{DISCLAIMER}

This information was prepared as an account of work sponsored by an agency of the U.S. Government. Neither the U.S. Government nor any agency thereof, nor any of their employees, makes any warranty, expressed or implied, or assumes any legal liability or responsibility for the accuracy, completeness, or usefulness, of any information, apparatus, product, or process disclosed, or represents that its use would not infringe privately owned rights. References herein to any specific commercial product, process, or service by trade name, trade mark, manufacturer, or otherwise, does not necessarily constitute or imply its endorsement, recommendation, or favoring by the U.S. Government or any agency thereof. The views and opinions of authors expressed herein do not necessarily state or reflect those of the U.S. Government or any agency thereof. 
INL/EXT-20-58404

Revision 0

\title{
Aluminum Spent Fuel Performance in Dry Storage Task 4 Aluminum Oxide Sampling of ATR Dry-Stored Fuel
}

\author{
Phil Winston, Task Lead \\ Scott Middlemas TGA Analysis \\ Alexander Winston, Sample Prep and SEM Analysis \\ Jatuporn Burns, TEM preparation \\ Kevin Tolman, X-ray Diffraction Analysis \\ Xiang Liu, TEM Data Collection \\ Jeffrey Aguiar, TEM Data Analysis
}

May 2020

Idaho National Laboratory

Idaho Falls, Idaho 83415

http://www.inl.gov

Prepared for the

U.S. Department of Energy

Office of Environmental Management

Under DOE Idaho Operations Office

Contract DE-AC07-05ID14517 



\title{
Aluminum Spent Fuel Performance in Dry Storage Task 4 \\ Aluminum Oxide Sampling of ATR Dry-Stored Fuel
}

\author{
INL/EXT-20-58404
}

Revision 0

May 2020

Approved by:

Philip L. Winston

Date

Editor/Author/Engineer

\section{Date}

Josh J. Jarrell

Used Fuel Relationship Manager, INL 


\section{SUMMARY}

To acquire information regarding the oxide surface composition of irradiated, pre-dry-storage aluminum fuels components, samples were taken from three long-term dry-stored Advanced Test Reactor (ATR) fuel elements at CPP-603. The samples taken included surface scrapings from the outer surface of Plate 19 on the fuel elements, as well as corners cut from the exposed upper ends of the fuel element side plates. The fuel had been removed from the reactor in 1985 and was stored in the CPP-603A wet storage basins until 1997, when it was moved into the CPP-603 Irradiated Fuel Storage Facility. Six samples were taken by scraping (two from each element) and 12 samples were taken by cutting (nipping) exposed side plate corners (four from each element). The scraped samples were obtained by linear surface removal typically over 24 inches of fuel assembly length using either two or three scraper points in the scraper module. The scraped sample product was 100-200 micron diameter and similar in consistency to that of coarse saw-cut fines. The scraped depth was approximately $0.4 \mathrm{~mm}$. The corner samples were taken using a pneumatically-driven metal nipper that cut a triangular sample approximately $10.6 \mathrm{~mm}$ ( 0.4 inches) along each side. The total thickness of the corner samples is nominally $9 \mathrm{~mm}(0.35$ inches).

Two of the corner (nipped) samples were mounted and polished for electron microscopy. Electron microscopy indicates an oxide layer of approximately 5 microns. Energy Dispersive Spectrometry analysis from Scanning Electron Microscopy compositionally confirmed that the oxide layers present on the samples were 2-6 microns thick.

X-Ray Diffraction (XRD) analysis was performed on two of the granular (scraped) samples. Results indicated the oxide layer present in the material was predominately $\mathrm{AlOOH}$ as boehmite.

Thermogravimetric Analysis (TGA) was done on two granular samples in five heating stages from 100 to $500^{\circ} \mathrm{C}$, and yielded indications that as much as a $7 \%$ mass change occurred during heating. The most significant change was noted in the intervals between temperatures 200 and $300^{\circ} \mathrm{C}$. Relatively lesser losses were noted between 300 and $500^{\circ} \mathrm{C}$.

The oxide thickness and compositional analysis of the corner samples were corroborated by Transmission Electron Microscope (TEM) and scanning transmission electron microscopic crystallographic analysis. TEM lamellae were prepared in the Focused Ion Beam (FIB) instrument. Only two nipped samples were analyzed. The consistency of the analytical results suggests these samples have oxide thickness and boehmite oxide composition consistent with those established by autoclave prior to irradiation.

The condition of the oxide layer indicates that limited change has occurred as a result of irradiation and at-reactor wet storage and subsequent dry storage. The highly visible oxide growths appear to correspond with locations where mechanical abrasion disrupted the pre-irradiation boehmite layer. The area and volume of these growths represents less than $1 \%$ of the fuel element, but absent explicit sampling and chemical evaluation of the non-native oxide, it would be speculative to estimate the associated sorbed water content, making it difficult to predict potential pressurization for a sealed dry canister system. It appears the 
non-native oxide is somewhat porous, meaning that if the fuel storage environment changes, these locations may be points where corrosion would be initiated.

Video images from the sampling operation indicate that the cut ends and locations where the elements were handled using a "friction tool" have retained the large white oxide blooms. Otherwise, the fuel elements have a neutral medium gray external appearance with little evidence of corrosive attack or surface alteration. The individual fuel plates are clearly visible through the side plate openings and show no sign of oxide alteration or damage. 


\section{ACKNOWLEDGEMENT}

Assistance from Andy Gray, Alan Olaveson, Craig Carlson, Caleb Maynard, and Gary Landon for help in validation of the sampling tools and acquiring the samples from the ATR fuel elements, Claude Kimball for contract logistics and video review support, Marcie Anderson and Shawn Tigue for coordinating shipment, Al Carlson for retrieving video footage, Mark Taylor for Electron Microscopy Laboratory receipt scheduling, and Joanne Grimmett for receiving and completing the inter-building laboratory transfers is gratefully acknowledged.

The work of Jatuporn Burns in acquiring the TEM lamellae is also greatly appreciated. 


\section{CONTENTS}

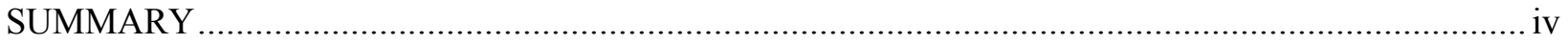

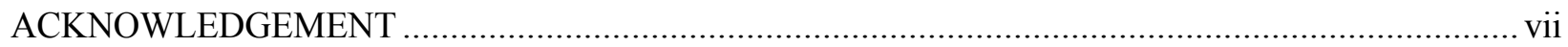

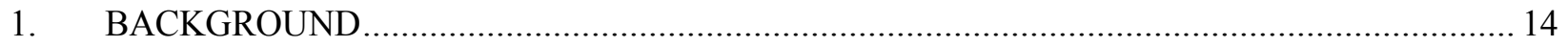

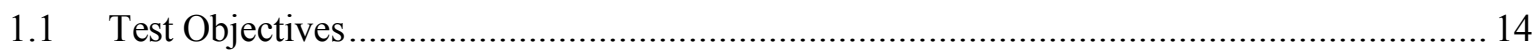

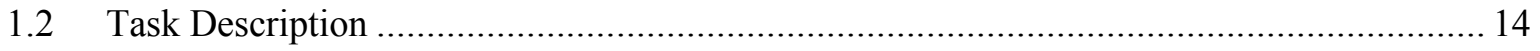

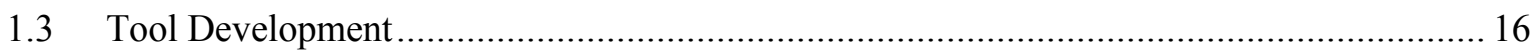

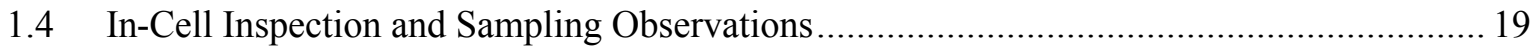

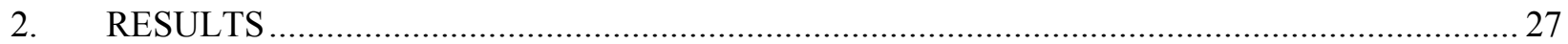

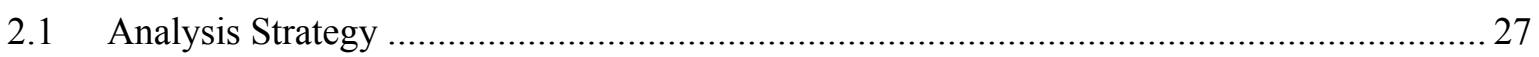

2.2 ATR Fuel Element Side Plate and Scraped Sample Methodology .................................. 28

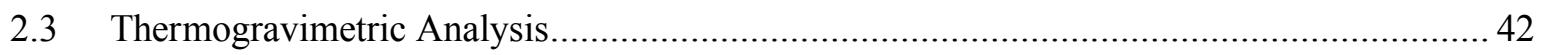

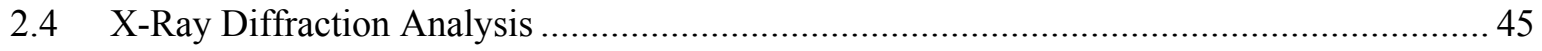

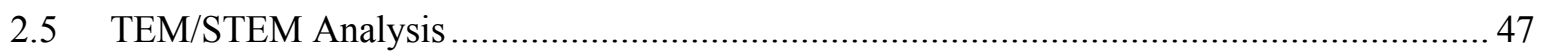

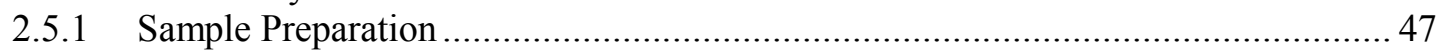

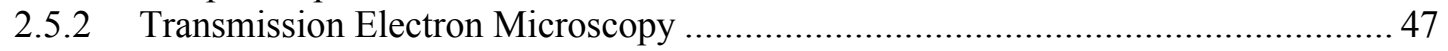

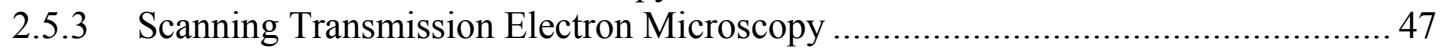

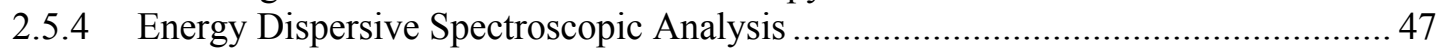

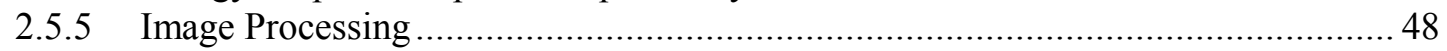

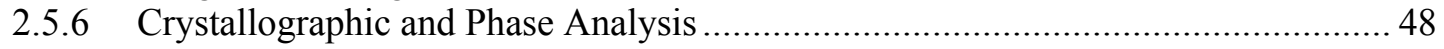

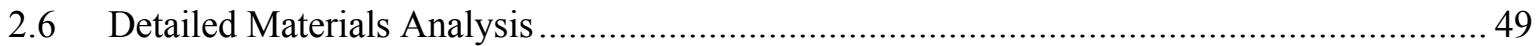

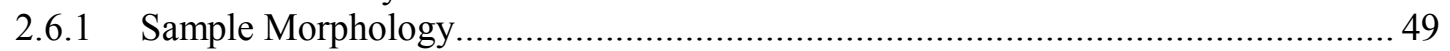

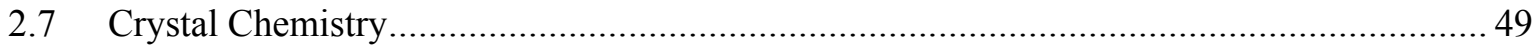

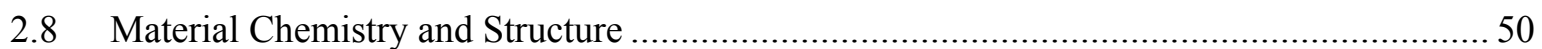

2.8.1 STEM Imaging and Mapping for Post A (Sample 3) ........................................... 51

2.8.2 STEM Imaging and Mapping for Post C (Sample 9) ........................................... 54

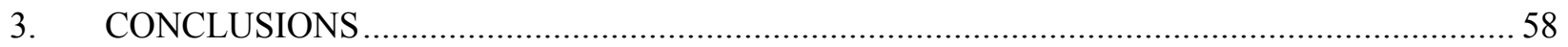

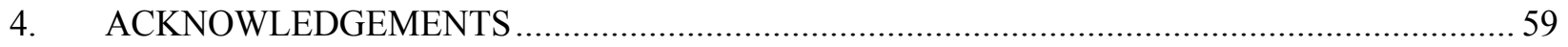




\section{FIGURES}

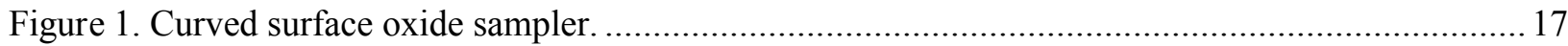

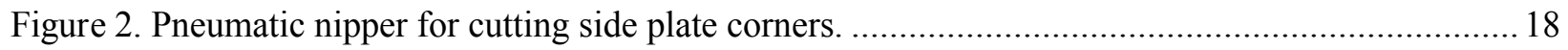

Figure 3. Capture from Sampling Video 8/25/2019 showing non-native oxide formation at

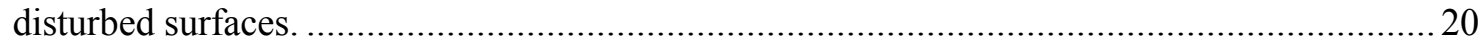

Figure 4. Closeup view of ATR Element lifted by side plate, showing corrosion around lift

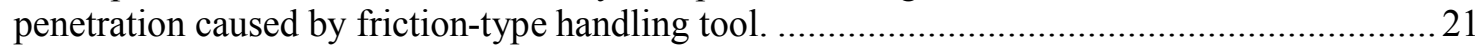

Figure 5. Side plate exposed, showing cut end corrosion and apparently unaffected side plate...............22

Figure 6. Comparison image of ATR Fuel in wet storage from 1997 transfer video............................. 23

Figure 7. Side plate of raised ATR Element showing side vents and apparently unaffected plates

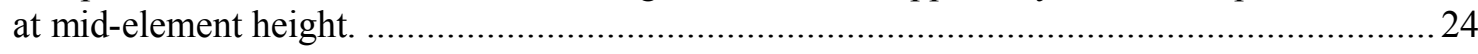

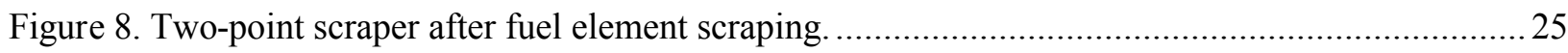

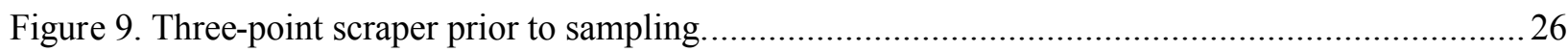

Figure 10. Collected granular and nipped samples in glovebox following receipt at EML....................29

Figure 11. Three-point sample scraper in EML glovebox following receipt at MFC ............................ 30

Figure 12. Nipped-corner samples showing variability in shape and size of acquired samples. ............... 30

Figure 13. Nipped-corner sample with serrated fuel plate side............................................................. 31

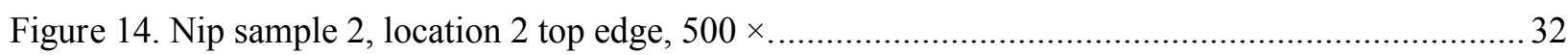

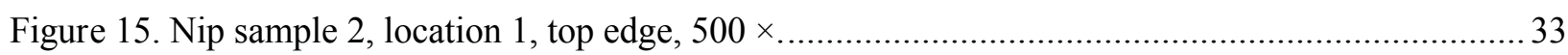

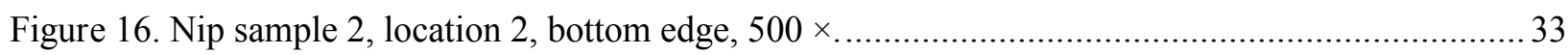

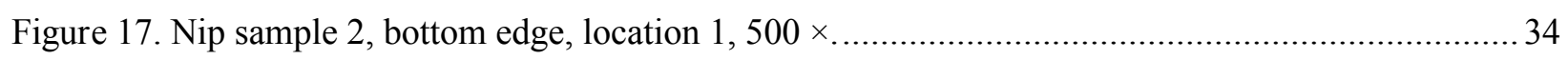

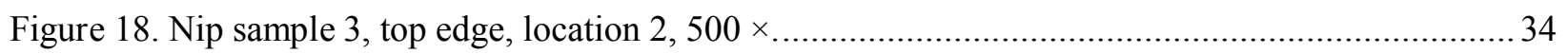

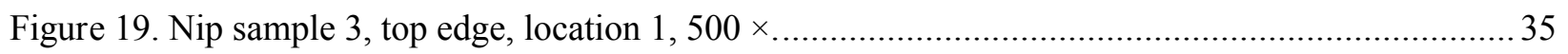

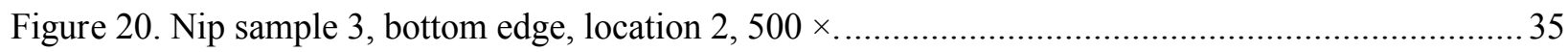

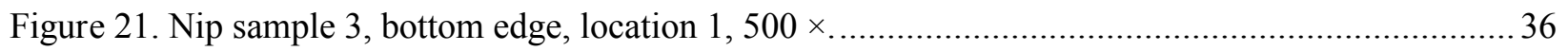

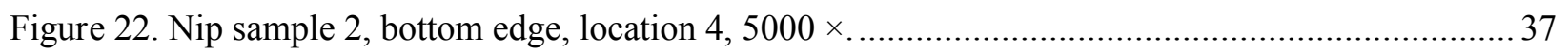

Figure 23. Nip sample 2, bottom, localized oxygen concentration (white area) .................................... 38

Figure 24. Nip sample 2, bottom, localized aluminum concentration (white area)................................ 39

Figure 25. Nip sample 2, bottom, location 4, iron localized iron concentration (white area).................. 40

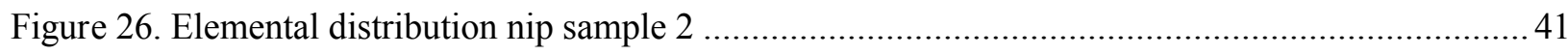

Figure 27. TGA run for scraped sample 2-1 percent change. ..................................................... 42

Figure 28. TGA run for scraped sample 2-1 mass change............................................................. 43

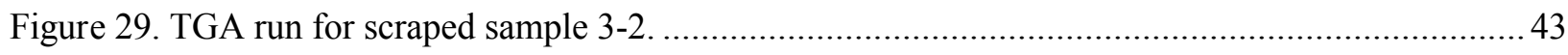

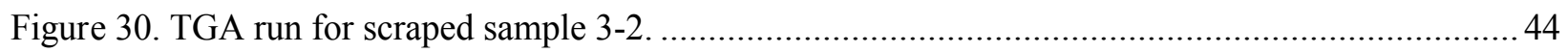

Figure 31. Graphical representation of TGA mass loss vs. temperature. ........................................... 45

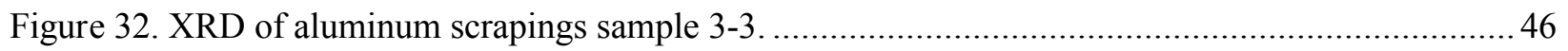


Figure 33. Overall Sample Morphology. (a, b) Cross-section sample areas for two separate regions, showing the overall oxide surface layering that forms on the Al base layer

Figure 34. Crystal chemistry phase identification. (a) Experimental XRD diffraction profile from Al cladding. (b) Analyzed diffraction profile based on known materials. Utilizing the latest trained crystal chemistry model, the same diffraction profile shows a high probability for (c) cubic followed by (d) hexagonal and (e) orthorhombic structure. Note within each of these crystal families reported the distribution is shown over space group.

Figure 35. STEM annular bright and dark field imaging identifying regions of interest. (a) Bright and (b) dark field cross-sectional imaging. The exposed surface layering, grain size distribution, and overall morphology are categorized as the surface, exposed layer, middle layer, and Al base metal.

Figure 36. Comparing grain size between the exposed and middle layer. (a) Grain size distribution for the exposed layer reports a highly nanocrystalline grain size with grains measuring less than $500 \mathrm{~nm}$ based on image segmentation of the (b) bright field STEM image. (c) Comparing to the middle layer (d) the distribution is significantly larger with on average grain size centered at $500 \mathrm{~nm}$ with tails to over $2 \mu \mathrm{m}$.

Figure 37. STEM-based imaging and EDS imaging. (a) Overview of STEM bright and (b) dark field image, where EDS mapping for (c) aluminum, (d) oxygen, (e) silicon, and (f) magnesium was mapped with better than $10 \mathrm{~nm}$ per pixel resolution.

Figure 38. STEM-based imaging to the sub-nanometer scale. (a) Overview STEM bright and (b) dark field images where a selective grain shows additional defects at the nanoscale. (c) Increasing the magnification to the sub-100 nm scale highlights a high degree of potential precipitation and texturing, including the presence of loops, line defects, and dislocations.

Figure 39. STEM-based imaging and EDS mapping for selective grain. (a) Overview of STEM bright and (b) dark field image, where EDS mapping for (c) aluminum, (d) oxygen, (e) silicon, and (f) magnesium over the grain. Note the grain was mapped with no better than $5 \mathrm{~nm}$ per pixel resolution.

Figure 40. STEM annular bright and dark field imaging identifying regions of interest. (a) Bright and (b) dark field cross-sectional imaging. The exposed surface layering, grain size distribution, and overall morphology are categorized as the surface, exposed layer, middle layer, and $\mathrm{Al}$ base metal.

Figure 41. STEM based imaging and EDS imaging. (a) Overview of STEM bright and (b) dark field image, where EDS mapping for (c) aluminum, (d) oxygen, (e) silicon, and (f) magnesium was mapped with better than $10 \mathrm{~nm}$ per pixel resolution. .55

Figure 42. STEM annular bright and dark field imaging identifying regions of interest. (a) Dark and (b) bright field cross-sectional imaging centered over the exposed surface layer. (c) Based on underlying grain size in the exposed surface layer, grains measuring less than $100 \mathrm{~nm}$ shown in (d) are consistent throughout.

Figure 43. STEM based imaging and EDS mapping over the exposed, middle and Al base metals. (a) Overview of STEM bright and (b) dark field image, where EDS mapping for (c) aluminum, (d) oxygen, (e) silicon, (f) magnesium, (g) platinum, (h) iron, and (i) chromium reveals the overall distribution. .56

Figure 44. STEM-based imaging and EDS over region 2. (a) Overview of STEM high-angle annular dark field of region 1, where over the area, (b) EDS mapping, (c) oxygen, (d) 
carbon, (e) aluminum, and (f) chromium were mapped with $1 \mathrm{~nm}$ pixel resolution. (g)

Overlapped element maps is superimposed over the area......

\section{Tables}

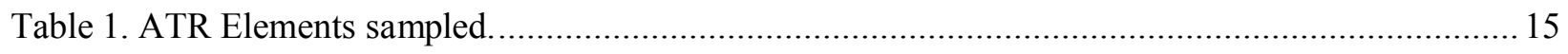

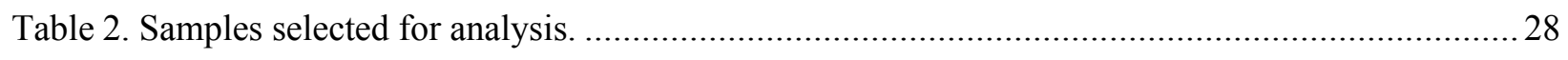

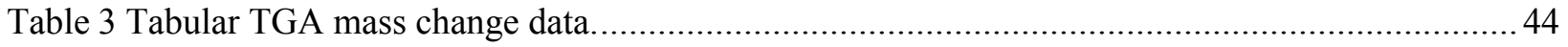




\section{ACRONYMS}

ASNF Aluminum-Clad Spent Nuclear Fuel

ATR Advanced Test Reactor

DTA Differential Thermal Analysis

EBSD Electron Backscatter Diffractometry

EDS Energy Dispersive Spectroscopy

EML Electron Microscopy Laboratory

FASB Fuels and Applied Science Building

FIB Focused Ion Beam

IMCL Irradiated Materials Characterization Laboratory

INTEC Idaho Nuclear Technology and Engineering Center (ex-Idaho Chemical Processing PlantICPP)

MFC Materials and Fuels Complex

PFIB Plasma Focused Ion Beam

SEM Scanning Electron Microscope/y

STEM Scanning Transmission Electron Microscopy

TEM Transmission Electron Microscopy

TGA Thermogravimetric Analysis

WDS Wavelength Dispersive Spectrometry

XRD X-ray Diffraction 


\section{BACKGROUND}

The activities performed in Task 4 are based on the recommendations by the Aluminum-Clad Spent Nuclear Fuel Sub Working Group, which were captured in the Aluminum Clad Spent Nuclear Fuel: Technical Considerations and Challenges for Extended (>50 Years) Dry Storage [1]. As identified in the 2017 report, Aluminum Clad Spent Nuclear Fuel Long Term Dry Storage Technical Issues Action PlanTechnical and Engineering Activities [2], the conditions experienced by irradiated aluminum test reactor fuels following drying and extended storage may lead to degradation of the fuel integrity. The stability of the passive aluminum oxide surface on the fuel plates and any chemisorbed or physisorbed water in that layer is a factor in corrosive breakdown of the fuel assembly. Radiolysis of water in oxyhydroxides like boehmite may lead to oxidative corrosion of the aluminum. Knowledge of the chemical composition of the passive oxide layer and its oxyhydroxide content following drying and storage in air in unsealed canisters will allow predictive models to be developed for extended storage. Visual examination and physical sampling will provide baseline data to direct further research into the outcome of ultimately putting the fuel into sealed canisters for final disposition. It is assumed that some additional characterization may be necessary at a later date to assure that unexpected phenomena do not create unacceptable levels of fuel element degradation.

Scanning transmission electron microscopy (STEM) will allow determination of the crystallography of potential stable and metastable phases including $\mathrm{AlO}, \mathrm{Al}_{2} \mathrm{O}, \mathrm{Al}_{2} \mathrm{O}_{3}, \mathrm{AlHO}_{2}, \mathrm{Al}_{5} \mathrm{HO}_{8}, \mathrm{Al}(\mathrm{HO})_{3}$, $\mathrm{AlO}(\mathrm{OH})$. Evaluation of the phase distribution at nanoscale resolution will be used to confirm the chemistry and structure of potentially mixed phases present following irradiation and storage.

\subsection{Test Objectives}

This report covers the Task 4 secondary objective, which was to determine oxyhydroxide film thickness and composition of spent aluminum research reactor fuel following drying and vented canister storage in support of Task 1 . The initial task evaluated oxide thickness on discarded irradiated end adapters from ATR fuel elements that had been stored in the ATR canal following being cut off the element. This task addresses acquisition of samples from the complementary side plate and plate 19 fuel element components. Solid samples are to be cut off of the fuel side plates which correspond to the point from which the end adapters were cut, and granular samples are to be acquired by scraping off a layer of aluminum metal and oxide from the outer convex fueled plate (Plate 19). The choice for sampling this plate is based on the fact that Plate 19 is accessible and has a clad thickness of 0.040 inches versus that of 0.015 inches for the remaining plates, minimizing the chance of inadvertently penetrating the clad.

Once samples were acquired, they were analyzed using SEM to evaluate oxide thickness, XRD and TEM to determine crystallographic and chemical composition to determine the oxide type, and TGA to determine the sample dehydration response.

A graphic showing the typical ATR Element geometry is included as Appendix E.

\subsection{Task Description}

The task was to acquire samples from post-irradiation, long-term dry-stored aluminum components that could be readily transferred to a laboratory for oxide characterization. To achieve this, it was necessary to develop a sampling technique to scrape surface oxide and to cut corners from the exposed ATR element side plates. It was necessary to develop tools and a procedure for retrieval of ATR fuel elements from a CPP-603 Irradiated Fuel Storage Facility (IFSF) canister.

The following ATR elements with extended duration both in wet and dry storage were identified as sampling candidates and are listed in Table 1. All of the elements were similar in burnup and history, and were located in the same fuel bucket, simplifying handling. 
Table 1. ATR Elements Sampled.

\begin{tabular}{|c|c|c|c|c|}
\hline $\begin{array}{c}\text { Fuel Element/ } \\
\text { Serial Number }\end{array}$ & Fuel Location & $\begin{array}{c}\text { Fuel } \\
\text { Piece/Thermal } \\
\text { Power (watt) } \\
\text { As of 4/6/04 }\end{array}$ & $\begin{array}{c}\text { Fuel Piece/Date } \\
\text { Received IFSF } \\
\text { Dry Storage }\end{array}$ & $\begin{array}{c}\text { Fuel Piece/Date } \\
\text { Received ICPP } \\
\text { CPP-603 A Wet } \\
\text { Storage }\end{array}$ \\
\hline XA425N & BU-GSF-ATR8-14 & 10.63 & $3 / 21 / 98$ & $7 / 8 / 85$ \\
\hline XA507N & BU-GSF-ATR8-14 & 11.01 & $3 / 21 / 98$ & $7 / 9 / 85$ \\
\hline XA508N & BU-GSF-ATR8-14 & 10.54 & $3 / 21 / 98$ & $7 / 9 / 85$ \\
\hline
\end{tabular}




\subsection{Tool Development}

The tools conceived to perform the sampling included a multipoint scraper that would acquire samples along the length of the face of the outer convex exposed Plate 19 using either two or three tubular cutting edge sample points, and a corner nipper that cut a small triangular section from the corner of the upper end of the exposed side plate. The rectangular external frame of the scraper incorporates rollers canted at a 22.5 degree angle that contact the side plates and constrain the fuel plate as it is lowered through the frame, ensuring consistent orientation of the element as it passes through the scrapers. The scraper points are angled at approximately two degrees from vertical so that the lower edge of the tube contacts the plate and collects the sample. The scraper points are loaded into a block that is spring loaded to allow uniform contact with the surface. The use of two and three-point scrapers allowed retrieval of two sets of sample material from the Plate 19 surface from different lines along the axis. Three-point scrapers tracked a line along the midpoint and two lines approximately one inch inboard of the side plates. Two-point scrapers tracked on lines between the middle and outboard lines sampled by the three-point. Figure 1 shows the scraper frame with a three-point scraper module installed.

The corner sampler is a mechanical nipper, normally a manually-operated tool for cutting ductile metal. The nipper was modified to be operated by a pneumatically-driven Acme-thread screw to close the jaws. Figure 2 shows the nipper during mockup testing.

To enable retrieval of the fuel from the storage bucket for sampling, a grip tool was developed to allow the side plates to be contacted and the fuel element lifted. The grip tool was constructed from a Vise-Grip-type locking plier with flat plate grip normally used in handling sheet metal. The grip plate was extended to allow deeper reach into the fuel storage bucket to clamp onto the side plate.

The initial tool design effort was intended to use a previous design that used a hook that engaged the fuel element below the top plate spacer (comb) that spans the fuel plate to assure uniform position. This design was vetoed by Idaho Nuclear Technology and Engineering Center (INTEC) Operations personnel because friction tools were used to handle fuel in CPP-603 wet storage operation. Friction tools were made with a flat blade screwdriver mounted on a 20 -foot pole. The blade was forced into the gap between fuel plates, distorting the plates, and allowing the fuel element to be picked up due to the friction between the blade and the bent plates. INTEC personnel believed that, when handling fuel elements whose plates had been distorted by handling with the a friction tool, it would be likely that the hook could become wedged between the plates where the friction tool had distorted them, making it impossible to remove, or have problems assuring that it engaged the comb completely.

The grip tools were staged on a tray that held the scraper and nipping tools positioned on top of the fuel storage bucket. The tray had a cutout that allowed access to one fuel element at a time, and could be rotated to align with the position of interest. Being able to position the tray was important because the "Lazy Susan" pedestal supporting the bucket in the canister did not work properly. The tray was intended to minimize the chance of dropping tools or other material into the bucket during fuel handling.

The images below show the tools during the prototype phase of testing, which included validation for remote hot cell operation. 


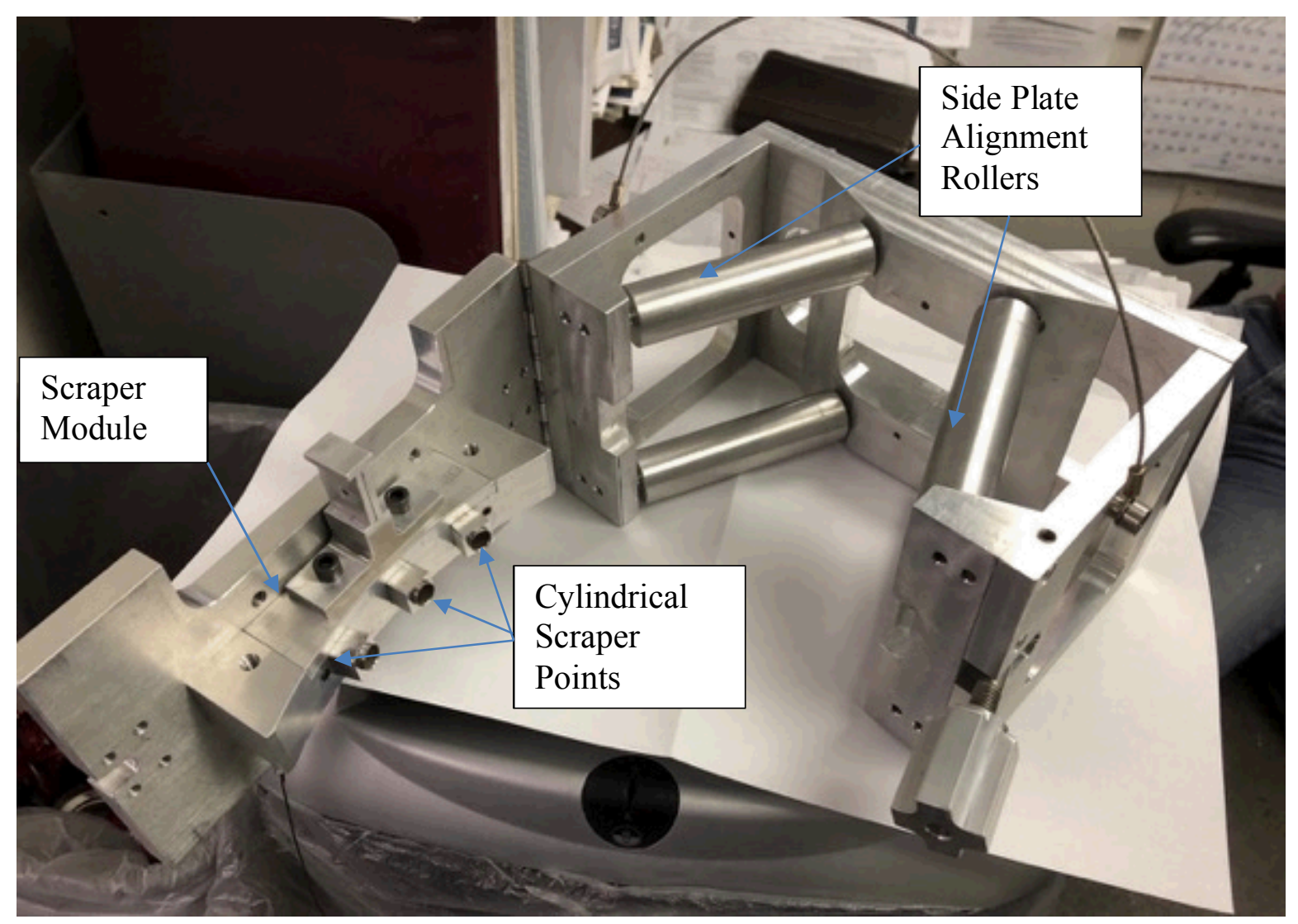

Figure 1. Curved surface oxide sampler. 


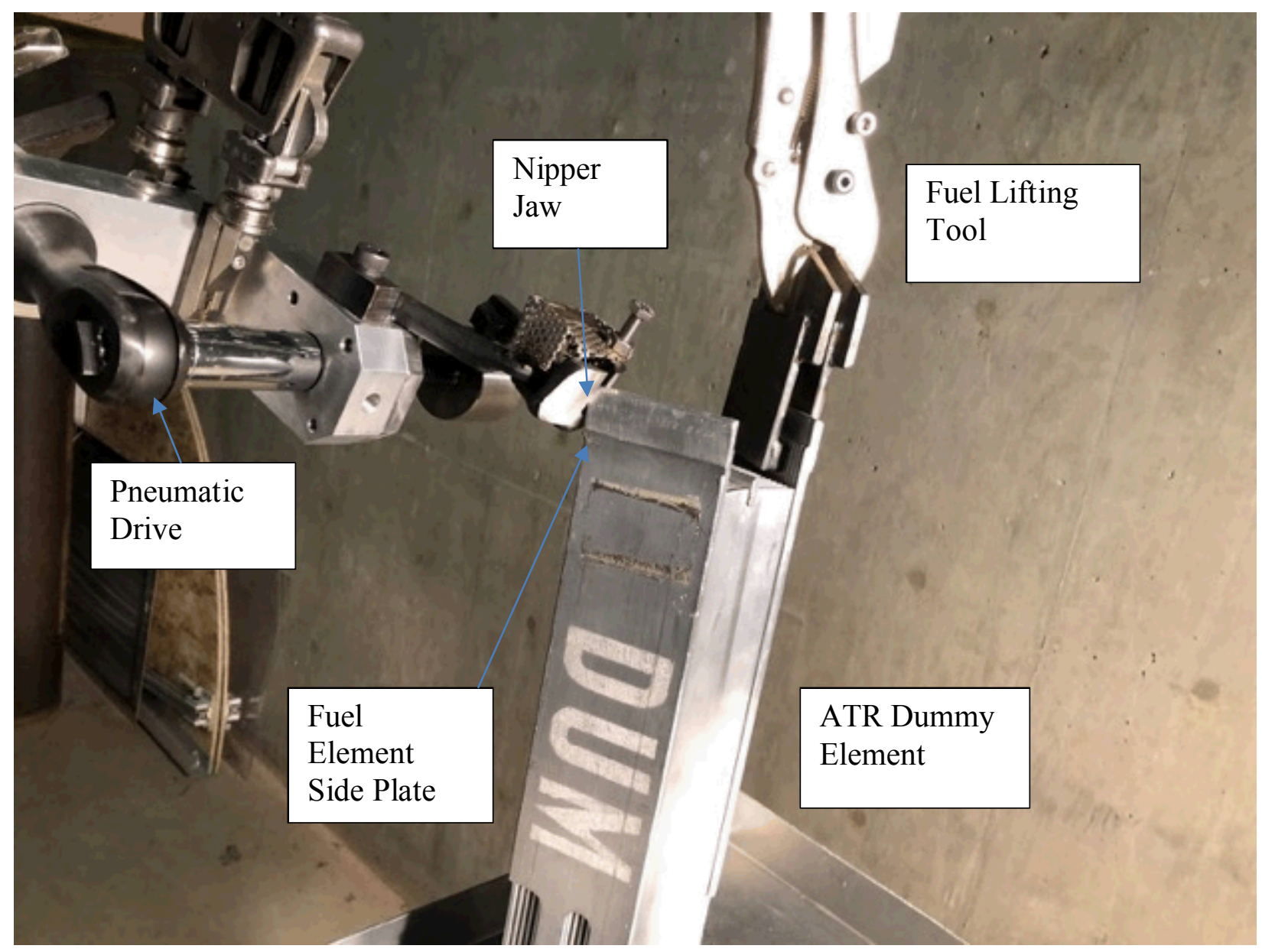

Figure 2. Pneumatic nipper for cutting side plate corners. 


\subsection{In-Cell Inspection and Sampling Observations}

The following images are taken from the video cameras used to support sampling and inspection operations that are located inside the CPP-603 Fuel Handling Cave. The cameras are typical CCTV surveillance cameras, meaning they are not specifically high-resolution image devices. The cameras are able to zoom in optically to a fairly high magnification, but due to the radiation levels in the cell, the cameras register some gamma noise "snow when positioned close to a source." Although they are mounted on movable arms at the perimeter of the cell, there is some loss of image quality because of their distance from the subject. The entirety of the sampling effort was recorded digitally, and is available in avi file format for those interested in viewing the process evolution.

Operationally, the task was to bring the desired canister with the bucket of interest into the Fuel Handling Cave and stage it on an elevated pedestal with a "Lazy Susan" base that allowed the bucket to be rotated to the desired position. Undue friction in the "Lazy Susan" meant that operations were limited to sampling at the angle of the bucket position available rather than being able to rotate the sampler to face the window, which was the orientation that was practiced during mockup testing.

The three fuel elements sampled were observed to be uniformly intact, being readily lifted as a single unit. There was no indication of loose fuel plates, or that the side plates were likely to separate, resulting in a splayed element. During the second scrape sampling operation, the in-cell tool that linked the crane hoist to the vise-grip tool attached to the fuel was inadvertently detached, allowing the fuel and tool to fall approximately 2 feet back into the bucket. The vise-grip tool was reattached to the crane using a sling, the fuel was raised back up to sampling position, and the remaining scraping operation was completed without incident.

The non-native oxide "bloom" that appears at points where mechanical distortion or abrasion occurred was not tested to determine how securely it was adhered, but it does not appear to have changed significantly between the time the fuel was removed from the CPP-603 basin (1997) and the time of sampling (2019). In comparative terms, it appeared that the bloom identified at the friction tool insertion point clearly spans two fuel plates and the gap between them for a width of approximately 0.180 inches. (Plate width + gap width + second plate; $0.050+0.077+0.050=0.177$ in). The edge of the same element where the end box was cut off appeared to have as much as 0.1 inch additional oxide growth on the exposed end. No specific effort was made to collect non-native oxide samples. Figures 3, 4, and 5 are video captures of the surfaces of the elements sampled, showing the localized non-native oxide formations. Figure 6 is a video capture from underwater fuel handling in 1997 that shows a similar oxide bloom visible on the fuel, presumably formed in the CPP-603 wet storage basin. Figure 7 shows the unobstructed fuel plates through the side-plate vent. Figures 8 and 9 show the scraper tool as deployed in the CPP-603 Fuel Handling Cave. 


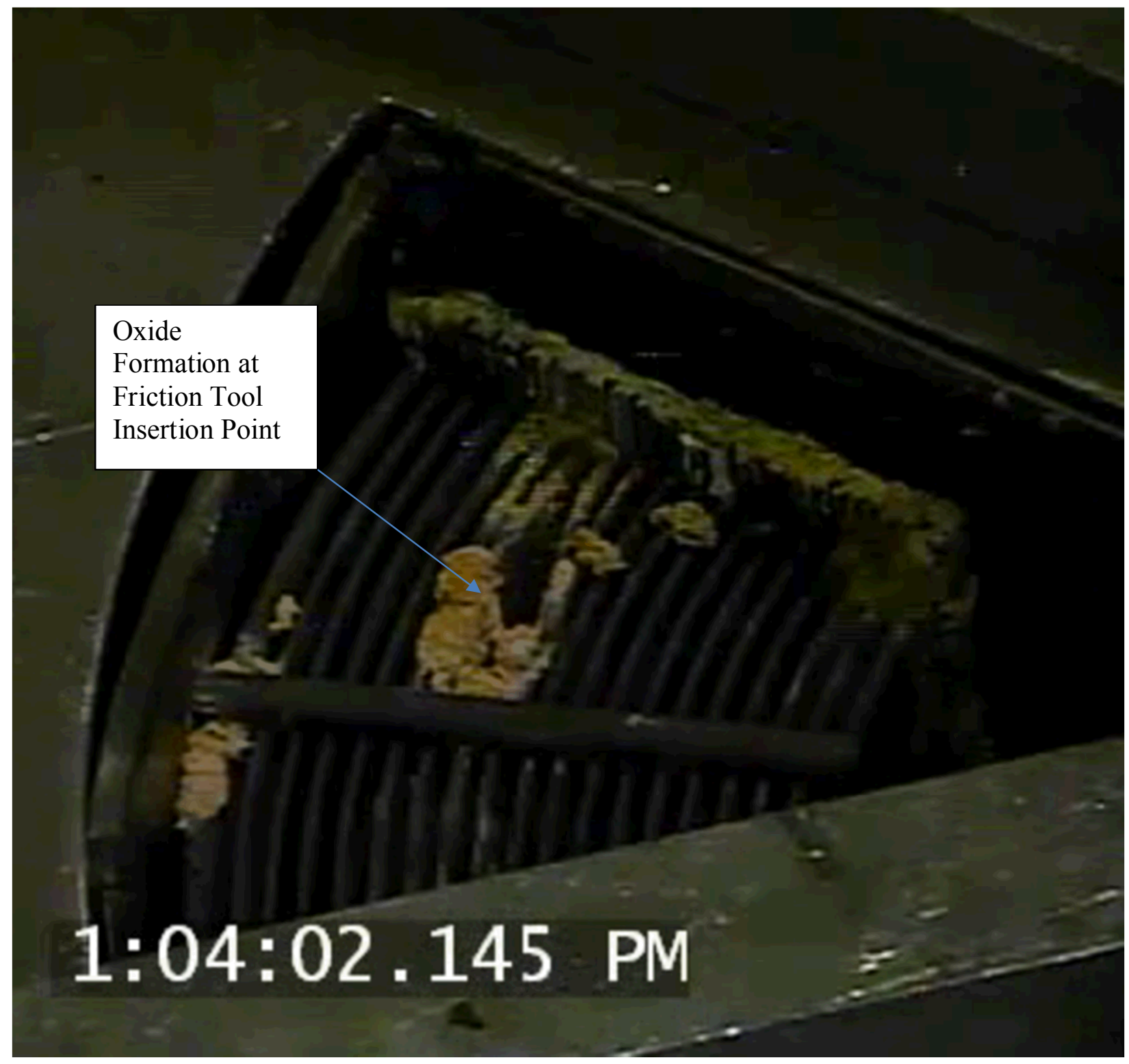

Figure 3. Capture from Sampling Video 8/25/2019 showing non-native oxide formation at disturbed surfaces. 


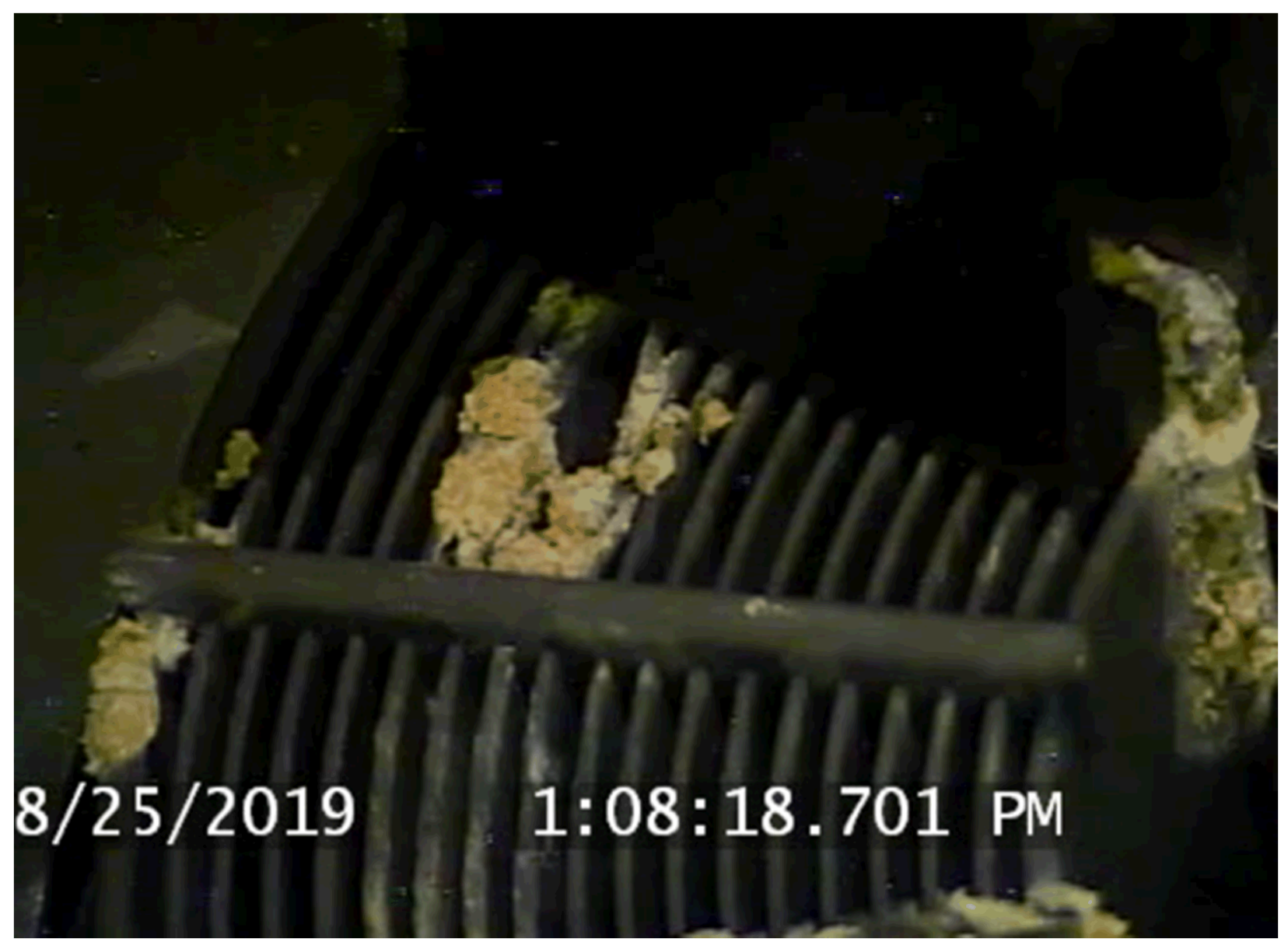

Figure 4. Closeup view of ATR Element lifted by side plate, showing corrosion around lift penetration caused by friction-type handling tool. 


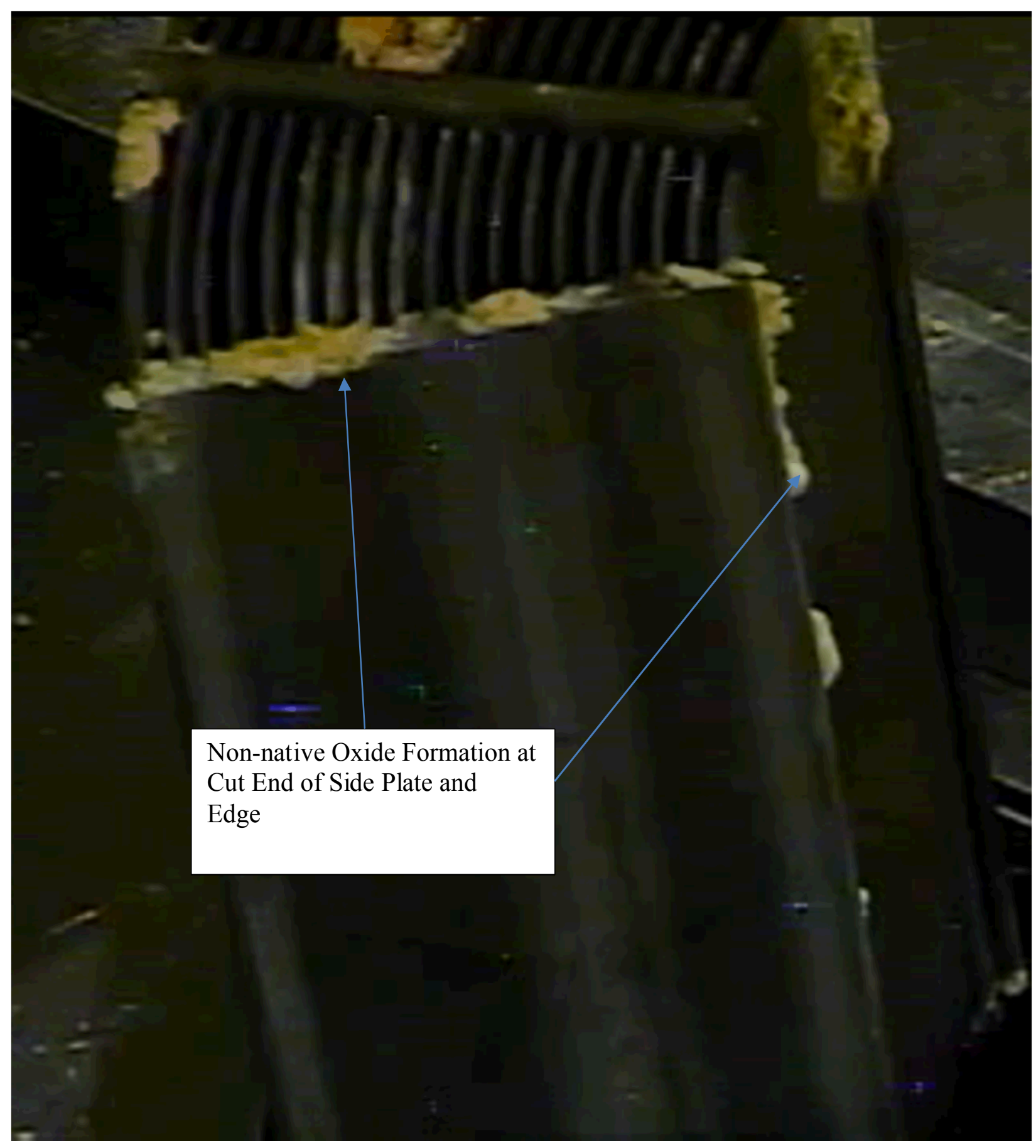

Figure 5. Side plate exposed, showing cut end corrosion and apparently unaffected side plate. 


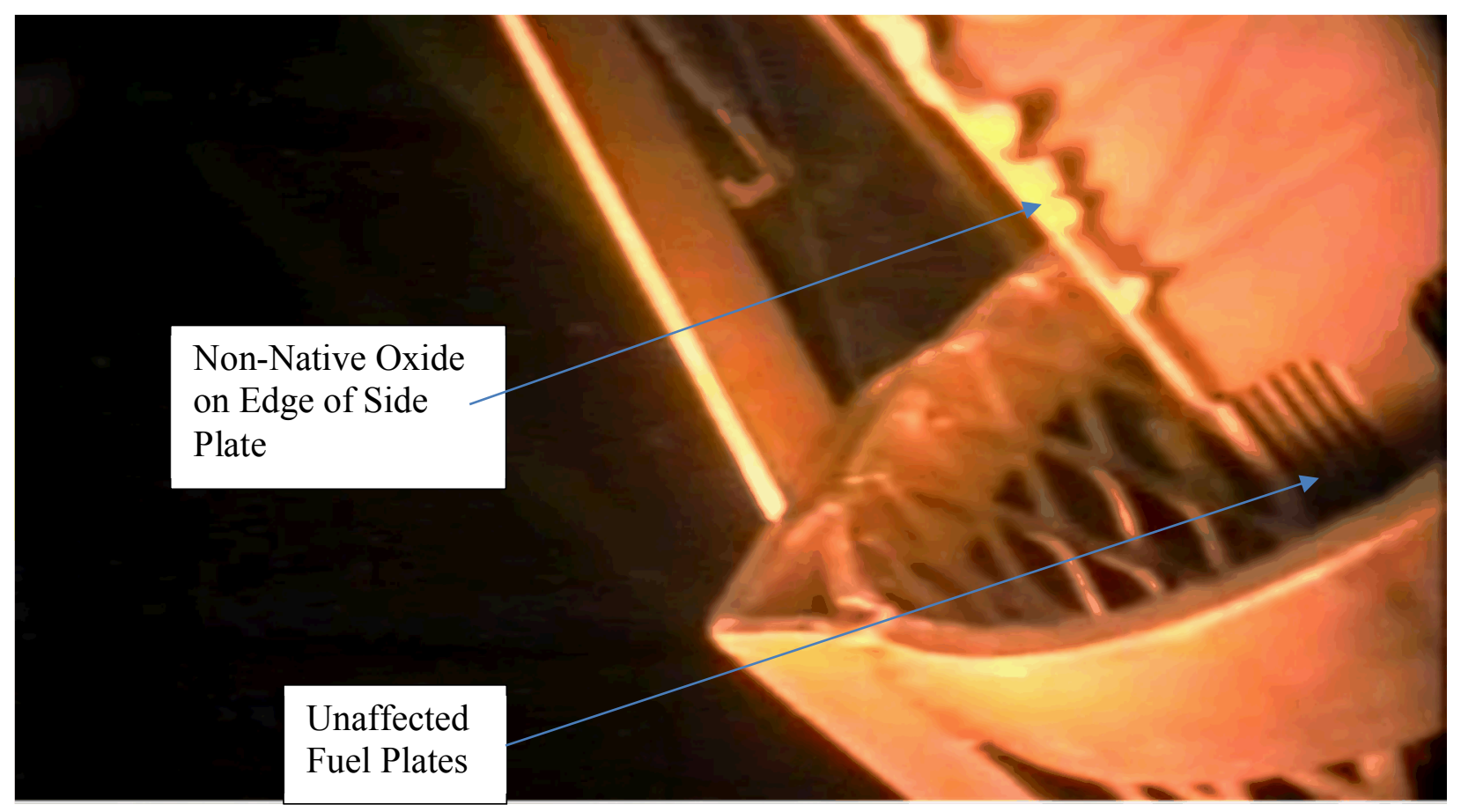

Figure 6. Comparison image of ATR Fuel in wet storage from 1997 wet to dry transfer video. 


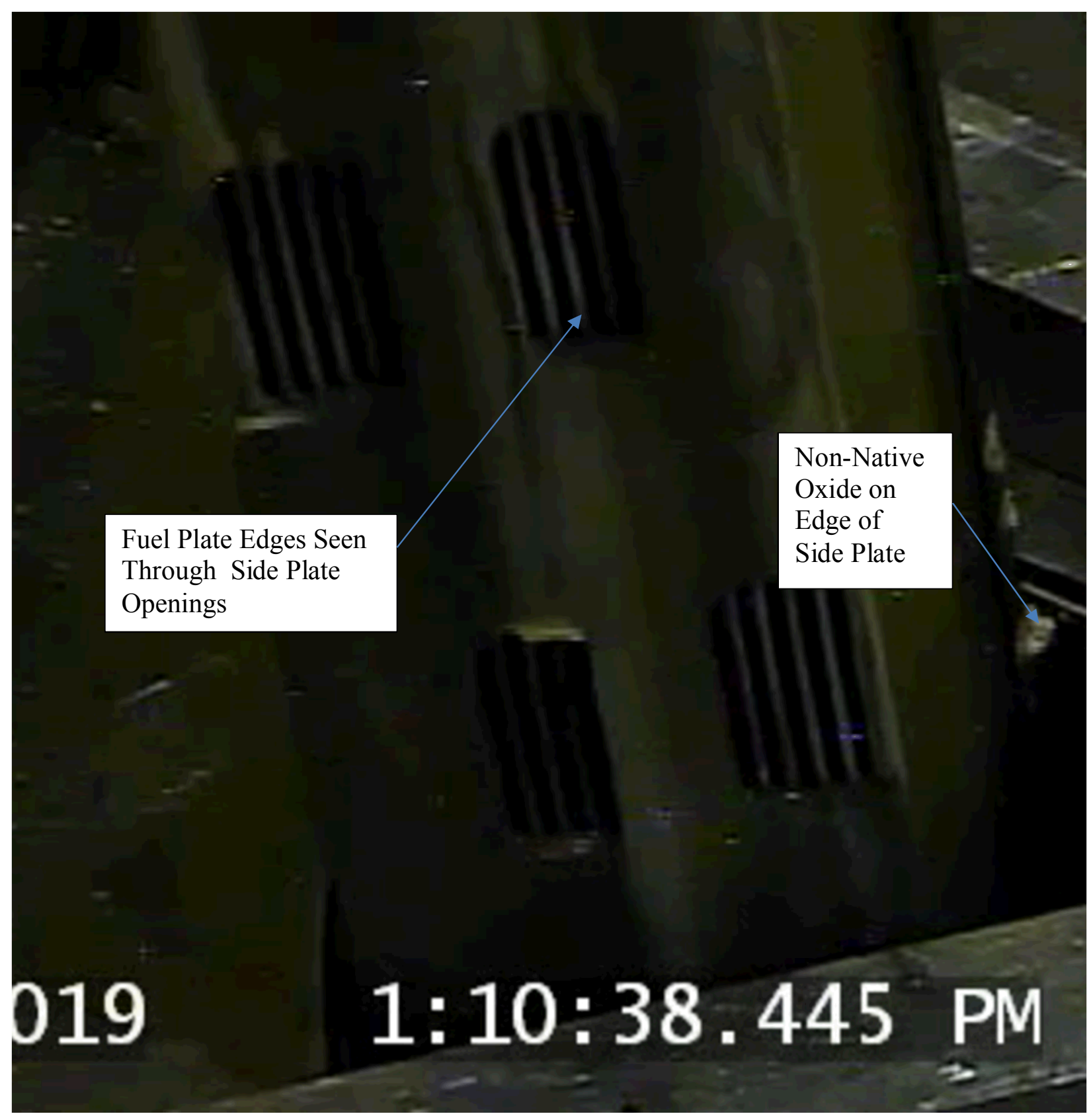

Figure 7. Side plate of raised ATR element showing side vents and apparently unaffected plates at midelement height. 


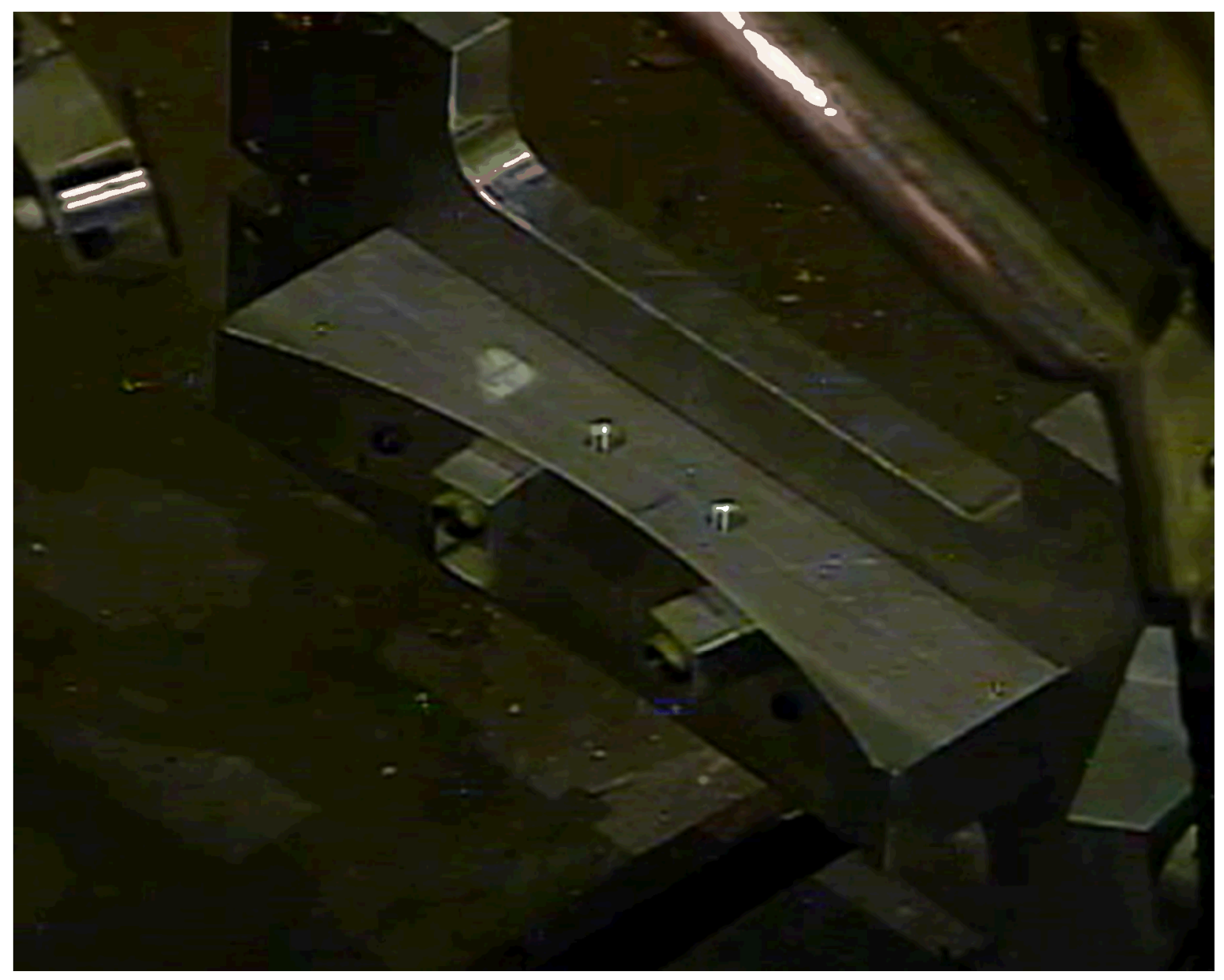

Figure 8. Two-point scraper after fuel element scraping. 


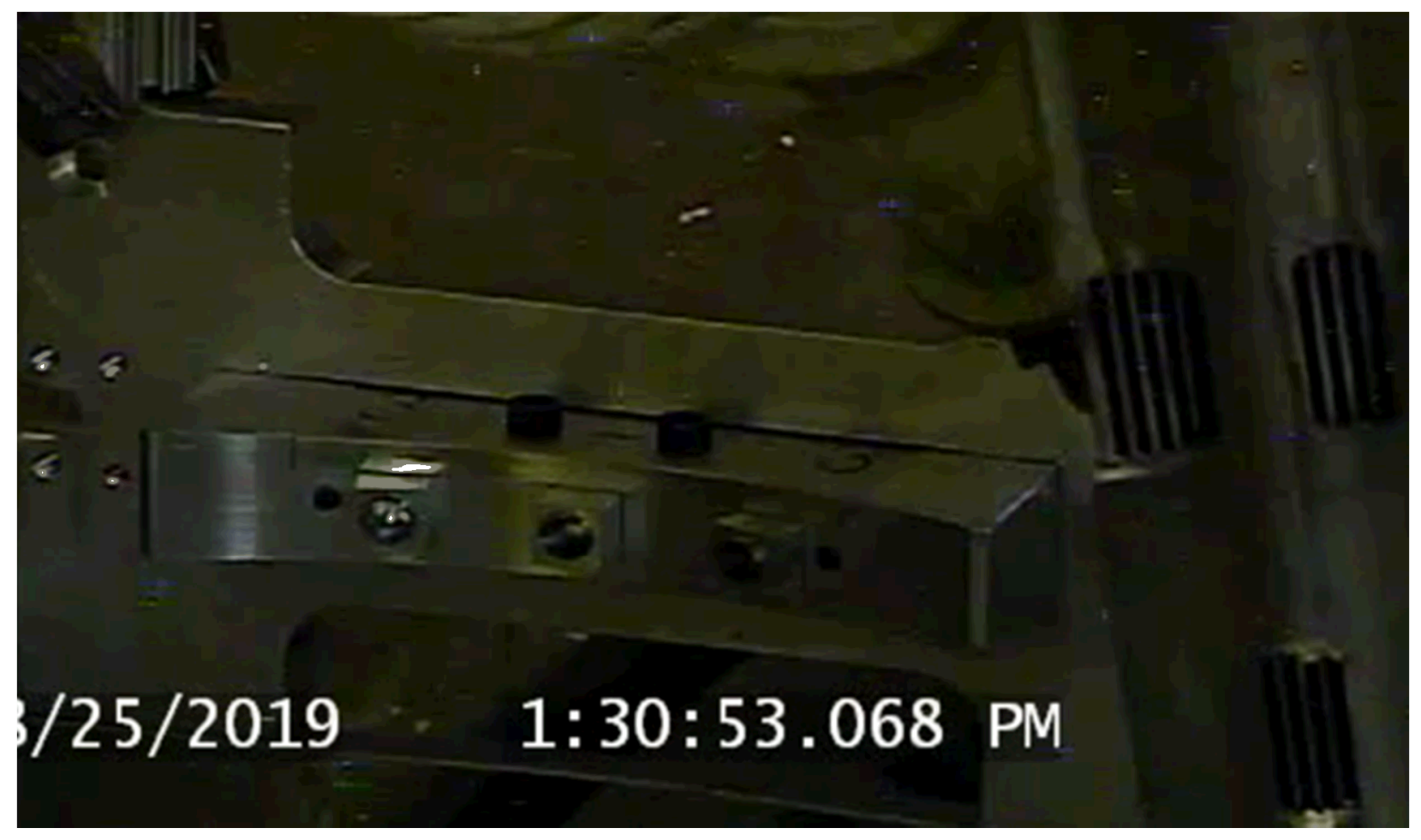

Figure 9. Three-point scraper prior to sampling. 


\section{RESULTS}

\subsection{Analysis Strategy}

Since there was some uncertainty about the ease with which any single analysis method would be able to detect the surface hydrated oxide species of interest, five methods were chosen to characterize the aluminum end box samples. These analyses included: (1) Scanning Electron Microscope (SEM); (2) Xray Diffraction (XRD); (4) Transmission Electron Microscope (TEM); and (5) Thermogravimetric Analysis (TGA). Use of these multiple techniques can also provide validation of data between analytical methods.

SEM provides visualization of the sample surface characteristics as well as the underlying chemical characteristics using Energy Dispersive Spectroscopy (EDS) and Wavelength Dispersive Spectroscopy (WDS) to determine the presence of specific elemental constituents. EDS gives the bulk metal alloy constituents, which is important to confirm that the samples are ASTM A6061 alloy, and representative of the main structure of the fuel assembly. By taking a series of EDS measurements across the depth of a horizontal cross section of sample, it is possible to detect the transition between bulk metal and surface oxide. Samples used for evaluating this transition are mounted in epoxy and carefully polished to expose the edge for EDS traverse measurements.

A Focused Ion Beam (FIB) instrument uses gallium or xenon ions to mill a trench into the sample surface for the purpose of acquiring a thin section appropriate for TEM.

XRD uses an incident X-ray beam to scan the sample surface and detect various specific crystallographic forms that can be correlated to the structure and chemistry that may be present. Macro XRD accommodates a sample size of approximately $6 \mathrm{~mm}$ by $6 \mathrm{~mm}$ and can penetrate an oxide thickness in excess of 100 microns. The sample size allows measurement of a comparatively large area, so as to avoid identifying a small artifact that may not be representative of the total sample. Micro XRD can be used to characterize thin oxide layers by using a less intense, but more focused X-ray source on the order of a few microns.

TEM can be used to determine composition of thin section samples that have been machined from the bulk using the FIB technique. Diffraction patterns generated as the electron beam passes through the sample provide a means to scan through the depth of the sample to determine changes in composition, crystallography, and oxide morphology. This will allow determination of whether the oxide present is boehmite, gibbsite, or another oxyhydroxide.

In Thermogravimetric Analysis (TGA), the sample is placed on an ultra-precise balance within an isolation volume that can be filled with inert gas (or air) and heated to drive off volatile species. Monitoring the mass change as the sample is brought to progressively higher temperatures and held at those temperatures for a specified time allows detection of release of waters of hydration. This measurement emulates the process that may be used for drying aluminum spent fuel and provides insight into the effects of elevated temperature drying. 


\subsection{ATR Fuel Element Side Plate and Scraped Sample Methodology}

To acquire information regarding the oxide surface composition of irradiated, pre-dry-storage aluminum fuels components, samples were taken from three long-term dry-stored ATR fuel elements at CPP-603. The samples taken included surface scrapings from the outer surface of Plate 19 on the fuel elements, as well as corners cut from the exposed upper ends of the fuel element side plates. The fuel had been removed from the reactor in 1985 and was stored in the CPP-603A wet storage basins until 1997 , when it was moved into the CPP-603B Irradiated Fuel Storage Facility. The scraped samples were acquired by linear surface removal over typically 24 inches of fuel assembly length with a scraper penetrating approximately 50 microns into the surface using either two or three scraper points in the scraper module. The corner samples were taken using a remotely-operated nipper that cut a triangular sample approximately $10.6 \mathrm{~mm}$ ( 0.4 inches) along each side. The thickness of the corner samples is nominally $9 \mathrm{~mm}$ ( 0.35 inches).

In total, six samples were taken by scraping and 12 samples were taken by cutting corners from three different elements. Because the task was performed using remote manipulator technology, there was some non-uniformity in success. In at least one instance, a two-point scraper was installed in an inverted orientation, resulting in no sample being acquired. The three-point scrapers were more consistently able to acquire samples. Corner samples varied based on the operators' ability to position the nipper, and the height of the exposed side plate. Side plate height above the fuel plates is inconsistent due to variations in the process of cutting off the end boxes underwater at the reactor in the ATR canal prior to shipment to CPP/INTEC.

Following sample acquisition, the individual pieces and scrapers were placed in a 2-gallon bucket inside a DOT-7A drum for shipping from INTEC to the Material and Fuels Complex (MFC). The samples were received in the Electron Microscopy Laboratory (EML), where the granular material from the multipoint scrapers was consolidated in glass V-vials and the nipped samples were inspected.

Once instrument time was available, $2 \mathrm{~mm} \times 2 \mathrm{~mm}$ square subsamples of nipped samples 2,3 , and 9 were mounted in epoxy, polished, and coated for SEM evaluation of oxide thickness.

Two of the V-vials containing granular samples (2-1 and 3-2) were transferred to the MFC Analytical Laboratory, where they underwent TGA analysis for determination of dehydration response.

Two of the V-vials (3-3 and 2-3) were sent to the Fuels and Applied Science Building (FASB) for XRD analysis.

Two of the remaining nipped samples ( 3 and 9) had TEM lamellae removed from their flat surfaces which were eventually able to be transferred to the Irradiated Materials Characterization Laboratory (IMCL) for Transmission Electron Microscopy analysis. Table 2 lists the samples selected for analysis.

Table 2. Samples selected for analysis.

\begin{tabular}{|c|c|c|}
\hline \multicolumn{3}{|c|}{ Nipped (Side Plate corner) Samples } \\
\hline $\begin{array}{l}\text { Granular (Scraped) } \\
\text { Scraper Number }\end{array}$ & Sample Mass (g) & Fuel element Sampled \\
\hline $2-1$ & 0.035 & XA507N \\
\hline $2-3$ & 0.06 & XA508N \\
\hline $3-2$ & 0.054 & XA425N \\
\hline $3-3$ & 0.067 & XA508N \\
\hline \multicolumn{2}{|c|}{ Granular (Scraped) Plate 19 Face Samples } \\
\hline $\begin{array}{l}\text { Nipped (Side plate corner) } \\
\text { Sample Number }\end{array}$ & Sample Mass (g) & Fuel Element Sampled \\
\hline 2 & 0.328 & XA507N \\
\hline
\end{tabular}




\begin{tabular}{|l|l|l|}
\hline 3 & 0.272 & XA507N \\
\hline 9 & 0.173 & XA508N \\
\hline
\end{tabular}

The complete listing of the elements sampled is shown in the Operations data sheet as Appendix C.

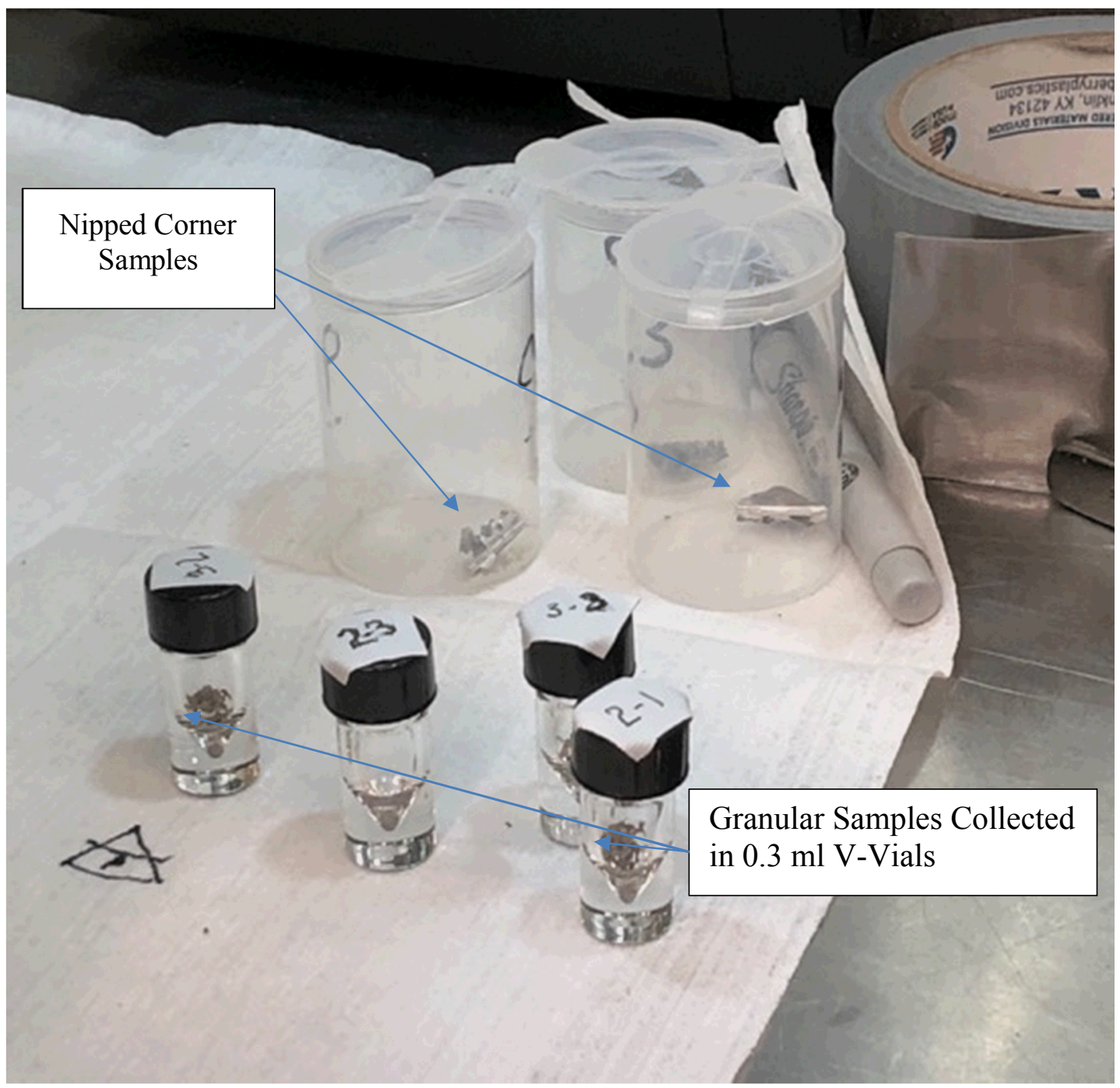

Figure 10. Collected granular and nipped samples in glovebox following receipt at EML. 


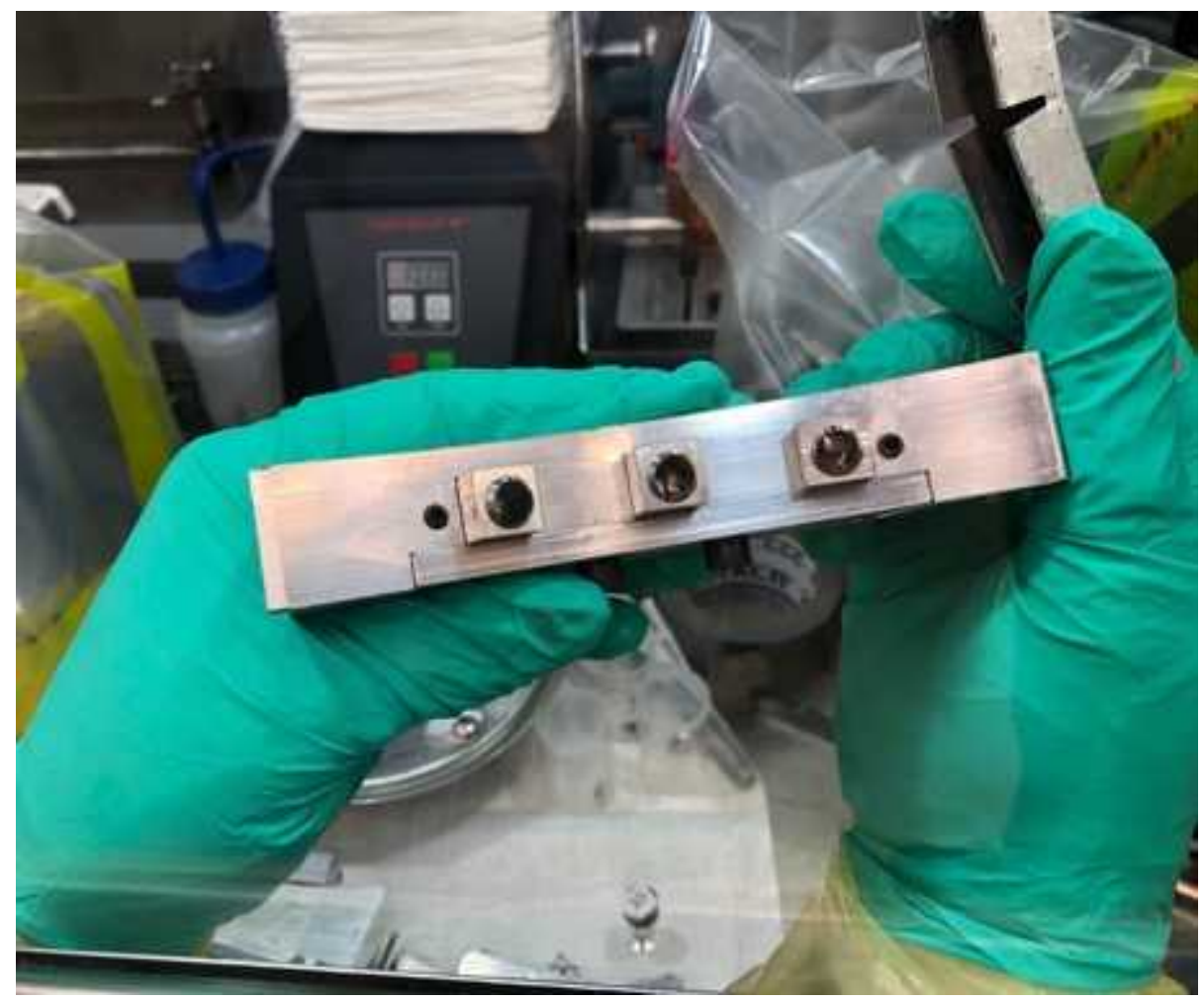

Figure 11. Three-point sample scraper in EML glovebox following receipt at MFC.

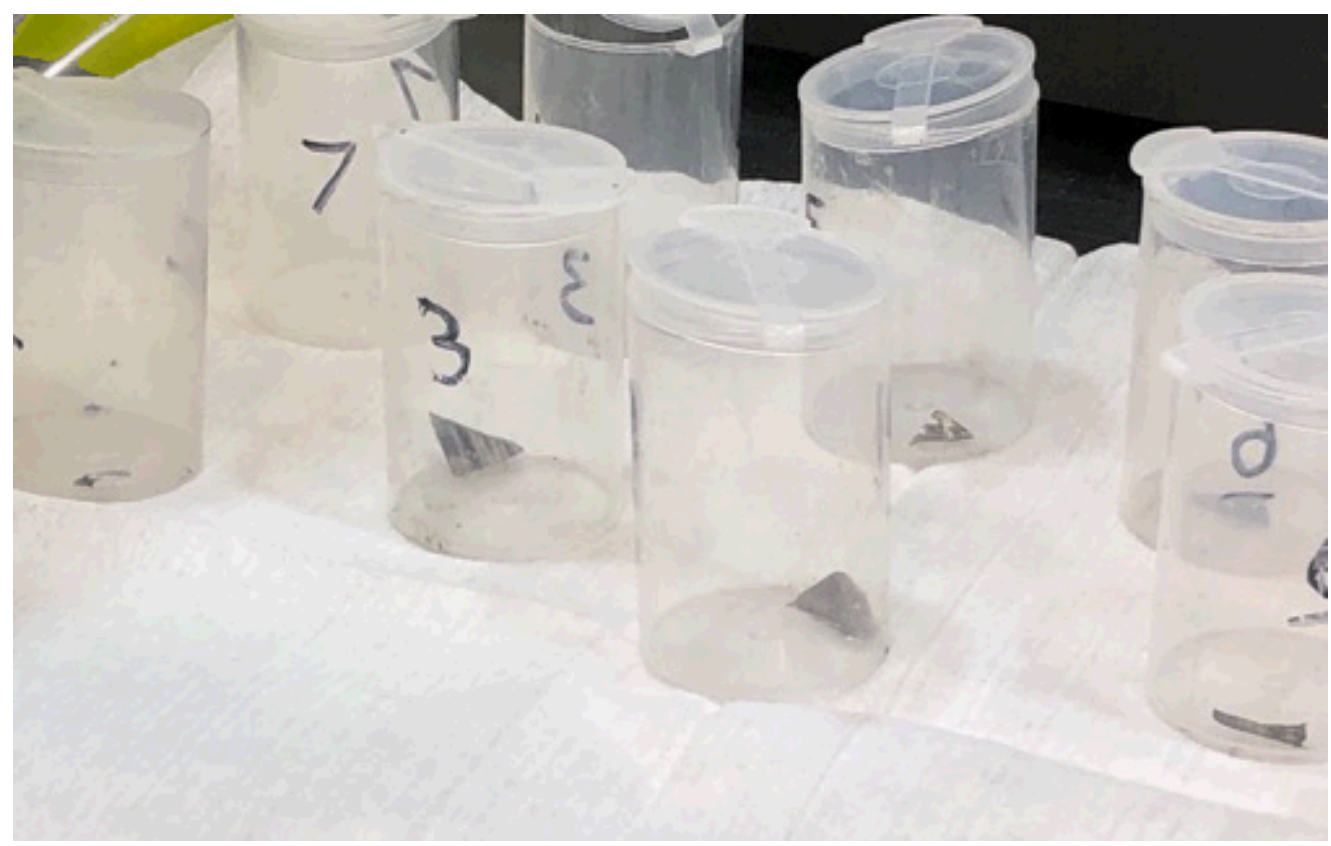

Figure 12. Nipped corner samples showing variability in shape and size of acquired samples. 


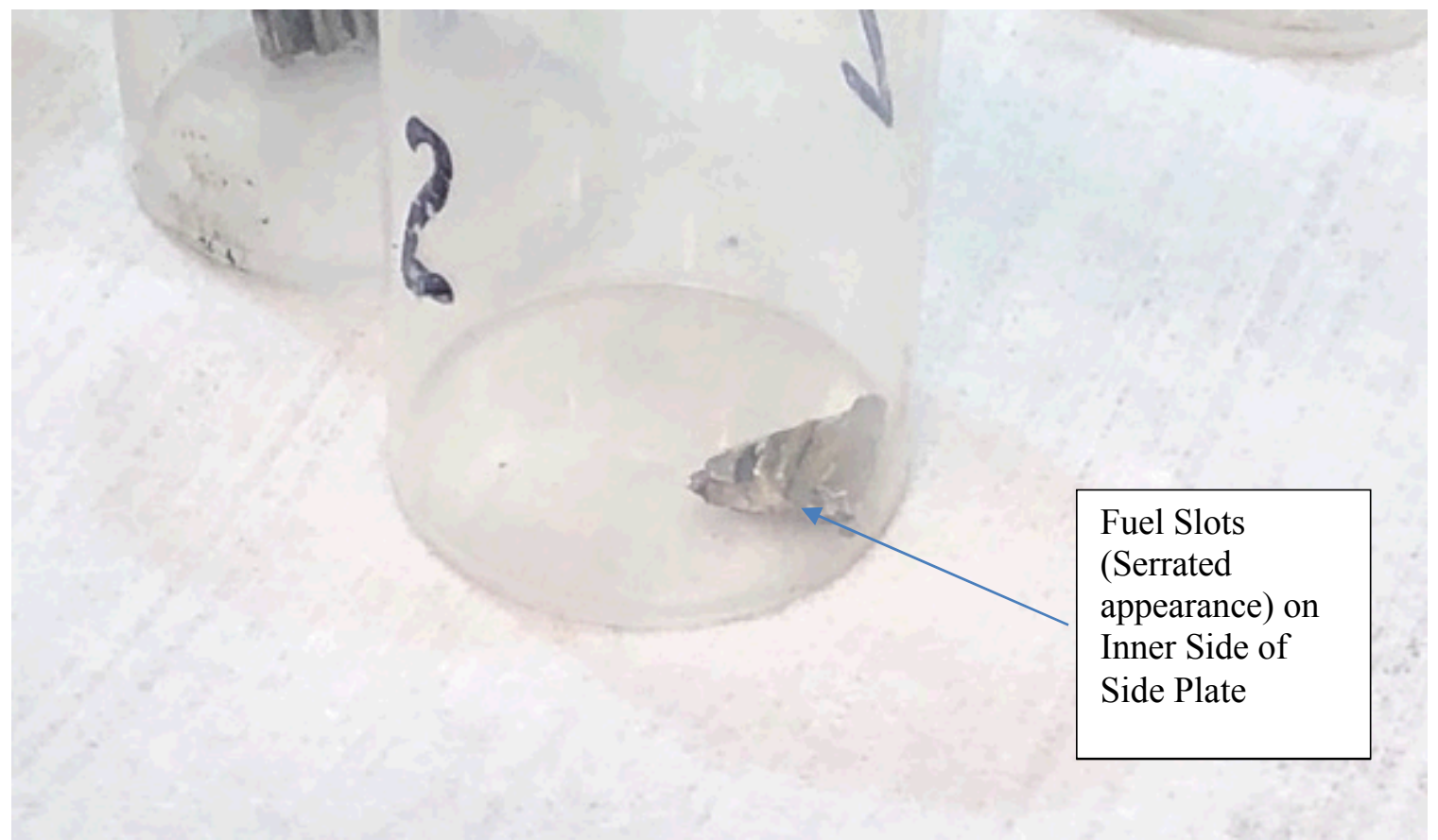

Figure 13. Nipped corner sample showing serrated fuel plate side.

\section{Scanning Electron Microscope Analysis}

The nipped corner samples were imaged using SEM to confirm composition and the depth of the oxide layer. The primary SEM samples were mounted in a 1-inch-diameter ring with Buehler Epo-Thin 2 long-set epoxy. The samples were polished to a $1 \mu \mathrm{m}$ finish using microscopic diamond suspensions ranging from 9-micron to 0.05-micron grit using an Allied HiTech autopolisher.

The prepared samples were scanned using a JEOL 7000FEG SEM with an Oxford Instruments EDS module to determine elemental composition of the sample as a function of position. Images were taken at several magnifications $(500-5000 \times)$ in the backscatter imaging mode to highlight differences in the sample composition.

The images of the examined samples show a clear demarcation between the bulk aluminum alloy and the oxide layer, with the latter being the darker layer in the micrographs (bright regions are metal precipitates). The contrast in the gray scale of the oxide and the bulk indicate that the oxide layer does not penetrate the body of the end box and has uniform thickness across the entire cross section, even in areas with initial surface roughness.

The fractured appearance of the oxide layer results from brittle nature of aluminum oxide shearing under the tangential polishing force leading to the delamination of the oxide layer, as seen in End Box 2 top and bottom, End Box 3 Top, and areas of End Box 9 top and bottom.

EDS was conducted using an Oxford Instruments X-Max Detector combined with the Inca analysis software. Area of interest point scans, line scans across the interface region, and general area mapping validated the demarcation of layers in the backscatter micrographs. The compositional change from 50 $\mathrm{wt} \%$ oxygen in the oxide layer to less than $5 \mathrm{wt} \%$ oxygen in the metal phase occurs over less than 3 microns. Based on the limitation of a 1-micron step size, the results are interpreted as an abrupt transition from oxide region to bulk aluminum.

The results of the EDS mapping show a monolayer region of high-oxygen concentration consistent with aluminum oxide. The remaining material is oxygen poor. The map of aluminum in all samples show 
a region of lower concentration $\mathrm{Al}$ (light gray) where the oxygen was high and a region high in $\mathrm{Al}$ (bright white) where the oxygen concentrations were low. (Mapping shows relative concentrations, not exact values). Figures 14 through 21 show the oxide edge transition at multiple locations at several magnifications. Figures 22 through 26 show elemental detection locations of the oxide edge transition.

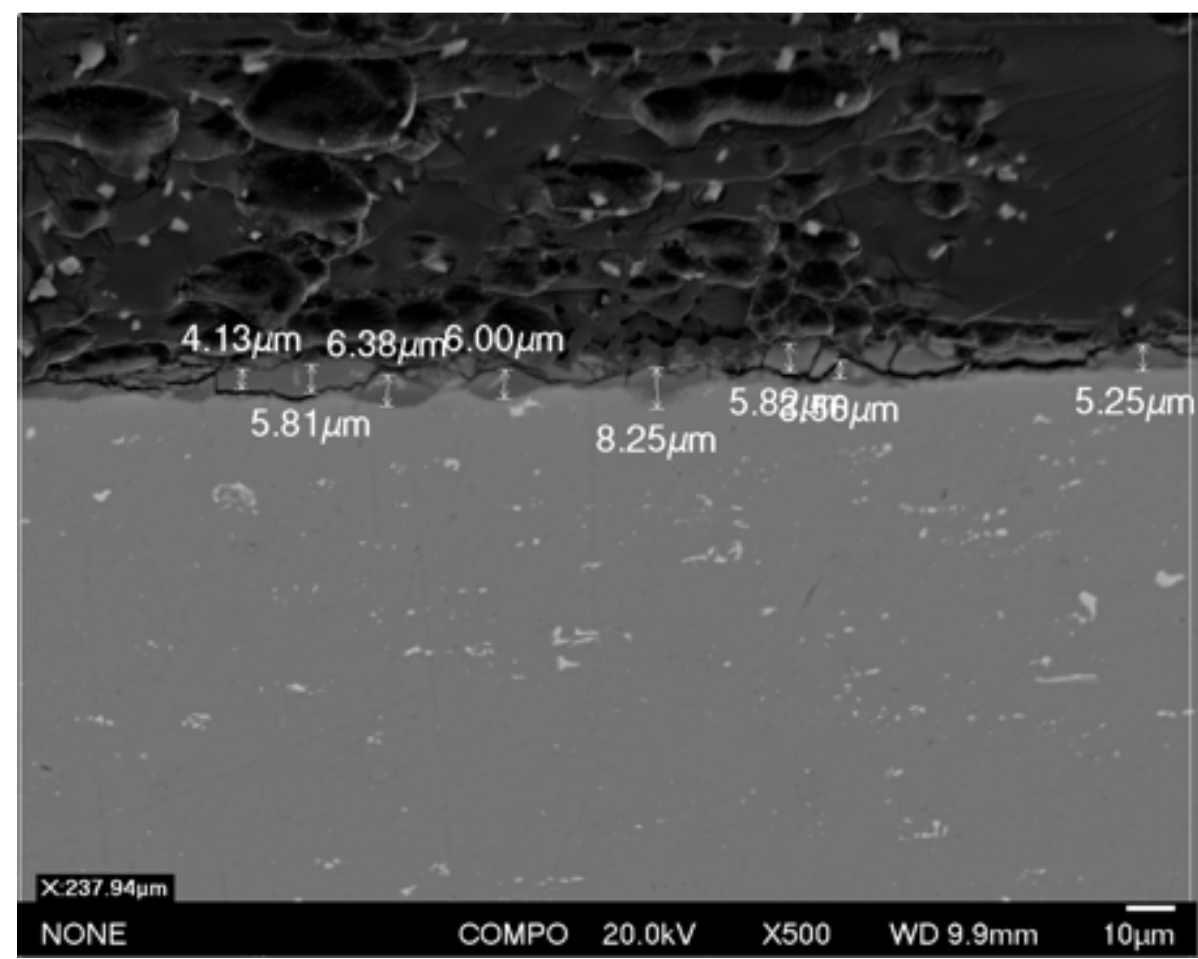

Figure 14. Nip sample 2, location 2 top edge, $500 \times$. 


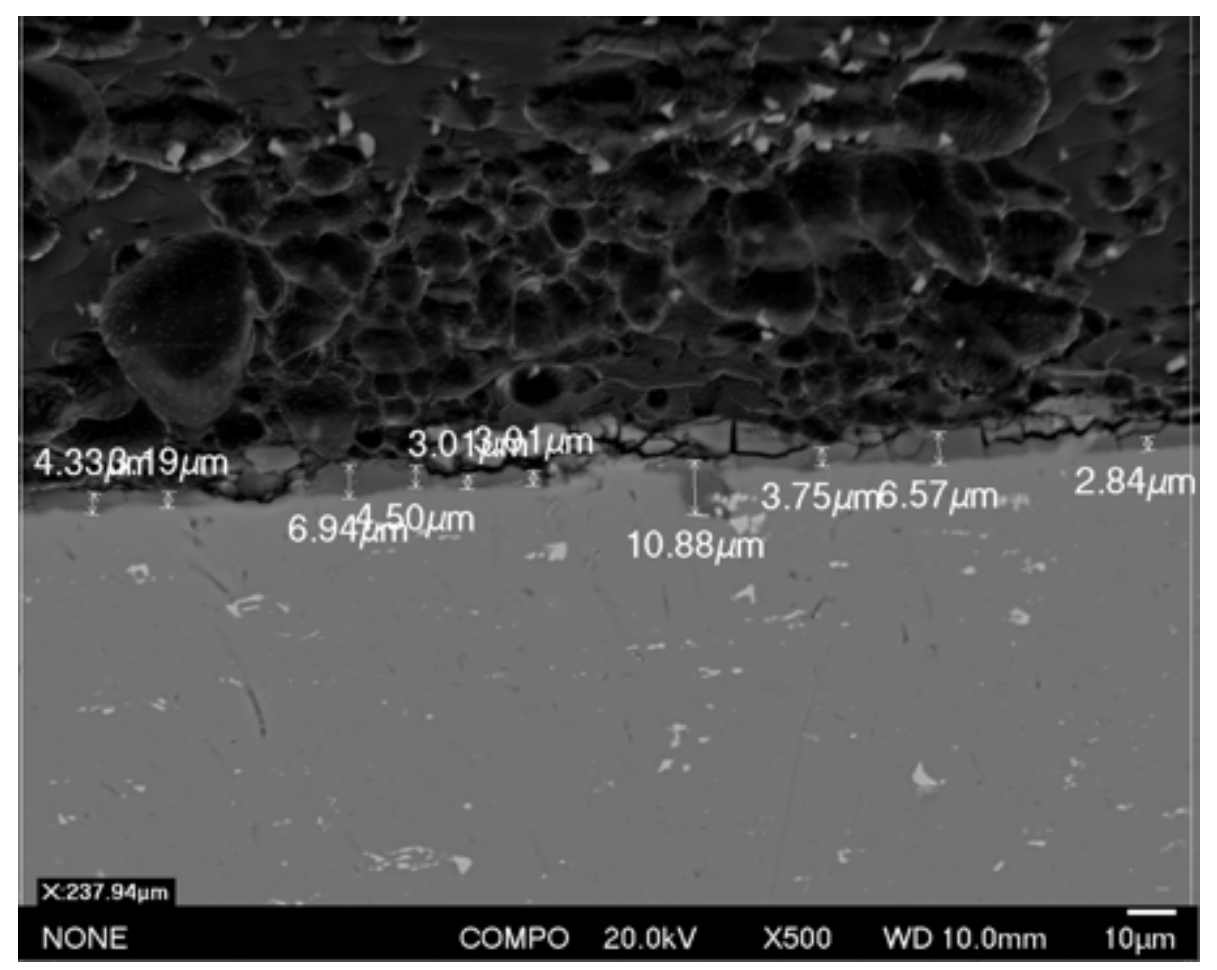

Figure 15. Nip sample 2, location 1, top edge, $500 \times$.

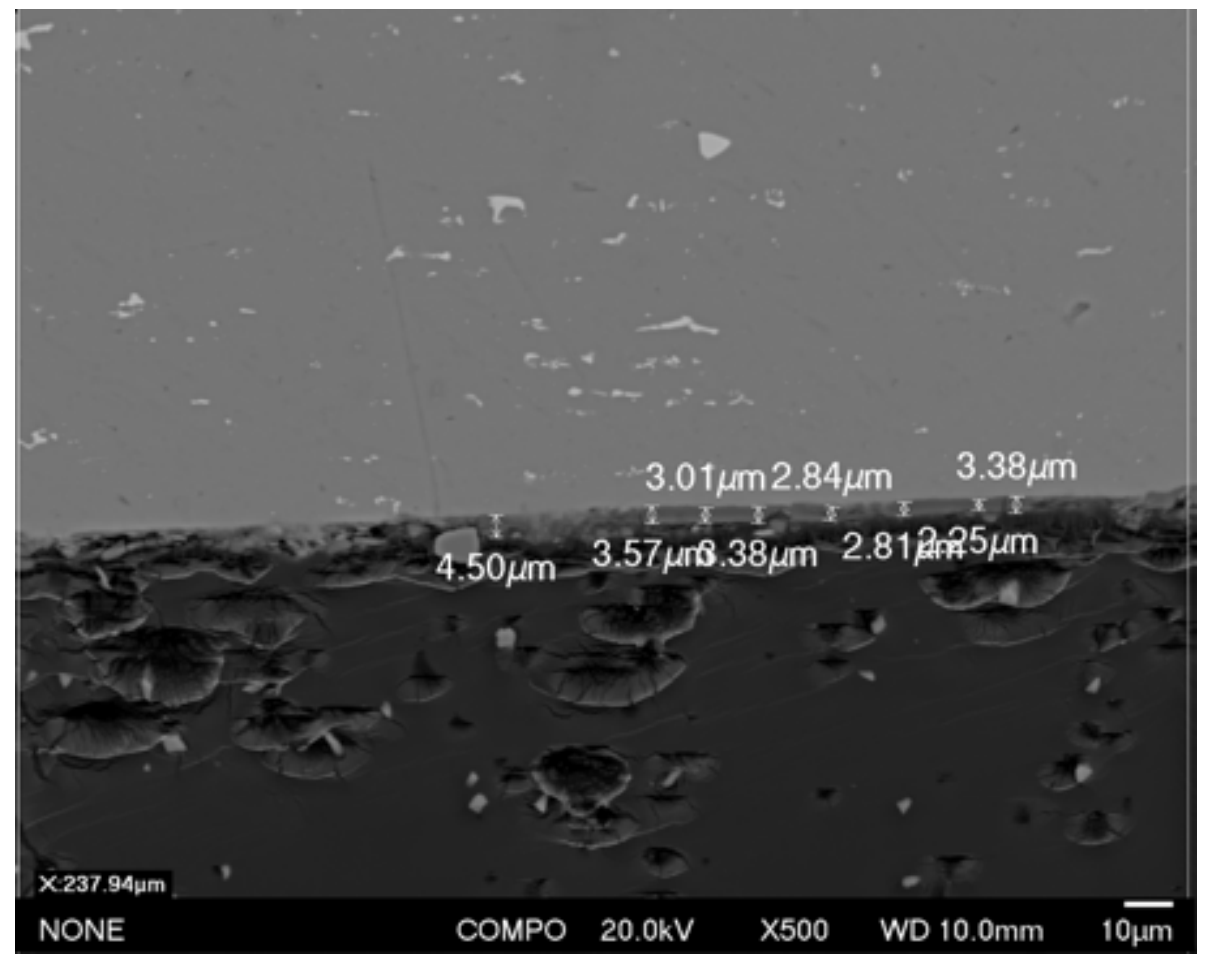

Figure 16. Nip sample 2, location 2, bottom edge, $500 \times$. 


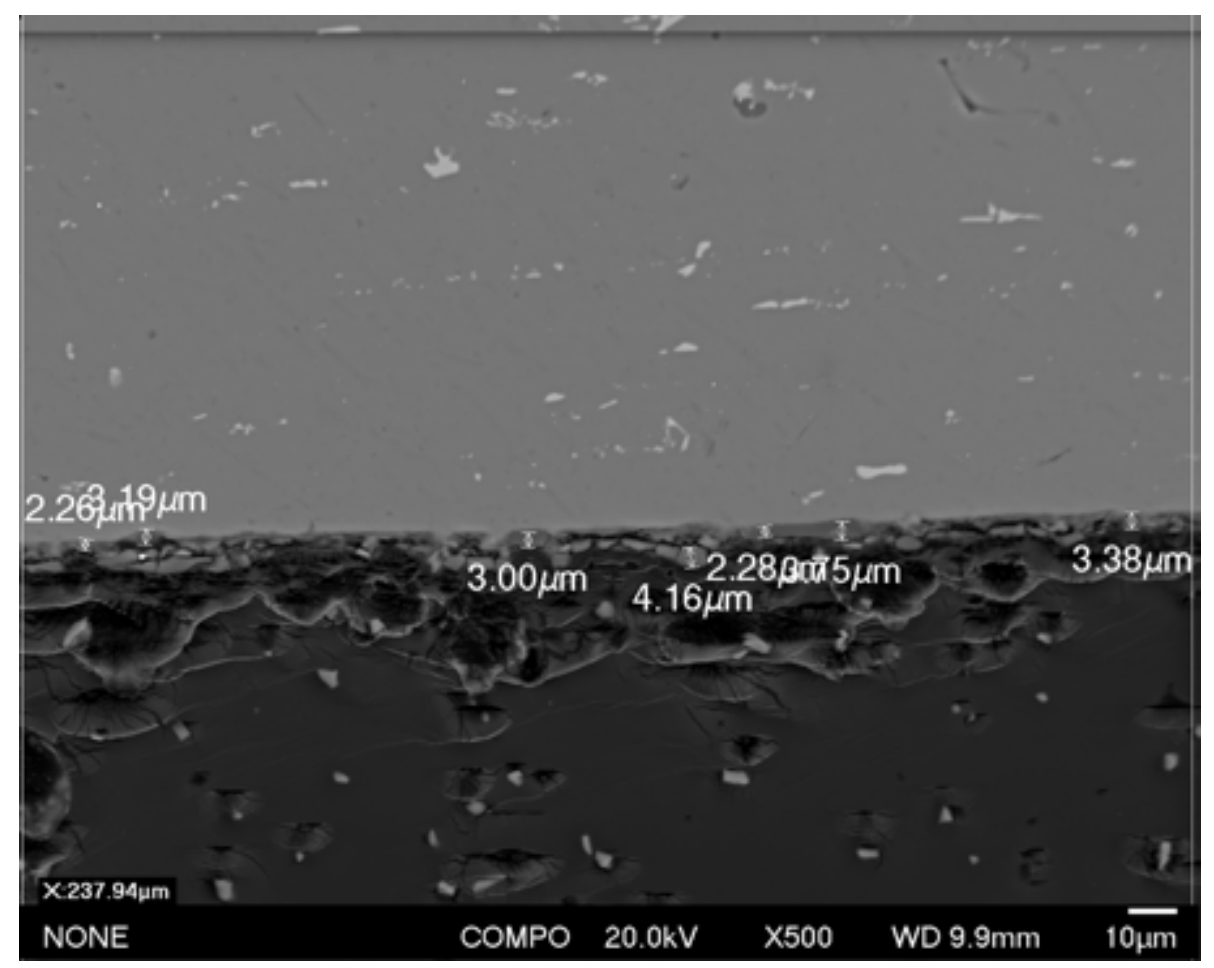

Figure 17. Nip sample 2, bottom edge, location 1, $500 \times$.

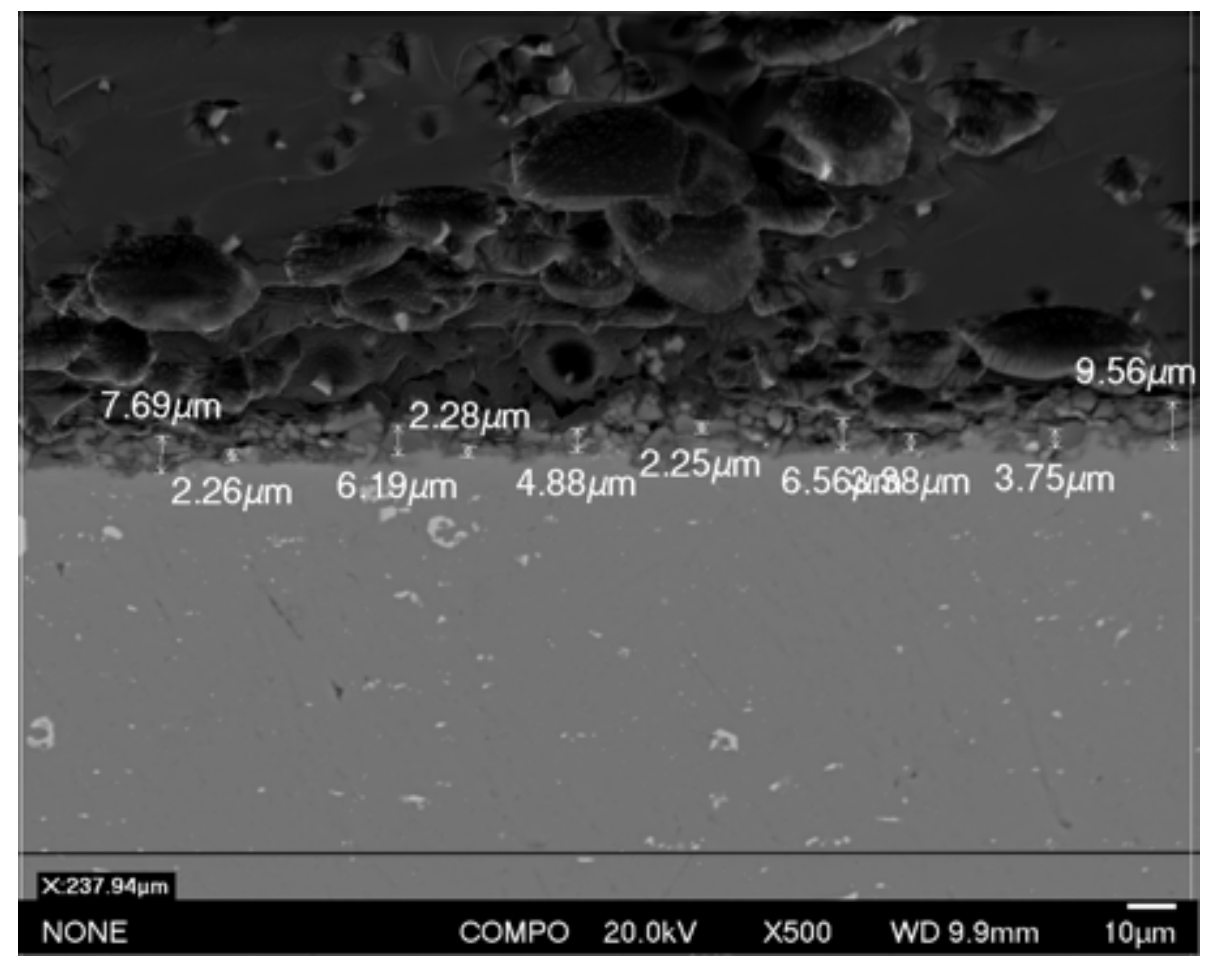

Figure 18. Nip sample 3, top edge, location 2, $500 \times$. 


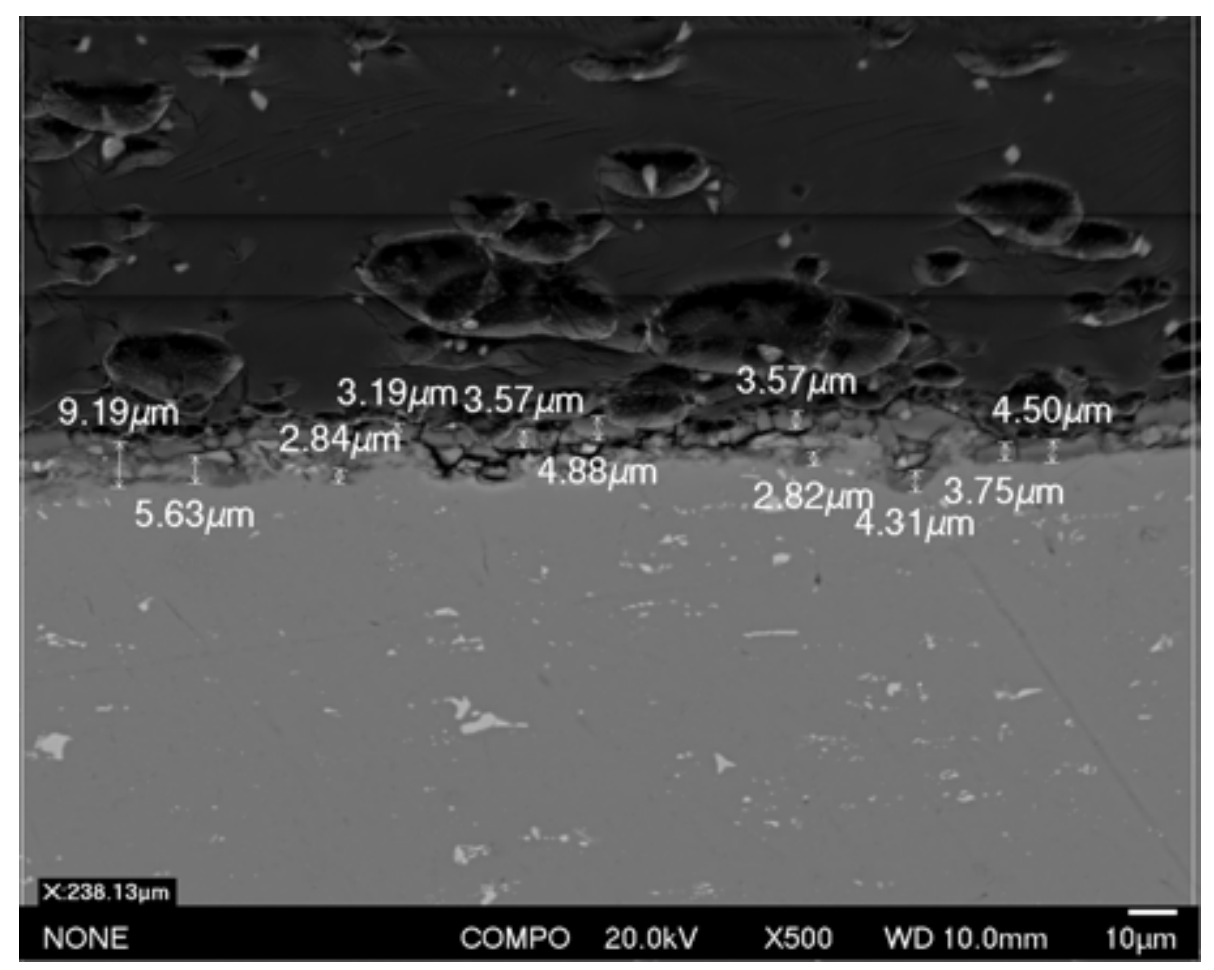

Figure 19. Nip sample 3, top edge, location 1, $500 \times$.

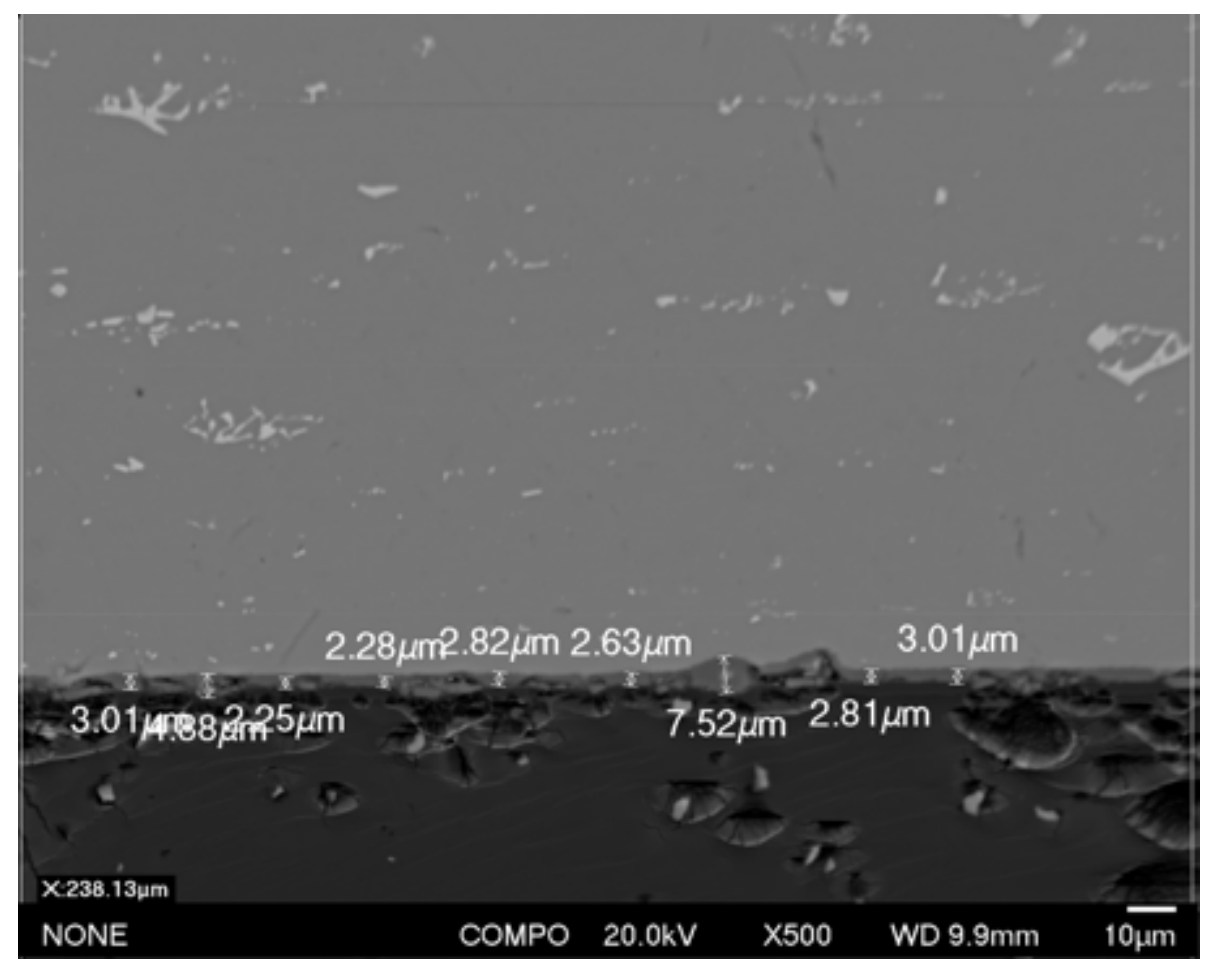

Figure 20. Nip sample 3, bottom edge, location 2, $500 \times$. 


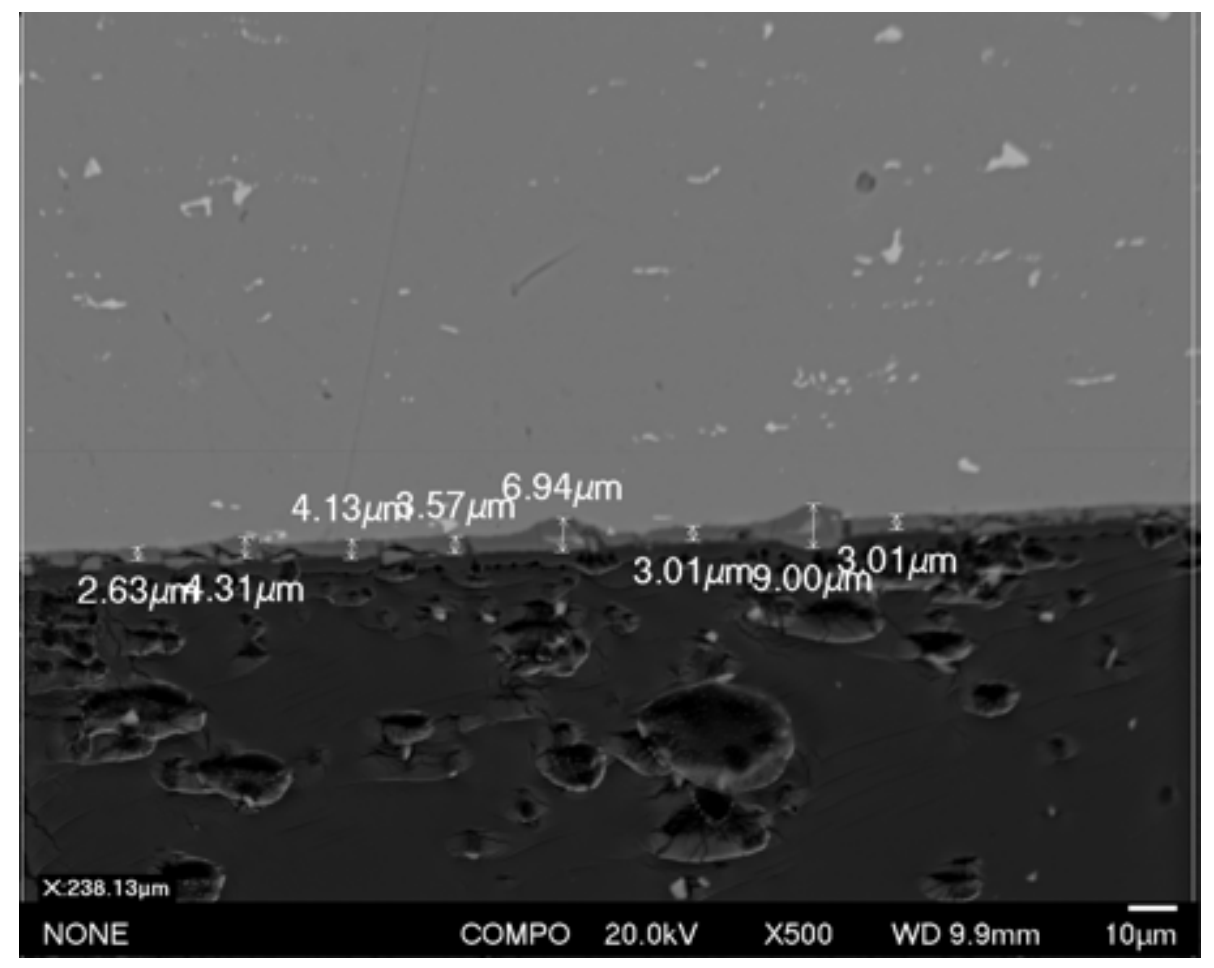

Figure 21. Nip sample 3, bottom edge, location 1, $500 \times$. 
Project: Project 1

Owner: OIEngineer

Site: ATR EB 2 B 5kx 4 map

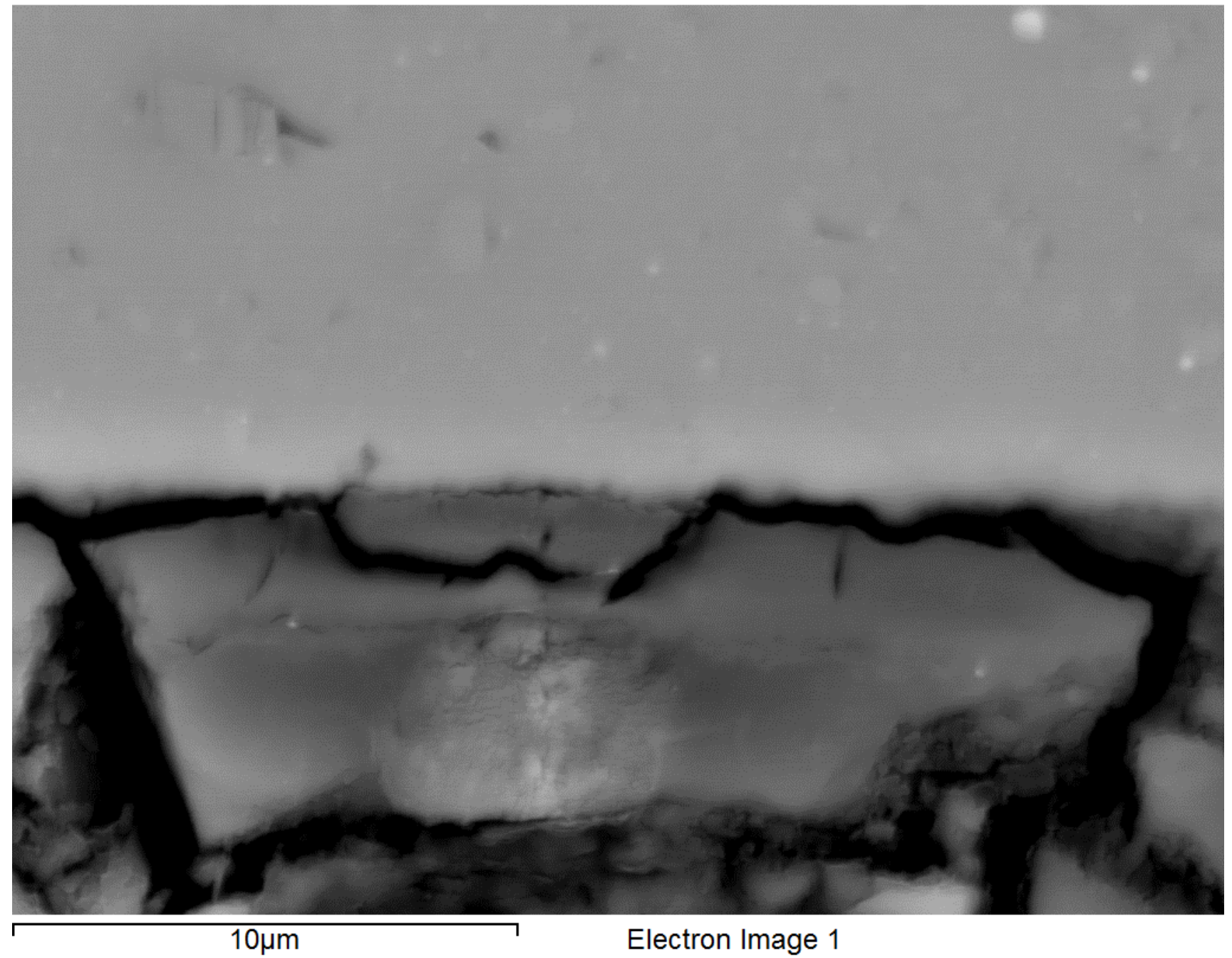

Figure 22. Nip sample 2, bottom edge, location 4, $5000 \times$. 
Project: Project 1

Owner: OIEngineer

Site: ATR EB 2 B 5kx 4 map

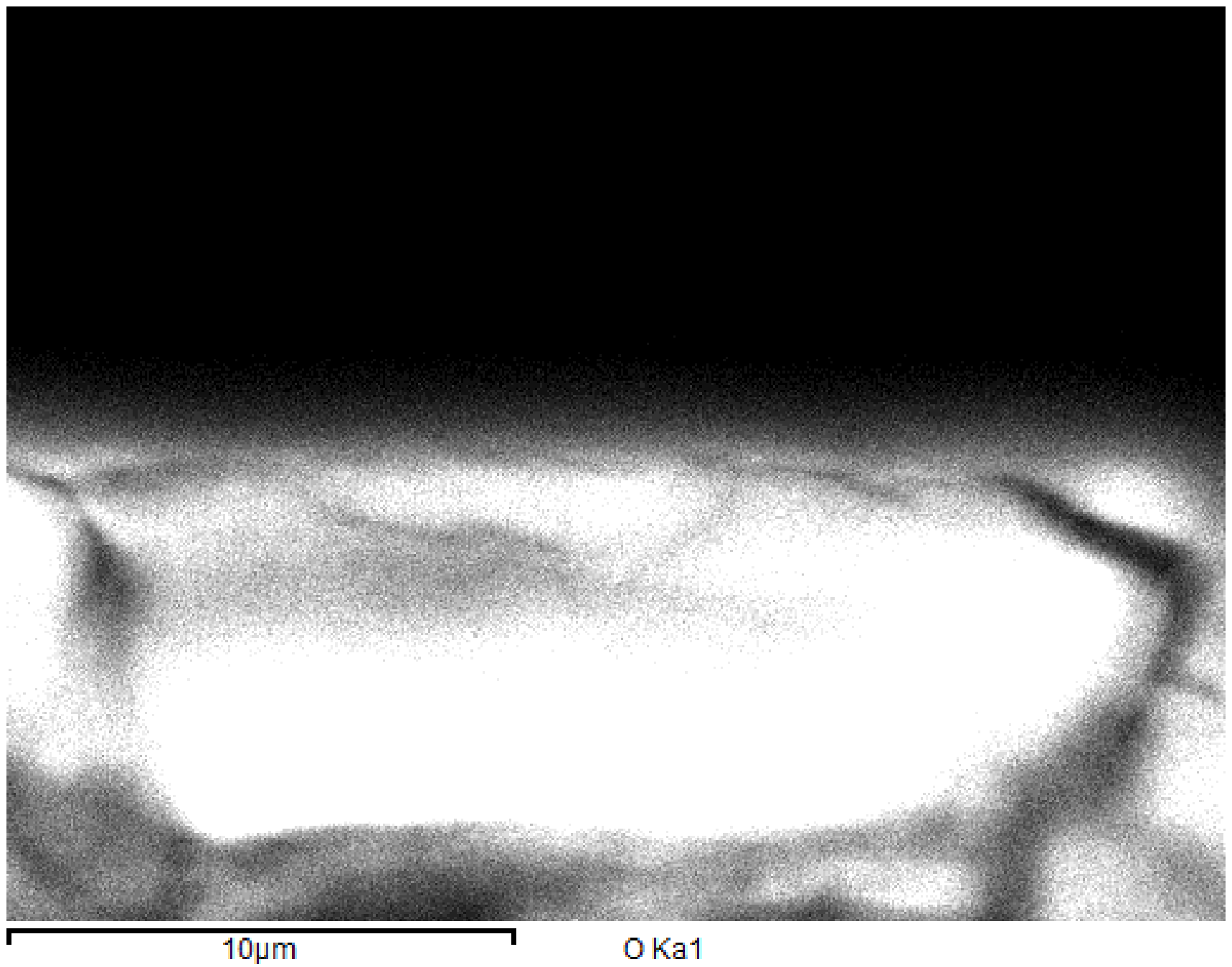

Figure 23. Nip sample 2, bottom, localized oxygen concentration (white area) . 


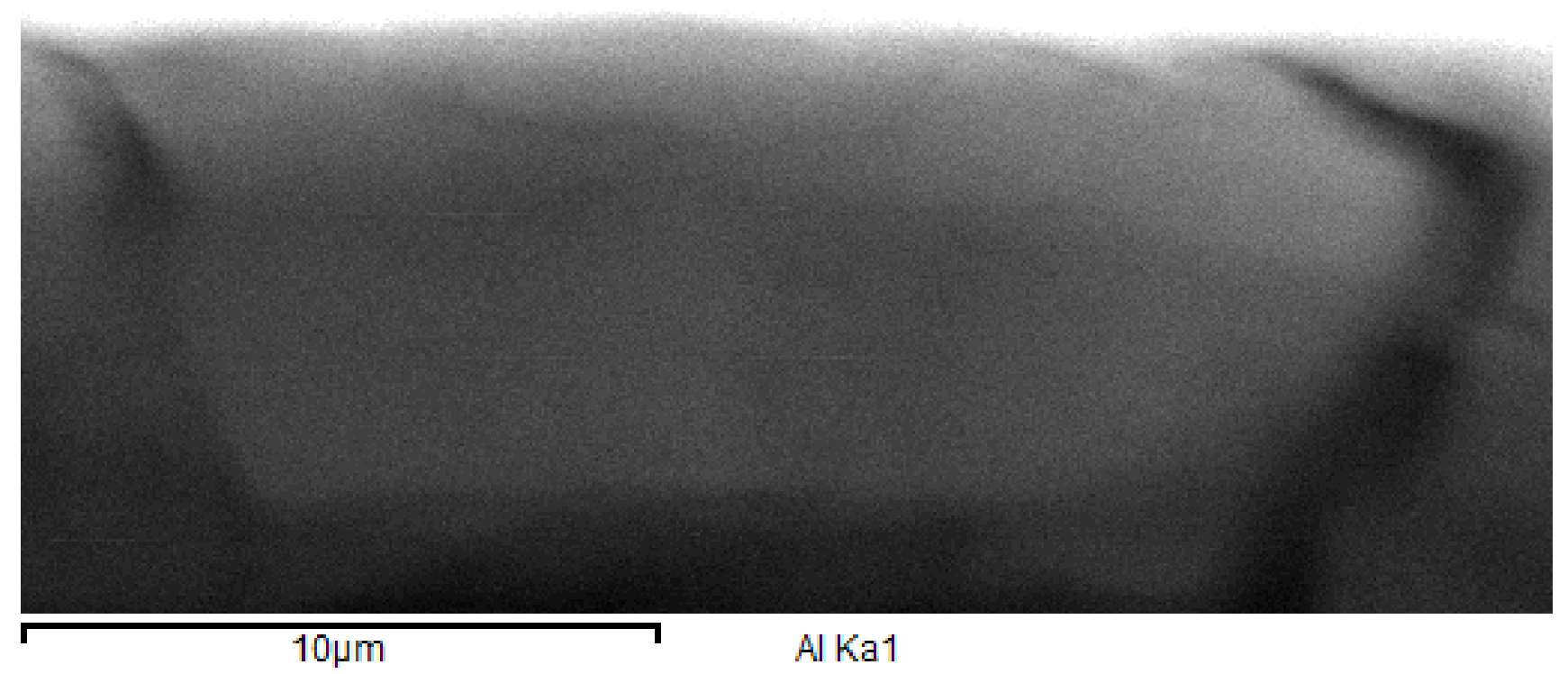

Figure 24. Nip sample 2, bottom, localized aluminum concentration (white area). 
Project: Project 1

Owner: OIEngineer

Site: ATR EB 2 B 5kx 4 map

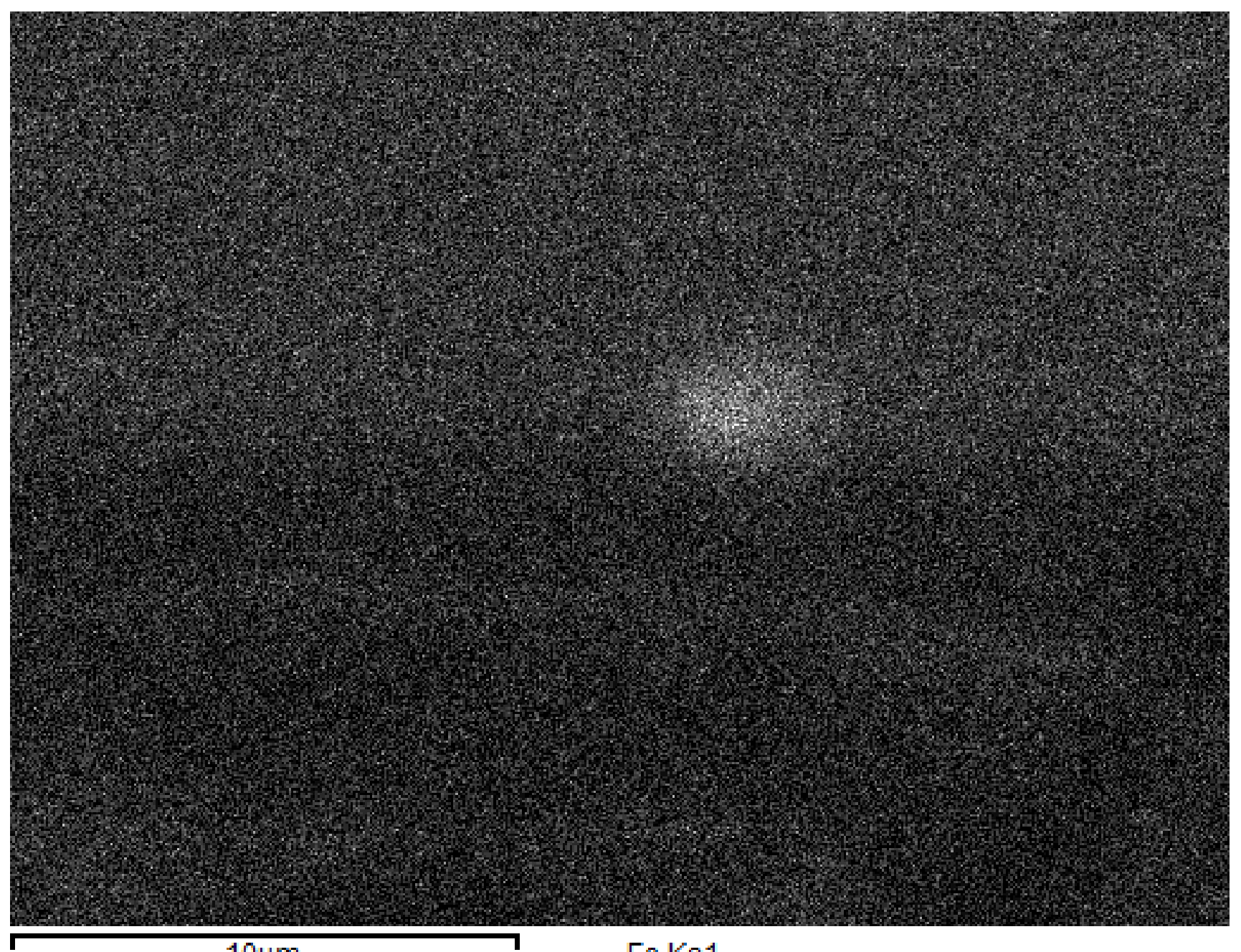

$10 \mu \mathrm{m}$

Fe Ka1

Figure 25. Nip sample 2, bottom, location 4, localized iron concentration (white area). 


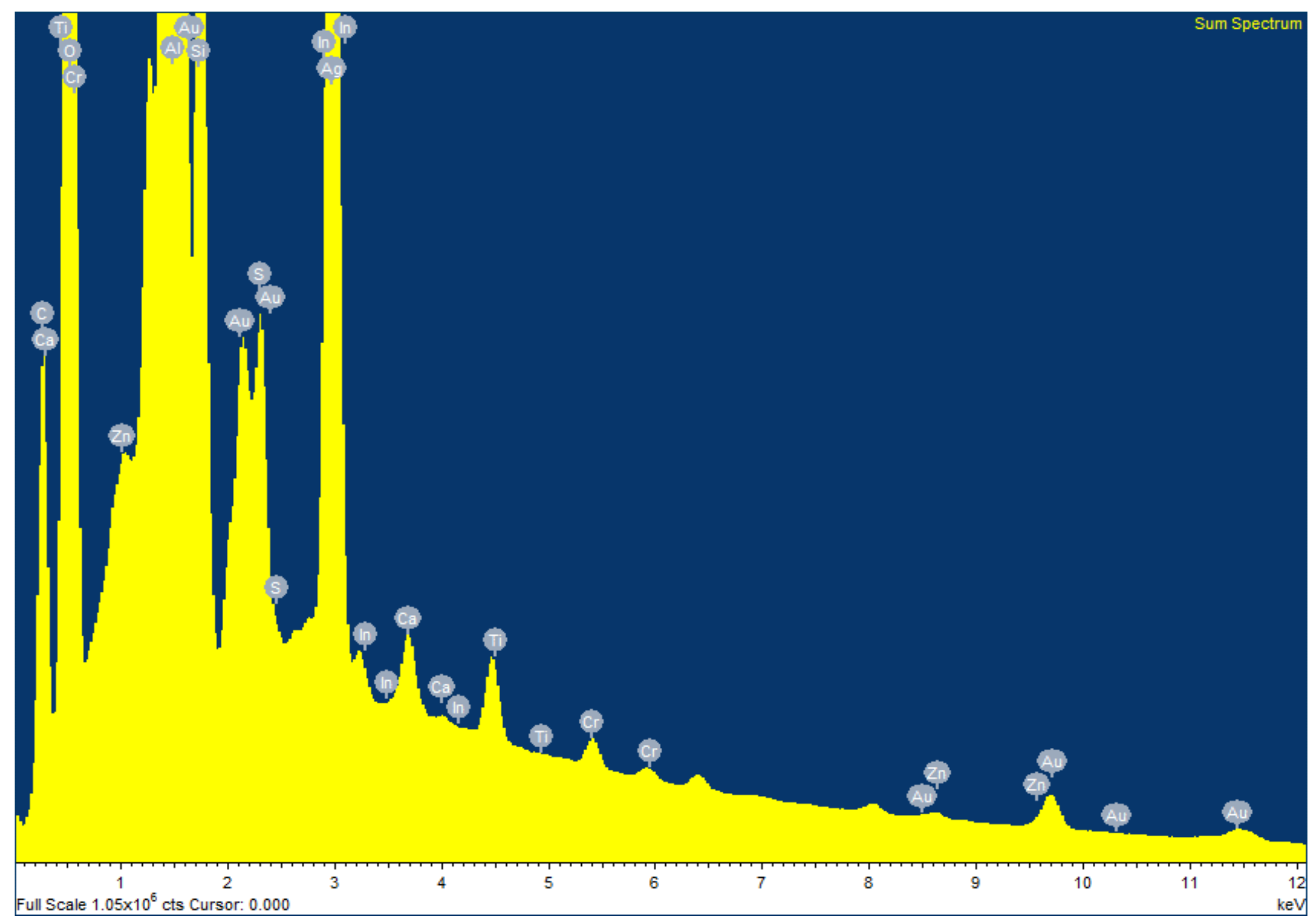

Figure 26. Elemental distribution nip sample 2

A series of increasing-magnification SEM images are included as Appendix B. 


\subsection{Thermogravimetric Analysis}

Test method: Two samples of aluminum oxide scrapings were submitted for TGA analysis. The measurements were conducted on a simultaneous thermal analyzer, Netzsch model STA449 F3 Jupiter system, in the "TGA only" mode. The system was operated with ultra-high purity argon at $50 \mathrm{ml} / \mathrm{min}$. Due to the purity of the influent gas, no moisture or oxygen traps were employed. The uncertainty on the temperature measurement is $\pm 2^{\circ} \mathrm{C}$ and the resolution on the balance is $\pm 1 \mu \mathrm{g}$. The temperature program was run as follows:

- Room Temperature to $100^{\circ} \mathrm{C}$ at $5^{\circ} \mathrm{C} / \mathrm{min}$

- Hold at $100^{\circ} \mathrm{C}$ for 1 hour

- Heat from $100^{\circ} \mathrm{C}$ to $200^{\circ} \mathrm{C}$ at $5^{\circ} \mathrm{C} / \mathrm{min}$

- Hold at $200^{\circ} \mathrm{C}$ for 1 hour

- Heat from $200^{\circ} \mathrm{C}$ to $300^{\circ} \mathrm{C}$ at $5^{\circ} \mathrm{C} / \mathrm{min}$

- Hold at $300^{\circ} \mathrm{C}$ for 1 hour

- Heat from $300^{\circ} \mathrm{C}$ to $400^{\circ} \mathrm{C}$ at $5^{\circ} \mathrm{C} / \mathrm{min}$

- Hold at $400^{\circ} \mathrm{C}$ for 1 hour

- Heat from $400^{\circ} \mathrm{C}$ to $500^{\circ} \mathrm{C}$ at $5^{\circ} \mathrm{C} / \mathrm{min}$

- Hold at $500^{\circ} \mathrm{C}$ for 1 hour

Total mass change for Sample 2-1 (initial mass $0.035 \mathrm{~g}$ ) was -7.1\%, while Sample 3-2 (Original mass $0.054 \mathrm{~g}$ ) was $-5.6 \%$. Figures 27 through 30 show screen captures of the instrument display for the two samples. As shown in Figure 31, both samples track similarly, with 2-1 and 3-2 being nearly parallel between 100 and $200^{\circ} \mathrm{C}$. Sample 3-2 continues at the same slope between 200 and $300^{\circ} \mathrm{C}$, while $2-1$ has less change in that region. The data indicate that the greatest percentage of water in the system is lost between 100 and $300^{\circ} \mathrm{C}$.

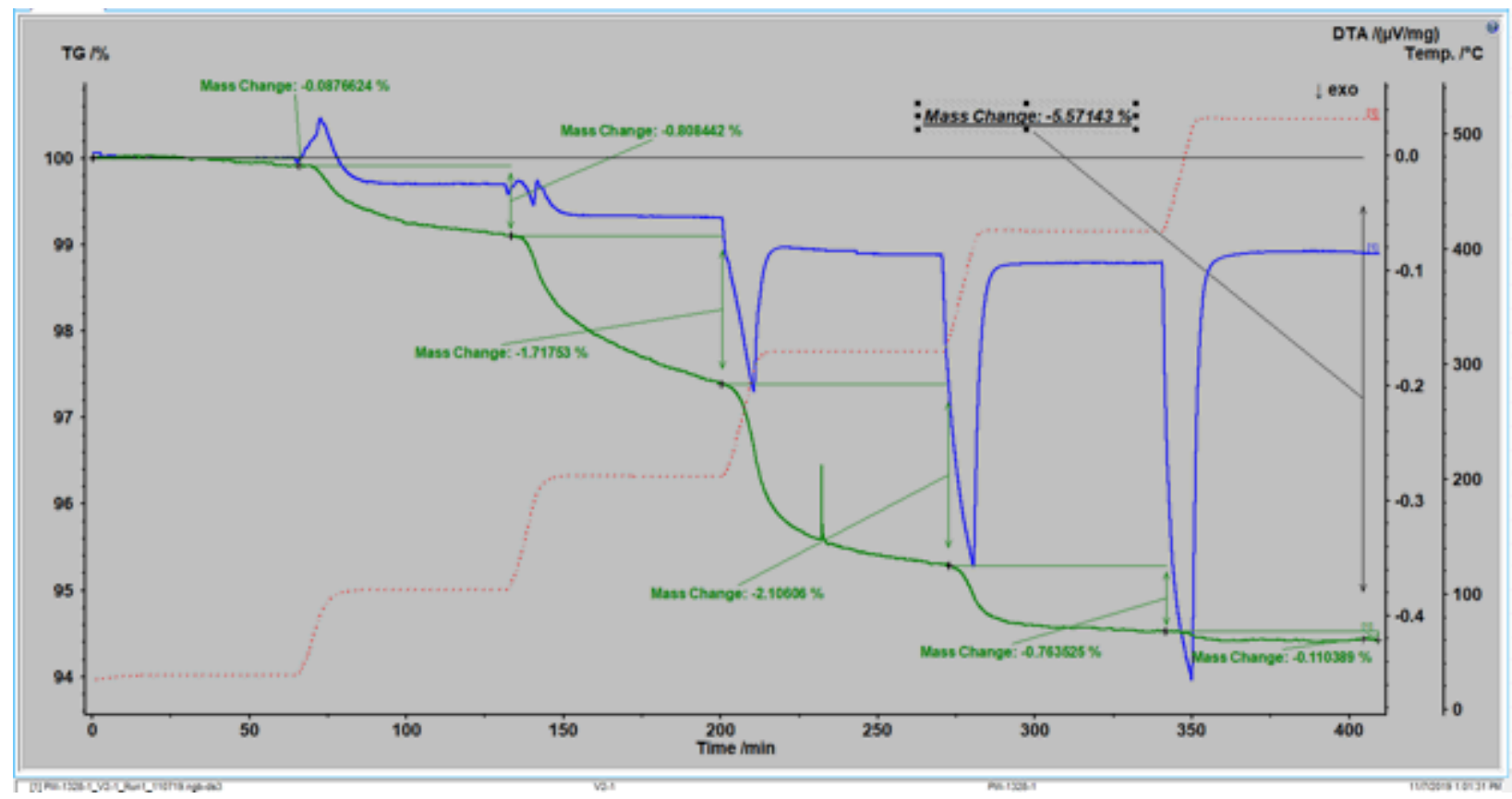

Figure 27. TGA run for scraped sample 2-1 percent change. 


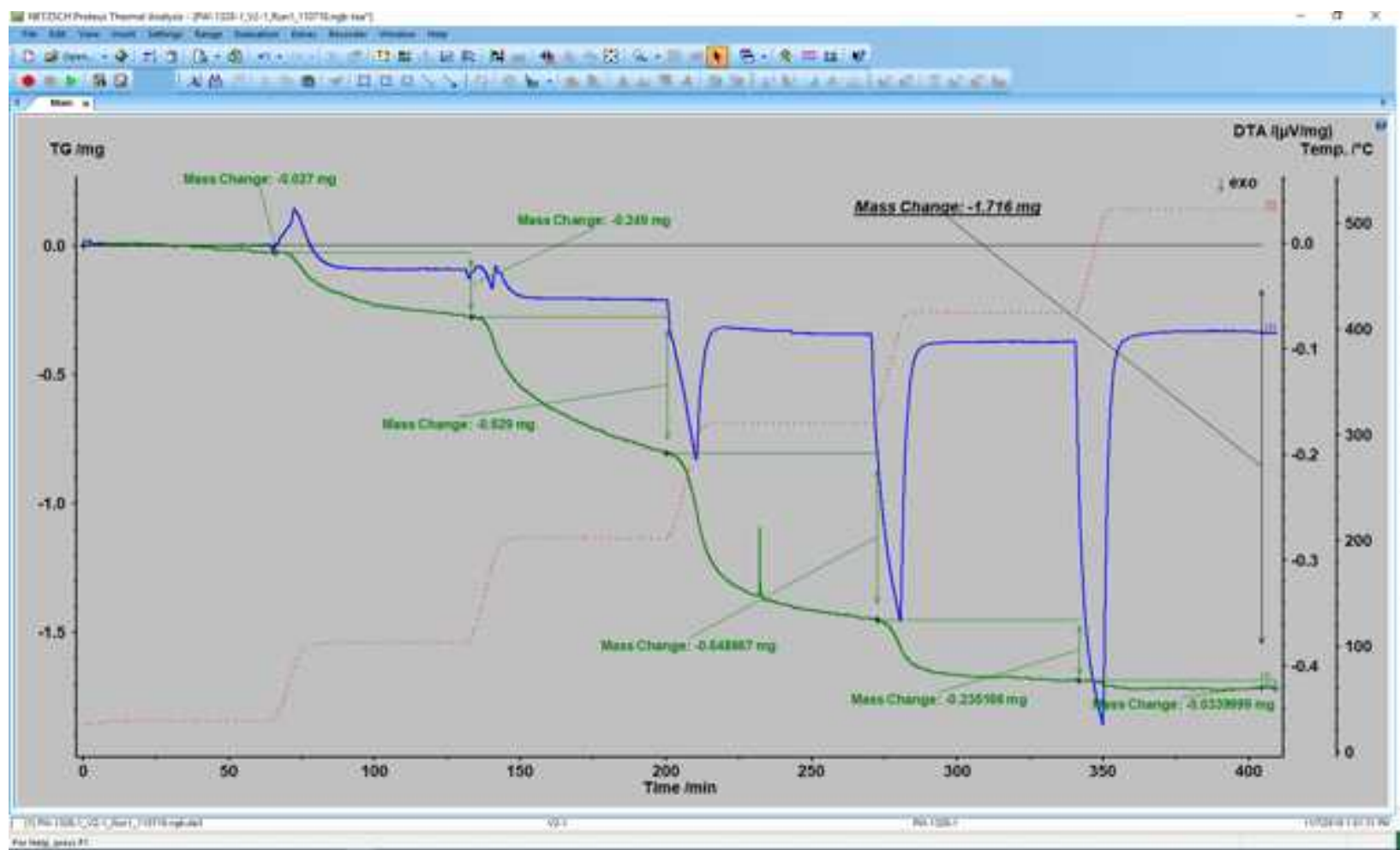

Figure 28. TGA run for scraped sample 2-1 mass change.

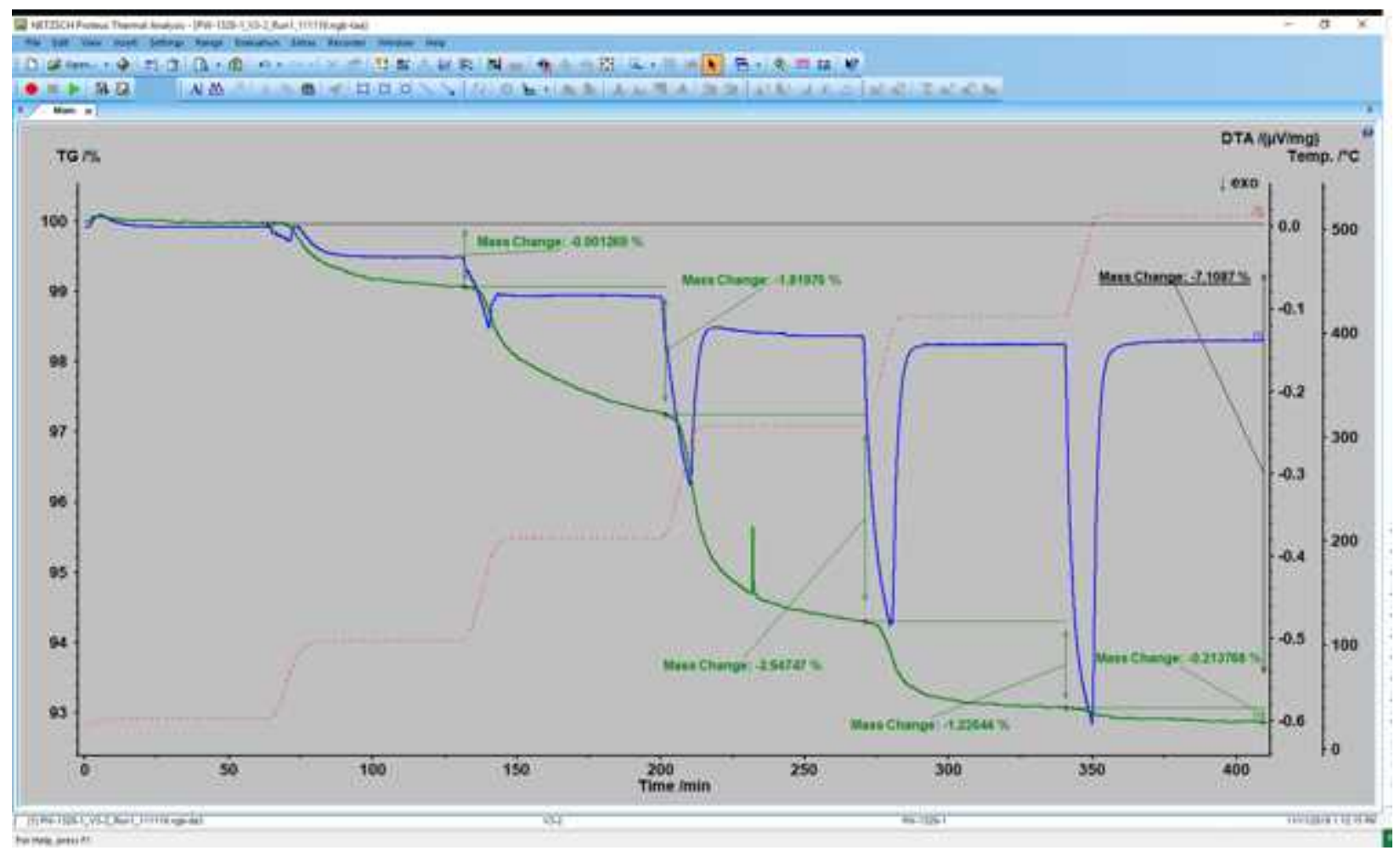

Figure 29. TGA run for scraped sample 3-2. 


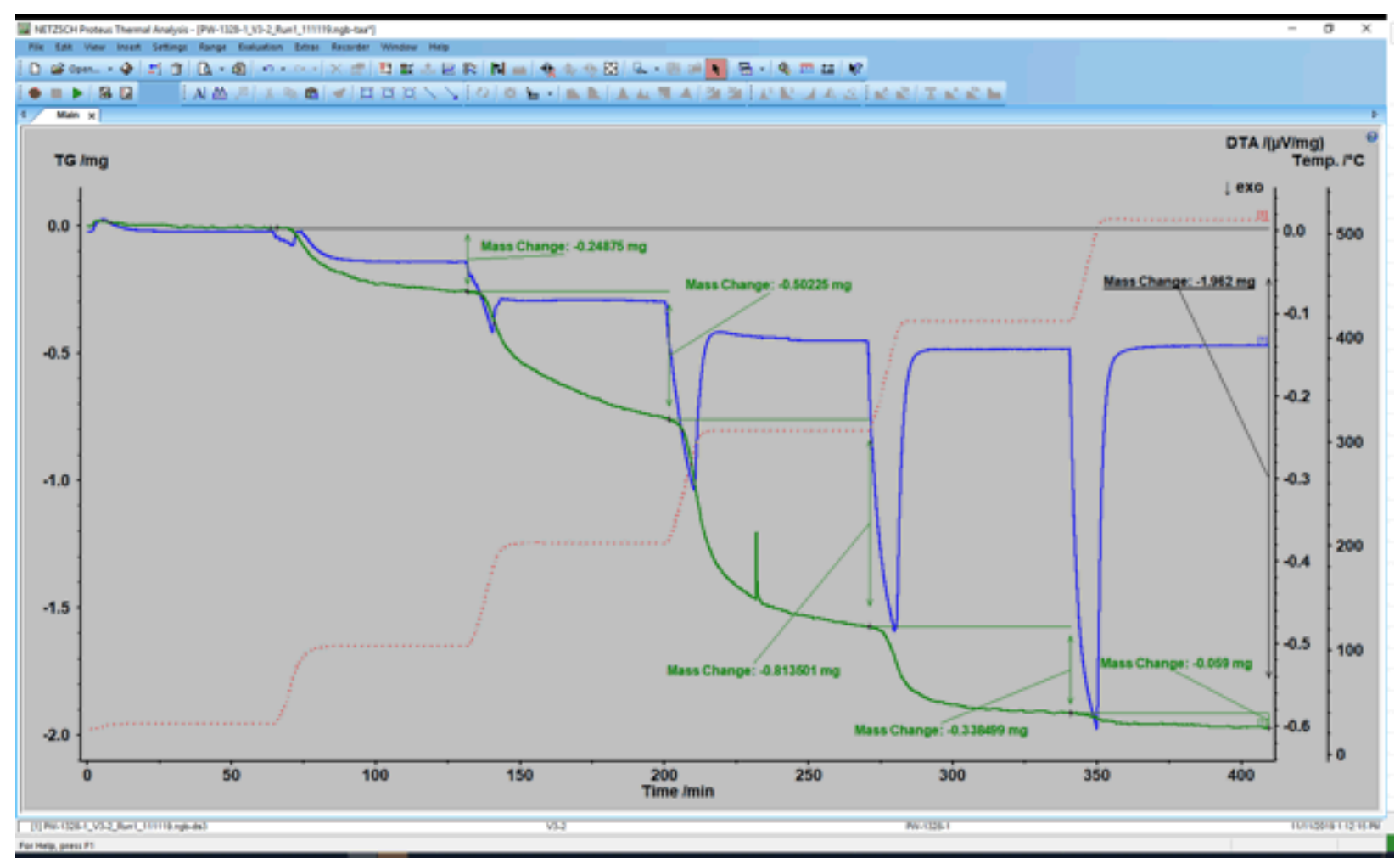

Figure 30. TGA run for scraped sample 3-2.

For the above figures, the values shown are TG signal (wt $\%$ or $\mathrm{mg}$ ), Differential Thermal Analysis signal $(\mu \mathrm{V} / \mathrm{mg})$, and temperature $\left({ }^{\circ} \mathrm{C}\right)$ vs. time. Exothermic (heat releasing) direction is down. Table 3 lists the specific interval mass changes.

Table 3 Tabular TGA mass change data.

\begin{tabular}{|l|l|l|}
\hline Sample 3-2 & Initial Mass & $\mathbf{3 5} \mathbf{~ m g}$ \\
\hline $\begin{array}{l}\text { Temperature } \\
(\text { Hold Time 1 hour) }\end{array}$ & $\begin{array}{l}\text { Mass Change } \\
(\mathrm{wt} \%)\end{array}$ & $\begin{array}{l}\text { Mass Change } \\
(\mathrm{mg})\end{array}$ \\
\hline $100^{\circ} \mathrm{C}$ & -0.9013 & -0.2488 \\
\hline $200^{\circ} \mathrm{C}$ & -1.8198 & -0.5023 \\
\hline $300^{\circ} \mathrm{C}$ & -2.9475 & -0.814 \\
\hline $400^{\circ} \mathrm{C}$ & -1.2264 & -0.3385 \\
\hline $500^{\circ} \mathrm{C}$ & -0.2137 & -0.059 \\
\hline Total & -7.1087 & -1.962 \\
\hline
\end{tabular}

\begin{tabular}{|l|l|l|}
\hline Sample 2-1 & Initial Mass & $\mathbf{5 4} \mathbf{~ m g}$ \\
\hline $\begin{array}{l}\text { Temperature } \\
(\text { Hold Time 1 hour })\end{array}$ & $\begin{array}{l}\text { Mass Change } \\
(\mathrm{wt} \%)\end{array}$ & $\begin{array}{l}\text { Mass Change } \\
(\mathrm{mg})\end{array}$ \\
\hline $100^{\circ} \mathrm{C}$ & -0.8084 & -0.249 \\
\hline $200^{\circ} \mathrm{C}$ & -1.7175 & -0.529 \\
\hline $300^{\circ} \mathrm{C}$ & -2.1061 & -0.6487 \\
\hline $400^{\circ} \mathrm{C}$ & -1.2264 & -0.2352 \\
\hline $500^{\circ} \mathrm{C}$ & -0.7635 & -0.0339 \\
\hline Total & -5.5714 & -1.716 \\
\hline
\end{tabular}




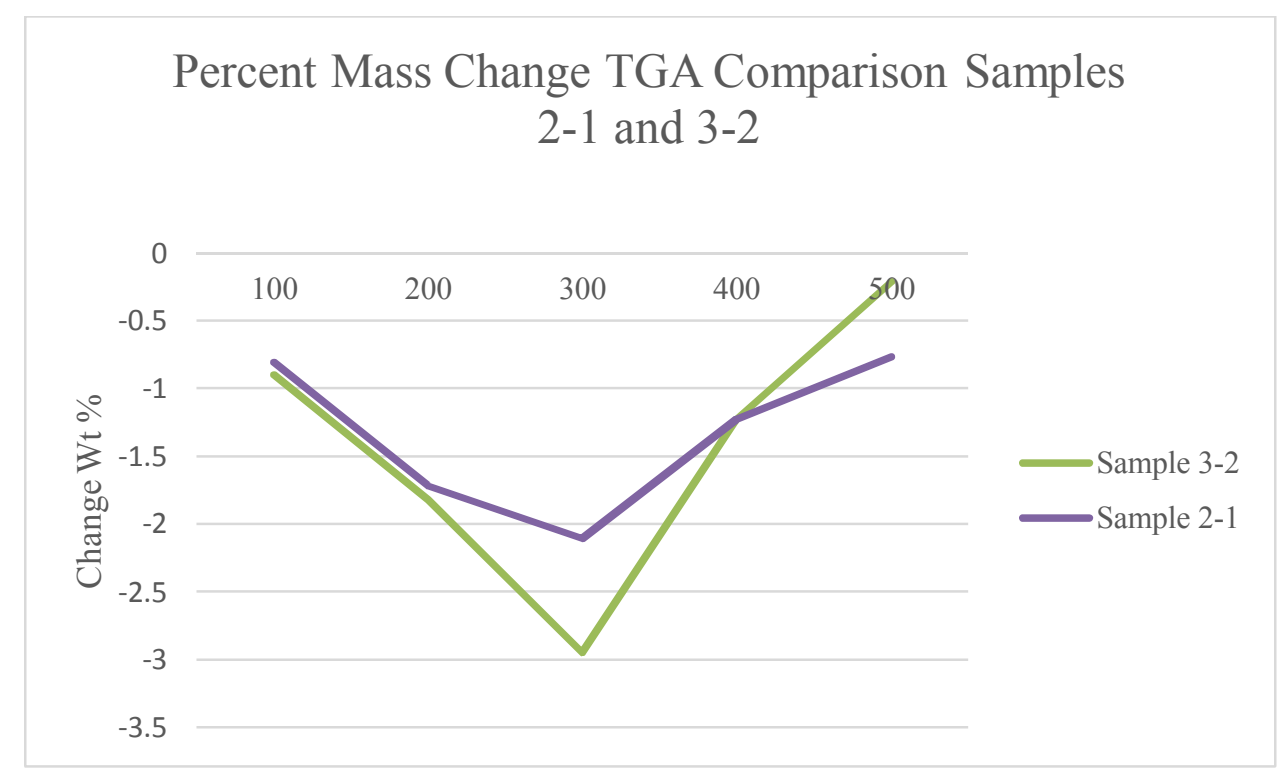

Figure 31. Graphical representation of TGA mass loss vs. temperature.

\subsection{X-Ray Diffraction Analysis}

XRD measurements were conducted using a Malvern-Panalytical Aeris powder diffractometer in Bragg-Brentano geometry $\theta-2 \theta$, with $\mathrm{Cu} K \alpha$ radiation $(\lambda=1.5418 \AA)$, over the $2 \theta$ range from 10 to $110^{\circ}$ with step width of ca. $0.01^{\circ}$ and 0.25 seconds per step. The sample holder for XRD measurement was covered with Mylar® film to protect the sample.

The diffraction patterns indicate a typical cubic aluminum phase and a possible Bohmite $(\mathrm{Al} \mathrm{O}(\mathrm{O} \mathrm{H}))$ orthorhombic $(\mathrm{Cmcm})$ type phase (i.e., exact chemistry of this orthorhombic phase was unclear); however, from the nature of the scrapings it is difficult to say if this material had a defect phase or any consistent information regarding crystallite/grain size. The shallow wide peaks of the $\mathrm{Al} O(\mathrm{OH})$ phase would suggest that it had some amorphous character. Figure 32 shows the specific peaks identified by XRD. 


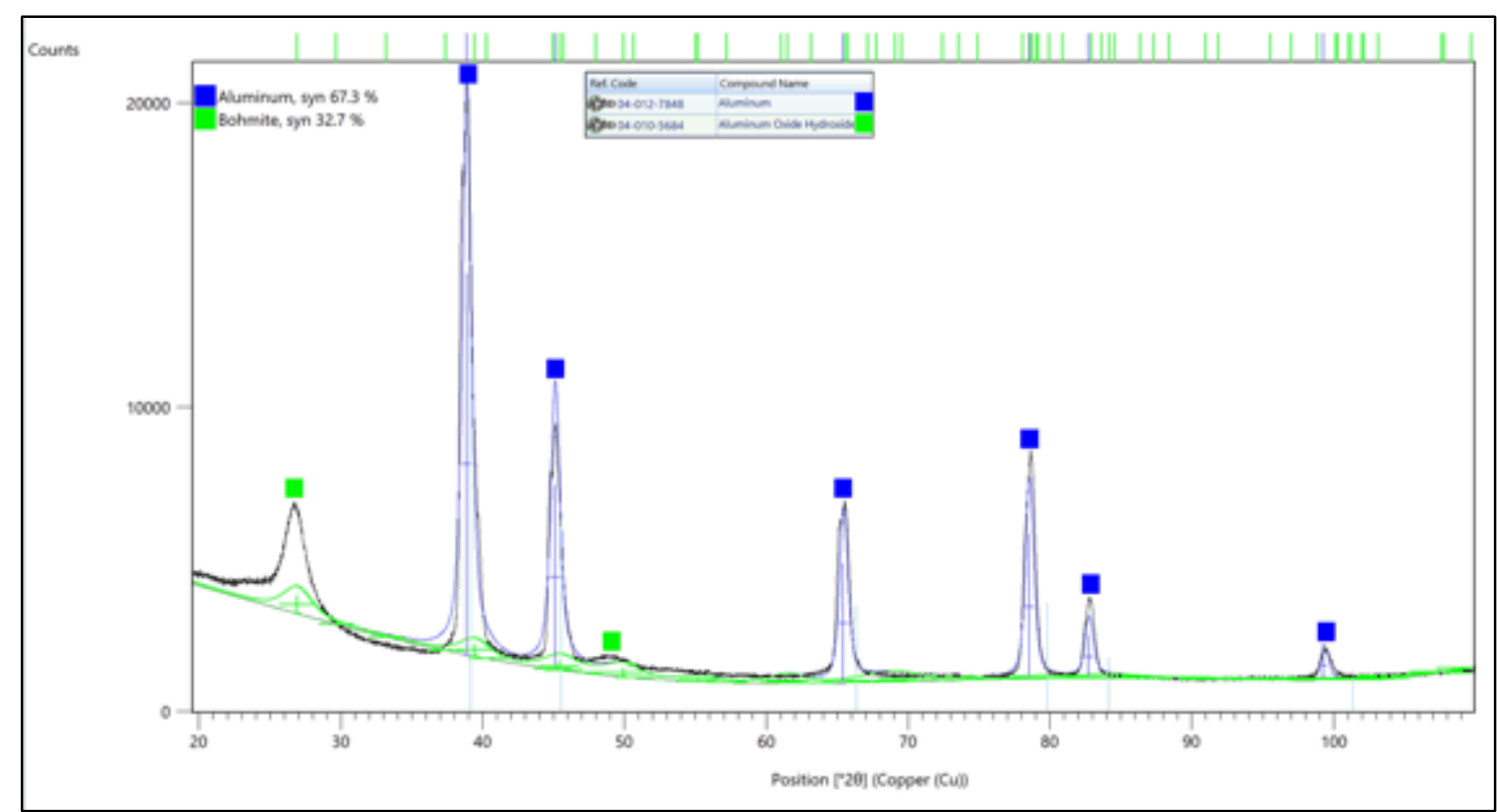

Figure 32. XRD of aluminum scrapings sample 3-3. 


\subsection{TEM/STEM Analysis}

\subsubsection{Sample Preparation}

A sample of the aluminum cladding was nipped from the end of a previously in-service assembly and cross-sectioned to evaluate the oxide scale, growth, and potential formation of any additional intergranular defects. The nipped specimen was evaluated with SEM and XRD. For more detailed analysis with high-resolution electron microscopy, two cross-section lamellae were lifted from the exposed surface and thinned to electron transparency, which is typically less than one mean free path at the operating voltage of the microscope. The Talos F200s is operated at $200 \mathrm{kV}$ with a total collection angle of $157 \mathrm{mrad}$. For aluminum, the mean free path is $84.52 \mathrm{~nm}$ and for $\mathrm{Al}_{2} \mathrm{O}_{3}, 91.82 \mathrm{~nm}$. Crosssectioning and lifting a site-specific sample from the exposed cladding was done using a FIB instrument to prepare lamellae measuring rough 8.2 microns by 15 microns. Inspection in the Talos STEM, utilizing convergent beam electron diffraction, determined that the sample thickness varied from 68.25 to over 130 $\mathrm{nm}$ at the bottom of the cross section. The sample was substantially thinned in the portion closest to the surface that had formed over the service life of the aluminum sample.

\subsubsection{Transmission Electron Microscopy}

Operating in TEM mode, high-resolution atomic-scale phase-contrast imaging resolved the overall sample morphology as well as underlying atomic structure and crystallinity. Consistent with phasecontrast high-resolution imaging, the smallest $3 \mu \mathrm{m}$ aperture was used to capture select area electron diffraction (SAED) patterns at various areas of the sample. The underlying aluminum grain and crystallographic chemistry patterns acquired served as a standard for comparison and validation of subsequent diffraction and crystallographic analysis for phase identification.

\subsubsection{Scanning Transmission Electron Microscopy}

Following TEM and SAED analysis, the Talos 200X was operated in STEM mode, utilizing nanoprobe settings with currents ranging from $10 \mathrm{pA}$ to less than $5 \mathrm{pA}$ for imaging simultaneously in low-, medium-, and high-angle annular imaging modalities. At the high angle (above $30 \mathrm{mrad}$ ), the convergent angles are sufficiently high to acquire atomic mass contrast imaging utilizing the farthest annular dark-field detector. Under this condition, the signal intensity in the image is related to atomic mass as a roughly square dependence. The exact intensity scales roughly by atomic number, $\sim Z^{1.92}$, where 1.92 is the latest measured exponent and $\mathrm{Z}$ is the average weighted atomic number. This slightly varies from the theoretical expectation of two made initially by Ernest Rutherford, resulting from the loss of electrons due to the geometry and detection efficiencies associated with current detectors. The images and chemical maps can be quantitatively compared to validate the indicated distribution of phases and elements based on the underlying intensity scale, considering all factors for the formation of a highannular dark-field image. At the medium-to-lower scattering angles, the electrons that form bright field images are consistent with an image formed based on elastic scattering within the sample. In this manner, light element sensitivity below atomic number $(Z=7)$, can be simultaneously achieved. By the principle of reciprocity, bright field imaging consistent with conventional phase-contrast TEM images are produced for comparison with the initial inspection of the samples.

\subsubsection{Energy Dispersive Spectroscopic Analysis}

Following imaging and diffraction models, the samples were examined for chemistry and distribution of elements using nanometer-resolved EDS mapping. STEM-based EDS was used to map and quantify distribution of elements using four simultaneously-operated windowless solid state electron drift detectors, forming a total collection of over 1 total steradian. A nanosized beam of $200 \mathrm{kV}$ electrons, with less than $0.90 \mathrm{eV}$ for the Schottky-based field emitter was used to excite characteristic X-ray emission at each pixel resolved within either $256 \times 256$ or $512 \times 512$ pixel area. Pending magnification, each pixel was further calibrated. The distribution of $\mathrm{Al}, \mathrm{O}, \mathrm{Mg}, \mathrm{Fe}, \mathrm{Pt}$, and $\mathrm{Cr}$ was mapped based on zero 
absorption factor calculation, considering weighted and calibrated k-factors for quantifying the chemical elements in terms of relative net counts, as atomic percentages at each pixel. Qualitative and full quantitative analysis is therefore reported in detail, allowing for a detailed understanding of the relative compositions and phases to within the limit of $180 \mathrm{ppm}$ for the setup specified. Based on the resulting analysis and data generated, detailed mapping and subsequent integration into statistically scrutinized profiles was performed using Matlab and MIPAR software to determine relative sizing of features, distributions, and statistical significance where appropriate.

\subsubsection{Image Processing}

Quantitative results on the sample including sizing and distributions of features are important to estimating fuel performance in long-term dry storage. Several imaging modalities of the Talos F200s produced information on the distribution size, and physical size of features contained within each image and as a collected sample. Collected images span more than hundreds of individual images. Each image was segmented and processed into binary images utilizing commercial software, including MIPAR ${ }^{1}$ and $M_{a t l a b^{2}}$. This data has been further reformatted and categorized to reflect variables, such as time, position, irradiation, and temperature profiling with grain size. Managing and analyzing images and data in this fashion further required the utilization of GPU and CPU-assisted parallel-based programming to stochastically sample, track, and measure features of interest (i.e., layers, cracks, voids, and pores), related quantities (i.e., number, size, length, spacing), and their weighted distributions in binary image transforms.

Routines for handling the data and constructing distributions have been developed using standard Matlab libraries and functions to provide an analytical framework and capability to parse datasets into physical quantities of interest, including (1) average sizing, (2) spacing using nearest neighbor analysis, (3) shape, and (4) density.

\subsubsection{Crystallographic and Phase Analysis}

The Wefers database of known crystallographic phases of aluminum oxides and hydrogenated oxides was used as a primary reference. ${ }^{3}$ Utilizing the crystallographic data from Tables 2.2, 3.2 and 4.3 in Wefers, individually constructed diffraction profiles, tables of allowed reflections and atomic spacing were calculated using the commercial software CrystalMaker and CrystalDiffract. After constructing each diffraction profile, the experimentally-collected diffraction patterns were azimuthally integrated into a single one-dimensional profile of the specific phase of the material. Determining the phase for each pattern was based on comparing peak-to-peak location correspondence with the reference data. With a higher than $90 \%$ confidence, individual crystallographic family assignments were subsequently made to each crystallographic-allowed Bragg spot reflection resolved in the diffraction pattern based on the identified phase.

Upon a first level validation of the crystallographic structure, a trained machine learning (ML)-based convolutional neural network $(\mathrm{CNN})$ for crystallographic identification was utilized to further assess the calculations mentioned above. Providing a first, second, and third level means of validation, the trained CNN classified over a one million different crystal structures to over $90 \%$ accuracy, where random and pseudo-random results are less than $10 \% .{ }^{4}$ Confidence in the reported phase and crystallographic presence is therefore robustly defined with alternate and cross-validated methods of analysis, providing additional insight into the crystal chemistry from collected diffraction data reported amongst these specimens. 


\subsection{Detailed Materials Analysis}

\subsubsection{Sample Morphology}

Cross-sections from the nipped specimens are reported in Figure 33 using SEM. In general, the two cross sections in Figure 33a and $\mathrm{b}$ report the overall liberated specimens are layered as follows:

carbonaceous surface layer, surface aluminum oxide, and polycrystalline aluminum. The specific layering is beyond imaging resolution for SEM. For the specific layer structures and chemistries, we will report on using high-resolution electron microscopy.

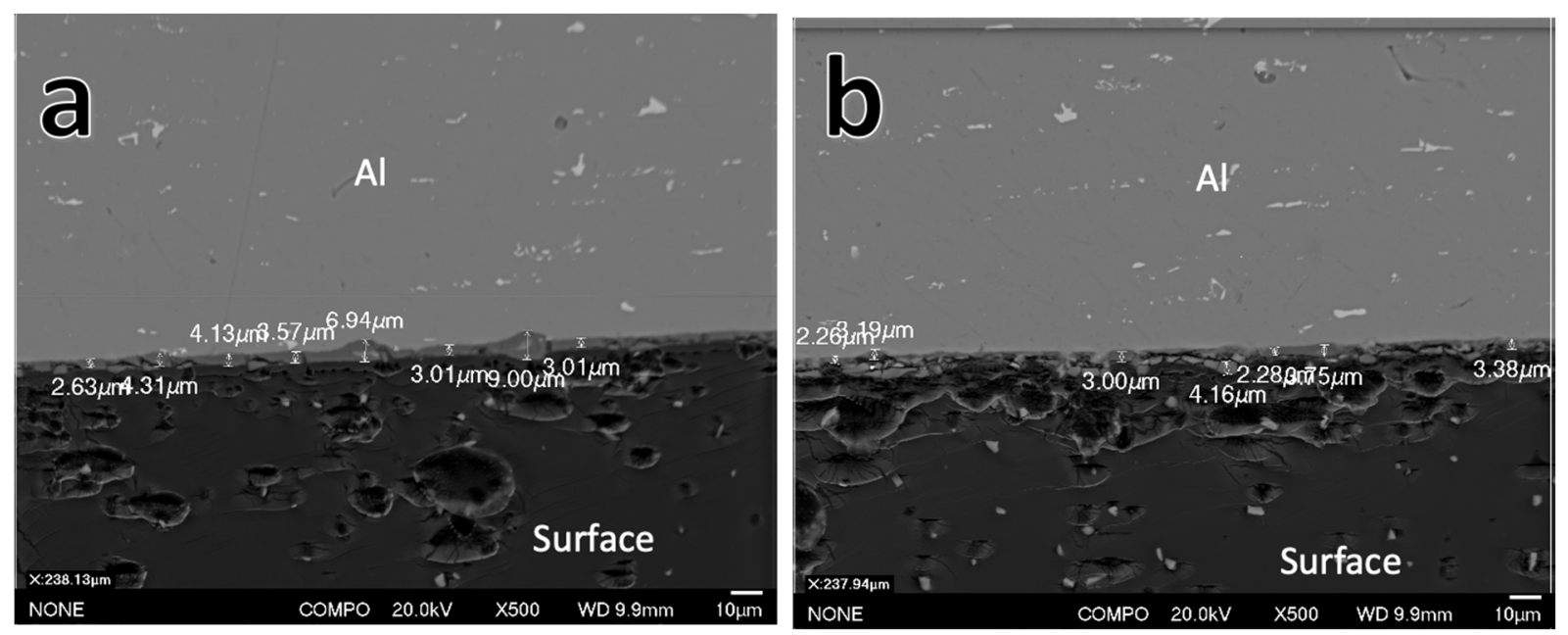

Figure 33. Overall Sample Morphology. $(a, b)$ Cross-section sample areas for two separate regions, showing the overall oxide surface layering that forms on the Al base layer.

\subsection{Crystal Chemistry}

$\mathrm{XRD}$ was performed to provide a more comprehensive understanding of the material. Figure $34 \mathrm{a}$ is the collected diffraction profile. Based on the closest identifiable structure, Figure $34 \mathrm{~b}$ is a common analysis that suggested that there was likely a typical cubic aluminum and a possible Boehmite $(\mathrm{Al} \mathrm{O}(\mathrm{O}$ $\mathrm{H})$ ) orthorhombic $(\mathrm{Cmcm})$ type phase, where the exact chemistry of this orthorhombic phase was unclear. The analysis was based on near matches to known phases.

Because the data were largely inconclusive when compared to known phases, a peak-to-peak correspondence with all known materials was computed using the latest trained neural network model for crystallography, reported by Aguiar et al. in Figure 34. ${ }^{4,5}$ Based on the results of combining multiple peaks and combinations across all known crystallographic chemistries, the cubic structure is indexed at the highest significance amongst the crystal families. Within cubic, there is a high probability reported in Figure $34 \mathrm{c}$ to classify within cubic to space group Fm3m, \#225. Al and $\mathrm{Mg}_{2} \mathrm{Si}$ equally structure in facecentered cubic.

In the second rank is the hexagonal crystal family, reported in Figure 34d, where space group $\mathrm{P} 63 / \mathrm{mmc}$ is found. Correspondence between the two well-known, reported, and overlapping phases for Al is consistent between the predictions and our understanding associated with Al.

At the third rank, the orthorhombic family is reported in Figure 34e, where unlike the previous analysis, the highest ranking space group was Pmmn. The preference for Pmmn, followed by Pcab, Immm, and $\mathrm{CmCm}$ is consistent with the presence for orthorhombic structured $\mathrm{AlOOH}$. Distinguishing between diaspore-structured $\mathrm{AlOOH}$ in space group Pbnm, \#62 from boehmite structured in CmCm, \#63 is challenged in the analysis. Based on the model, boehmite is predicted, while diaspore Pbnm was not, 
since it represents a significantly lower probability. To accompany reference crystallography data previously and currently reported for the multiple phases, the aluminum forms should be primarily in the orthorhombic structure, as boehmite.
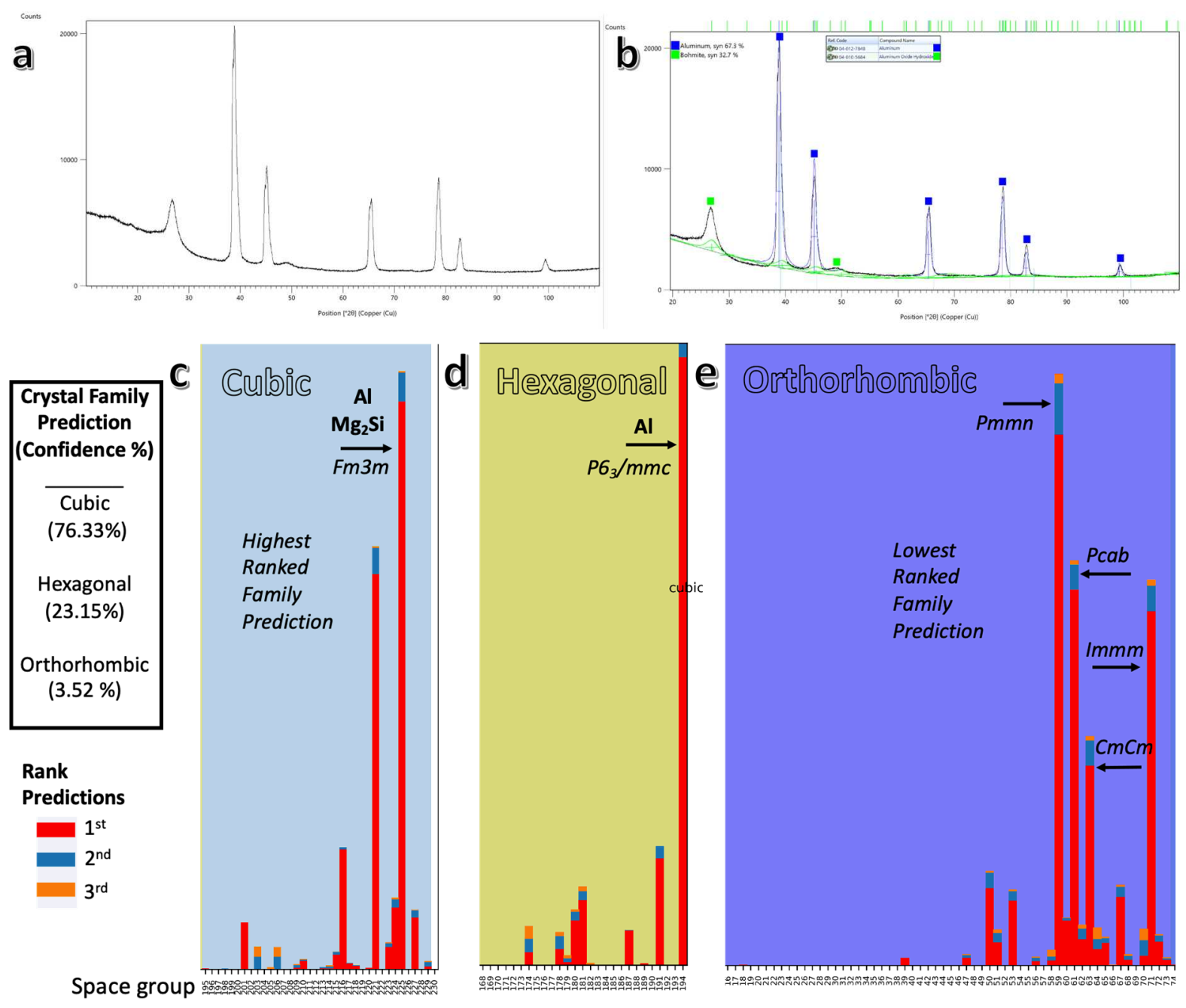

Figure 34. Crystal chemistry phase identification. (a) Experimental XRD diffraction profile from A1 cladding. (b) Analyzed diffraction profile based on known materials. Utilizing the latest trained crystal chemistry model, the same diffraction profile shows a high probability for (c) cubic followed by (d) hexagonal and (e) orthorhombic structure. Note within each of these crystal families reported the distribution is shown over space group.

\subsection{Material Chemistry and Structure}

Resolving the material chemistry over specific regions of each sample, we utilized the unique combination of high-resolution STEM imaging and nanometer-resolved EDS to report on the material chemistry and distribution over specific sample regions. Considering simultaneous bright and dark-field imaging modalities, each show the relative distinct atomic and phase contrast associated within the sample. Imaging inside the STEM reveals elementally-derived changes in contrast and highlight the chemistry changes at the nanometer scale. Over the next sections, two electron transparent lamellae samples are compared highlighting similar structure and chemistries from aged Al cladding from the ATR. 


\subsubsection{STEM Imaging and Mapping for Post A (Sample 3)}

Over the first sample, the distinct morphology and chemical distribution were resolved in the subsequent STEM imaging and EDS data. STEM-based EDS images were collected with better than 10 nanometer resolution, and were subsequently quantified into chemical maps for aluminum, oxygen, magnesium, silicon, iron and chromium. Each chemical map is weighted on relative scale, where net counts are reported as function of the color intensity, respective of each map.

Based on the imaging and chemical maps, there are few observations that can be reported based on the data:

- Surface grain structure differences. In alignment with potential prior surface preparation of the cladding, there is a significant difference in grain size from the surface to the Al base layer reported in detail for Figure 35 and Figure 36.

- Distinct Al-O profile. Based on the variation in the resolved $\mathrm{O}$ and $\mathrm{Al}$ near the surface, there is a build in Figure 37 of oxygen at oxide and surface layer interface. This suggests a bias for oxygen to prefer the interface and form an interaction layer.

- Minor elemental diffusion and precipitation. There are kinetics that drive diffusion of minority elements and defects as a result being exposed to an aqueous nuclear reactor environment. Based on the STEM EDS chemical maps in Figure 37, there is a preference for $\mathrm{Mg}$ and $\mathrm{Si}$ to build up at intergranular grain boundaries. In particular, at high resolution centered on a single grain in Figure 44, there is significant buildup of these species at grain boundary junctions reported in Figure 39, where there is known to be void space. The behavior does not suggest any differences in grainboundary orientation, or at least any that is resolvable from these initial maps.

The formation for $\mathrm{Mg} 2 \mathrm{Si}$ is proposed in those regions, where there is both $\mathrm{Mg}$ and $\mathrm{Si}$. Based on the elemental segregation and precipitation, there is a concern that the formation of these clusters impacts the mechanical integrity associated with the surface coating on the aluminum cladding. Elementally, the presence is elevated to easily detectable limits.
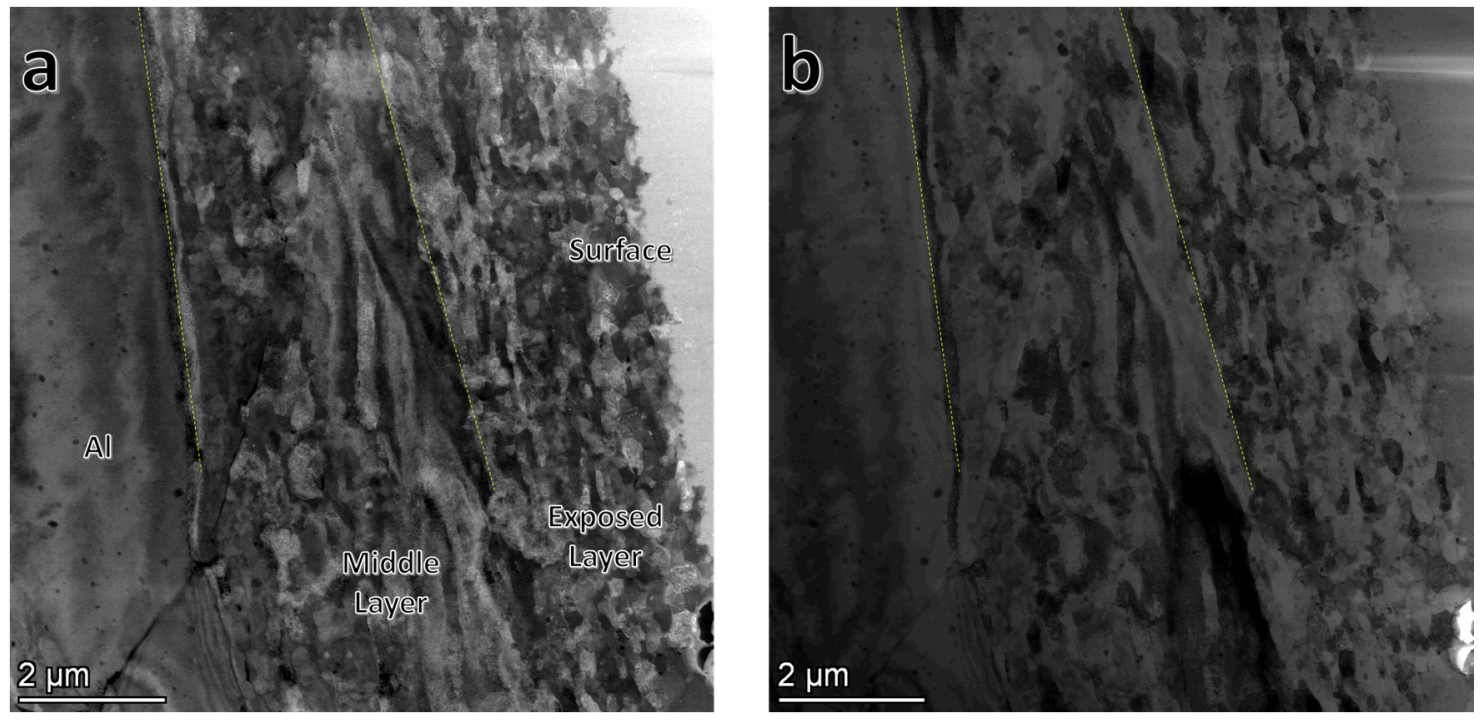

Figure 35. STEM annular bright and dark field imaging identifying regions of interest. (a) Bright and (b) dark field cross-sectional imaging. The exposed surface layering, grain size distribution, and overall morphology are categorized as the surface, exposed layer, middle layer, and Al base metal. 

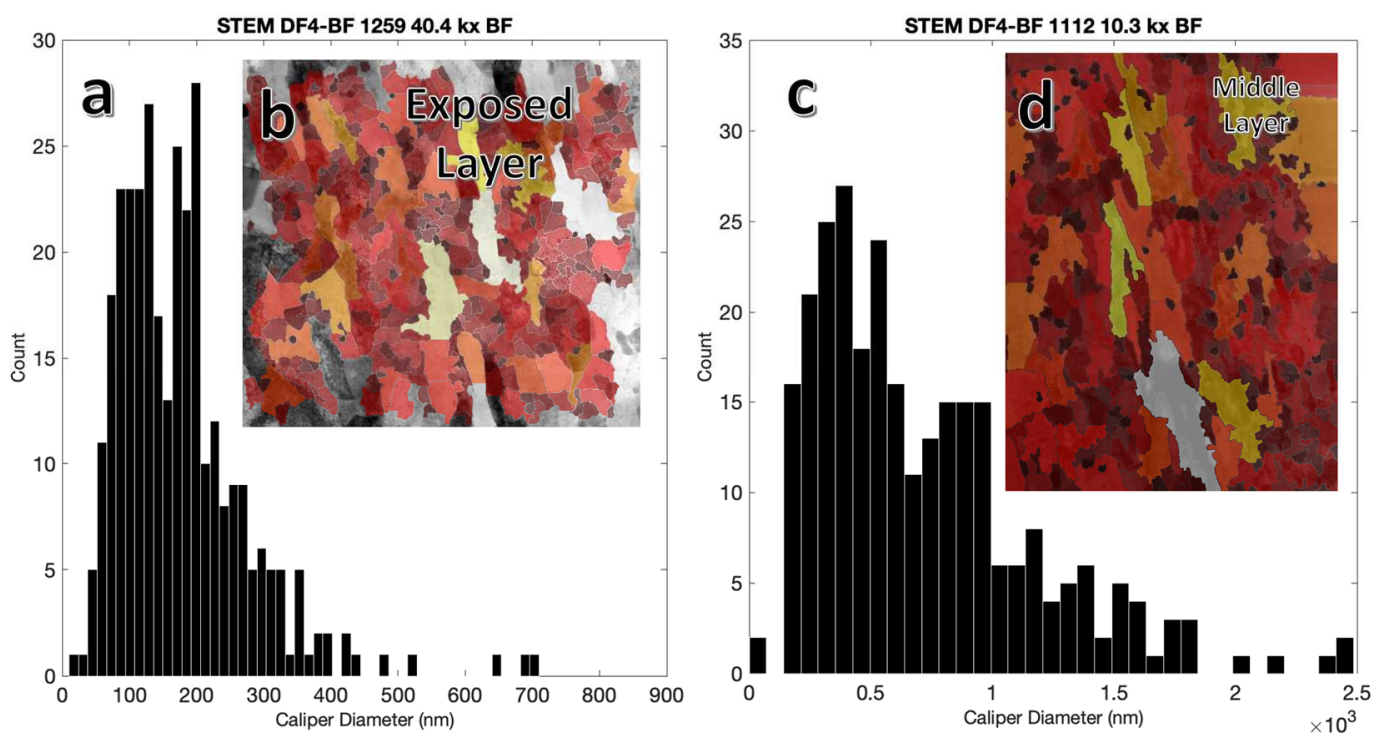

Figure 36. Comparing grain size between the exposed and middle layer. (a) Grain size distribution for the exposed layer reports a highly nanocrystalline grain size with grains measuring less than $500 \mathrm{~nm}$ based on image segmentation of the (b) bright field STEM image. (c) Comparing to the middle layer (d) the distribution is significantly larger with on average grain size centered at 500 nm with tails to over $2 \mu \mathrm{m}$.
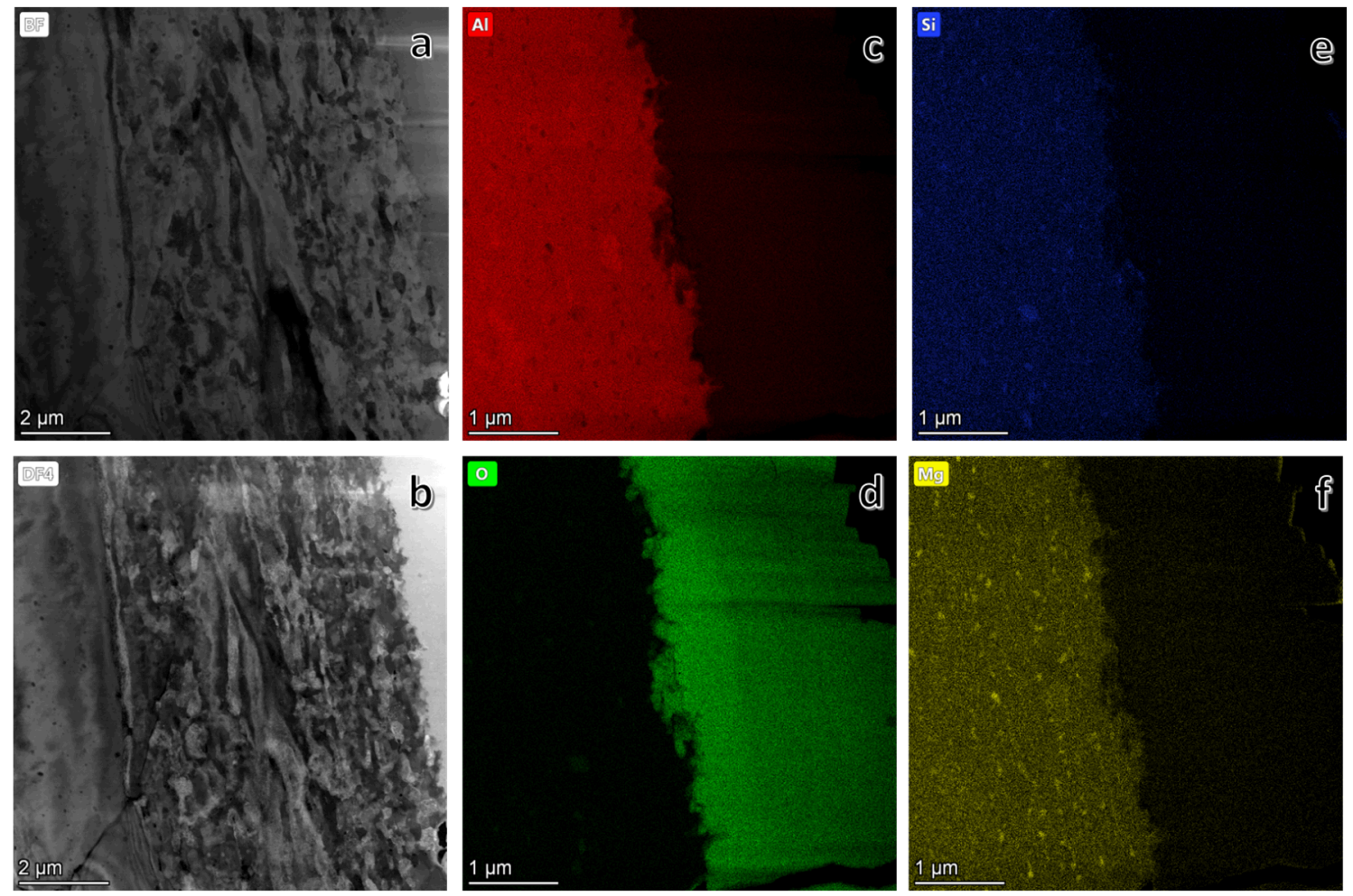

Figure 37. STEM-based imaging and EDS imaging. (a) Overview of STEM bright and (b) dark field image, where EDS mapping for (c) aluminum, (d) oxygen, (e) silicon, and (f) magnesium was mapped with better than $10 \mathrm{~nm}$ per pixel resolution. 

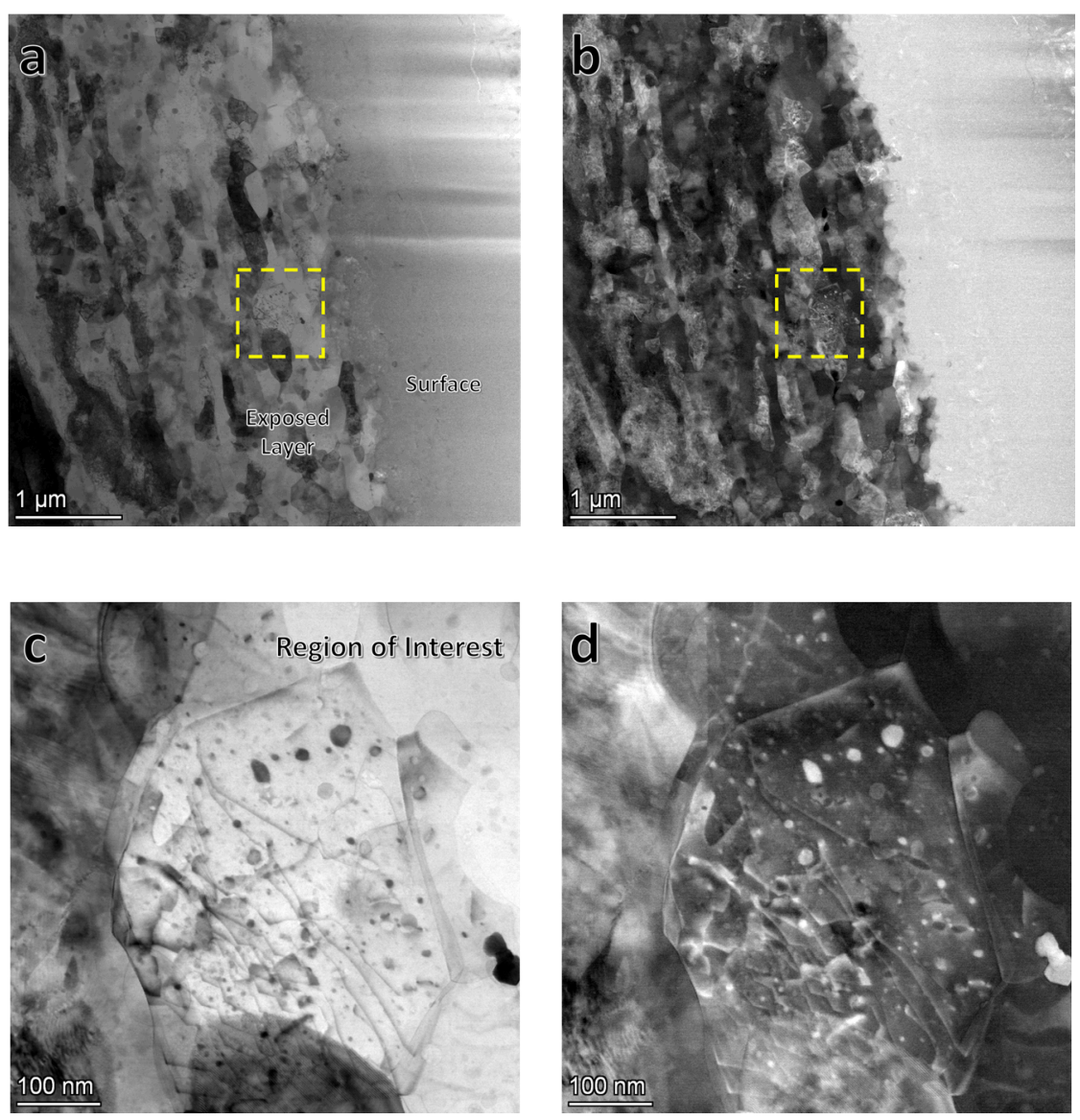

Figure 38. STEM-based imaging to the sub-nanometer scale. (a) Overview STEM bright and (b) dark field images where a selective grain shows additional defects at the nanoscale. (c) Increasing the magnification to the sub- $100 \mathrm{~nm}$ scale highlights a high degree of potential precipitation and texturing, including the presence of loops, line defects, and dislocations. 

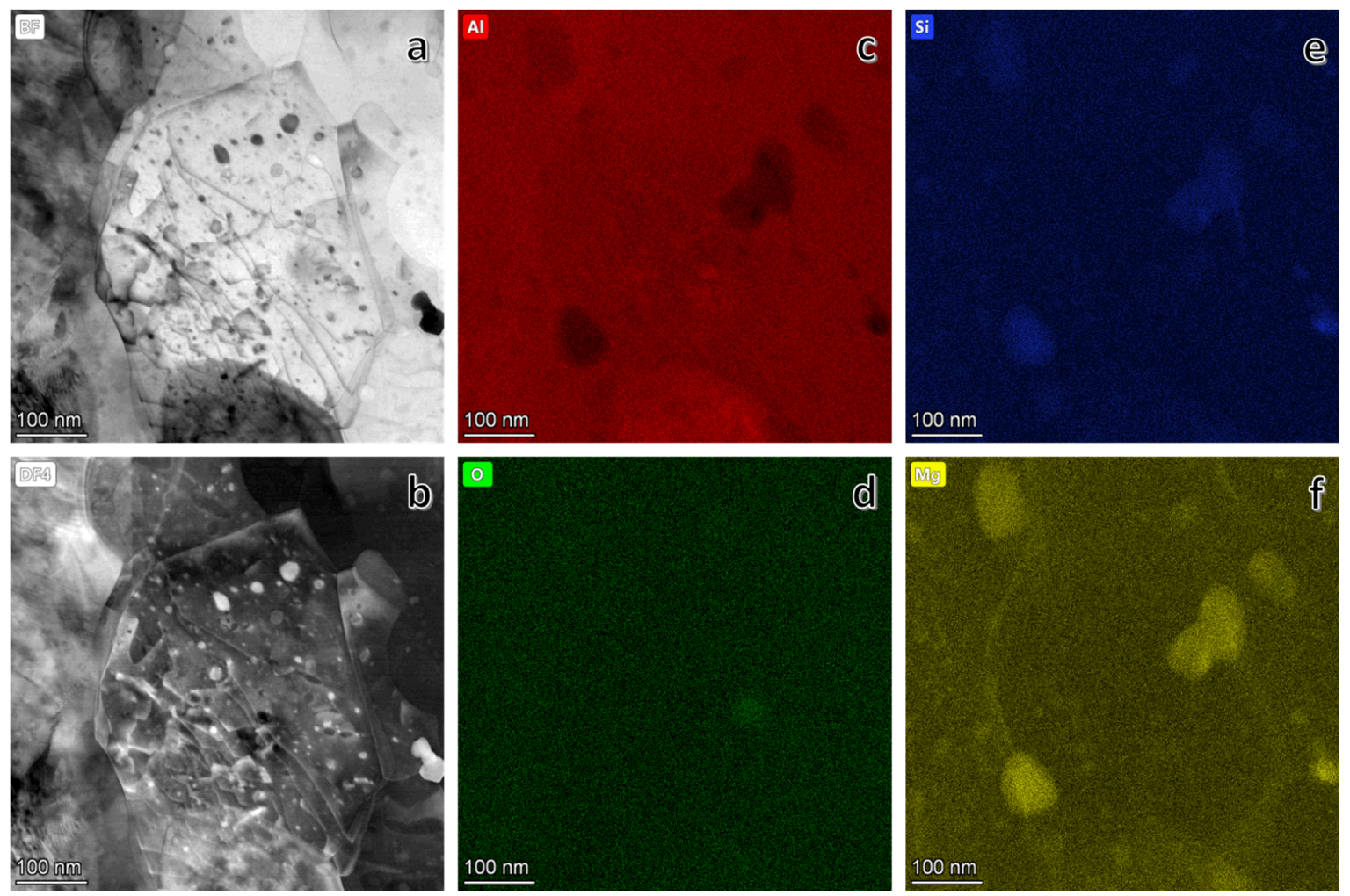

Figure 39. STEM-based imaging and EDS mapping for selective grain. (a) Overview of STEM bright and (b) dark field image, where EDS mapping for (c) aluminum, (d) oxygen, (e) silicon, and (f) magnesium over the grain. Note the grain was mapped with no better than $5 \mathrm{~nm}$ per pixel resolution.

\subsubsection{STEM Imaging and Mapping for Post C (Sample 9)}

Affirming the observations made over the first specimen, the same morphology and chemical distribution was resolved using STEM imaging and EDS.

Based on the imaging and chemical maps, there are a few observations that can be reported to further substantiate the observed structure and chemistry associated with the previous sample:

- Surface grain structure differences. Similar differences in grain size and structure are revealed in Figure 40, where the middle layer is thinner, but still present. This highlights potential variability in the thickness profile associated each layer.

- Al-O surface profile. Based on Figure 41, there is the same measurable build for oxygen at the surface to exposed layer interface. This corroborates a preference for oxygen to prefer bonding with Al to form an enriched oxide interaction layer.

- Elemental diffusion and precipitation beyond Mg and Si. Based on the STEM EDS chemical maps in Figure 41 and Figure 43, there is the same preference for $\mathrm{Mg}$ and Si buildup at grain boundaries and interiors. This is further corroborated in Figure 44 where there is significant species buildup at grain-boundary junctions that distinctly shows the additional presence of $\mathrm{Si}-\mathrm{Pt}$ and $\mathrm{Fe}-\mathrm{Cr}$ $\mathrm{O}$ not observed in the prior specimen. This corroborates a point that additional impurities became incorporated into the microstructure over the lifetime of the cladding. Additional insight into their formation is required to corroborate their origins. Based on observing elemental segregation and precipitation, there is a concern that the formation of these same clusters can impact the mechanical integrity associated with cladding. 

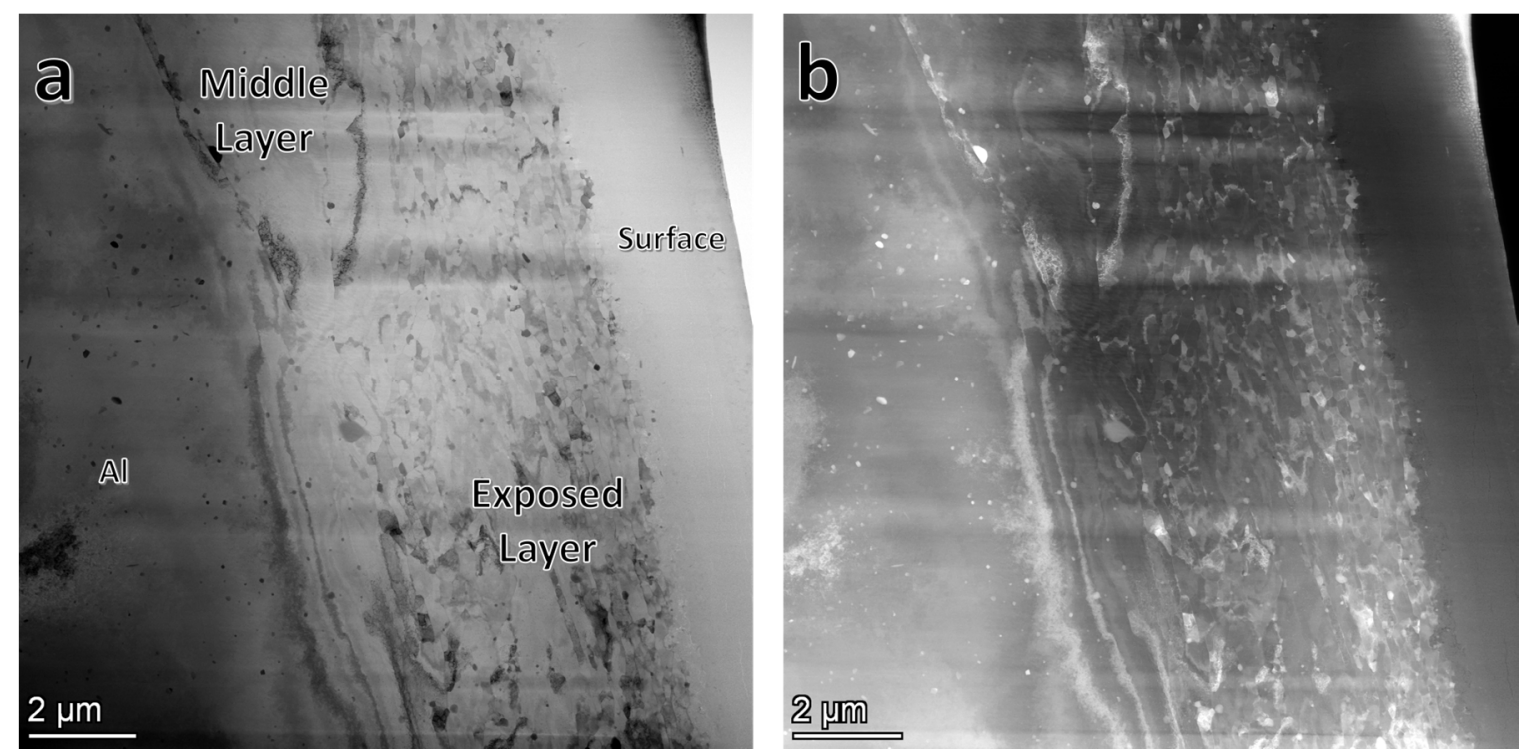

Figure 40. STEM annular bright and dark field imaging identifying regions of interest. (a) Bright and (b) dark field cross-sectional imaging. The exposed surface layering, grain size distribution, and overall morphology are categorized as the surface, exposed layer, middle layer, and Al base metal.
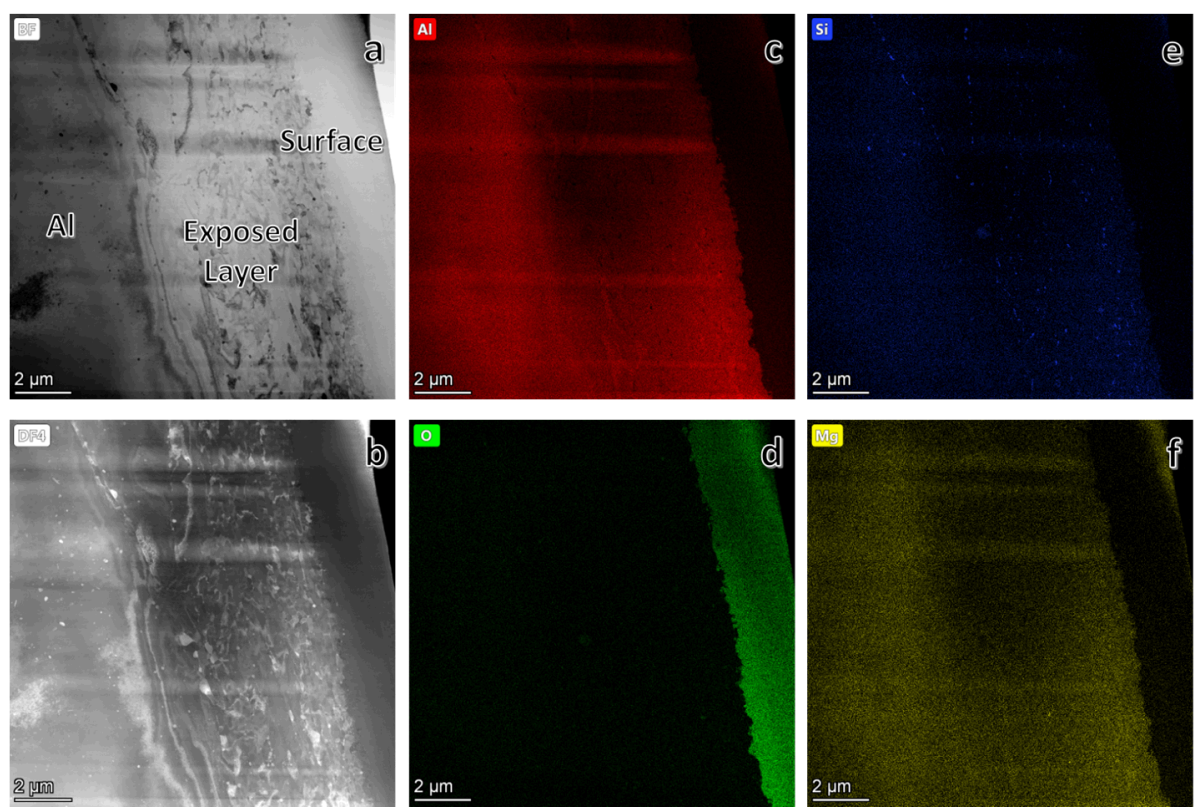

Figure 41. STEM based imaging and EDS imaging. (a) Overview of STEM bright and (b) dark field image, where EDS mapping for (c) aluminum, (d) oxygen, (e) silicon, and (f) magnesium was mapped with better than $10 \mathrm{~nm}$ per pixel resolution. 

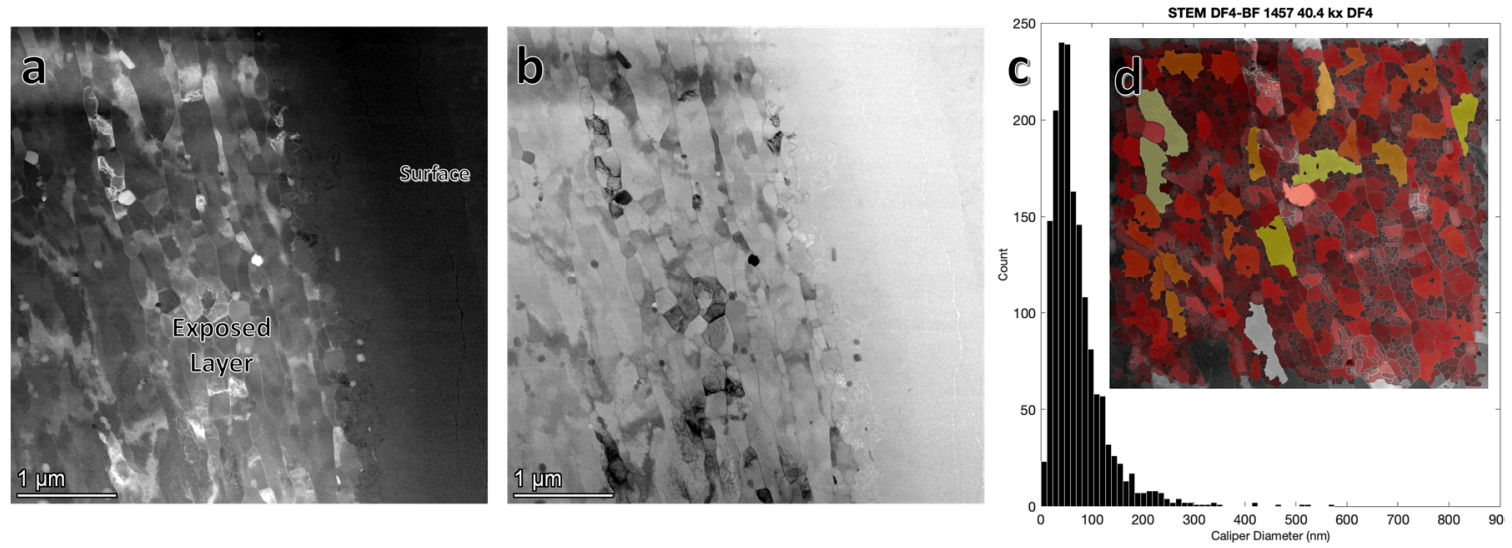

Figure 42. STEM annular bright and dark field imaging identifying regions of interest. (a) Dark and (b) bright field cross-sectional imaging centered over the exposed surface layer. (c) Based on underlying grain size in the exposed surface layer, grains measuring less than $100 \mathrm{~nm}$ shown in (d) are consistent throughout.
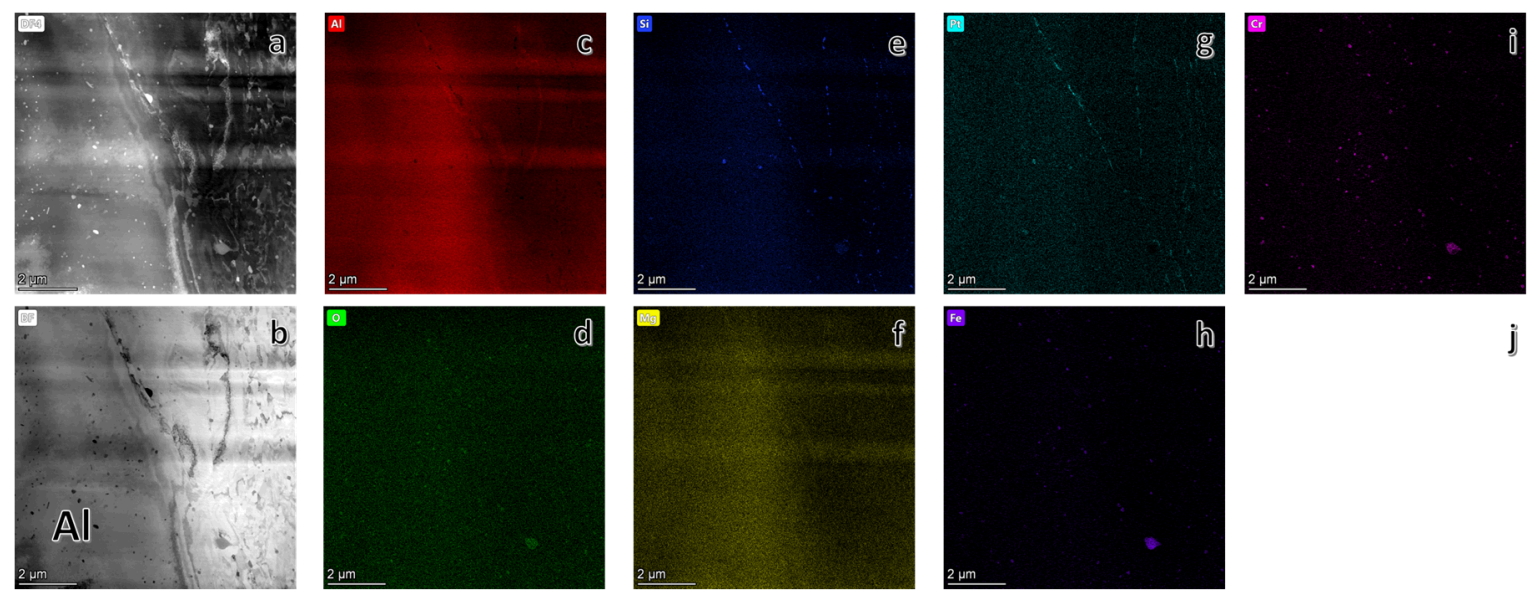

j

Figure 43. STEM based imaging and EDS mapping over the exposed, middle and Al base metals. (a) Overview of STEM bright and (b) dark field image, where EDS mapping for (c) aluminum, (d) oxygen, (e) silicon, (f) magnesium, (g) platinum, (h) iron, and (i) chromium reveals the overall distribution. 

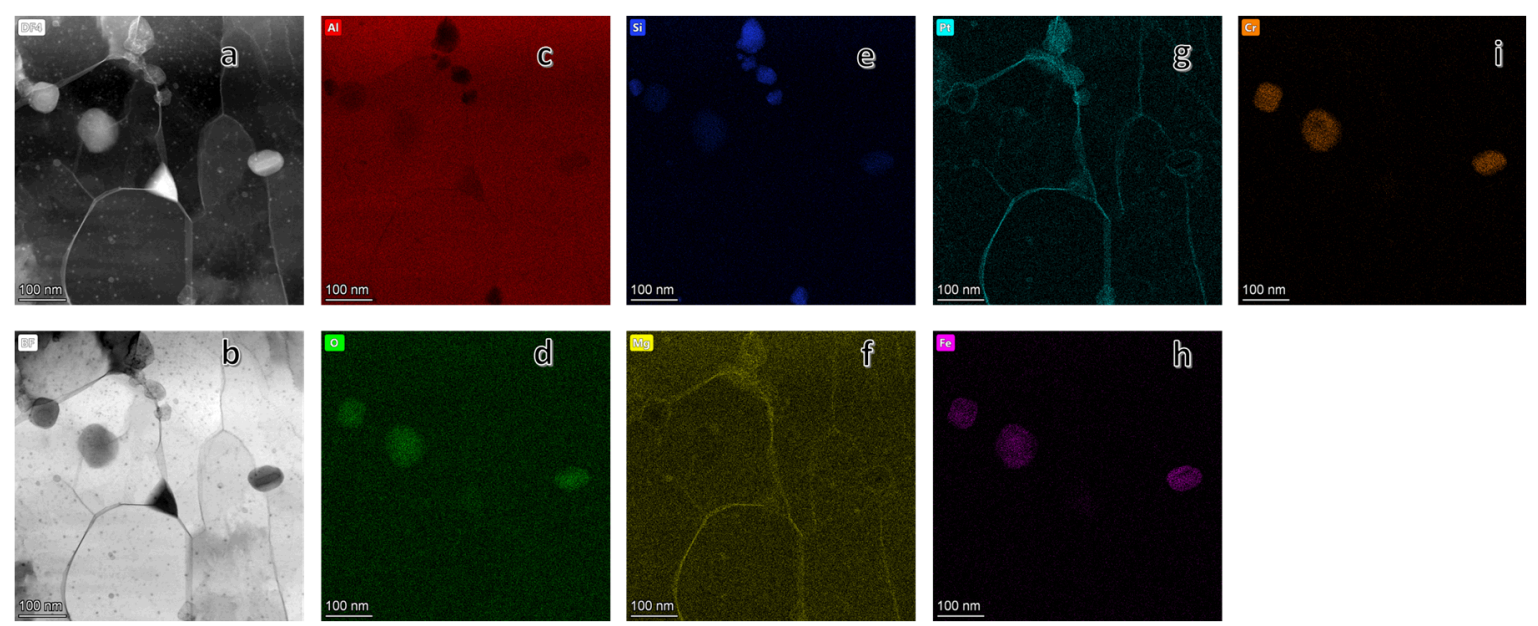

Figure 44. STEM-based imaging and EDS over region 2. (a) Overview of STEM high-angle annular dark field of region 1, (b) EDS mapping, (c) oxygen, (d) carbon, (e) aluminum, and (f) chromium mapped with $1 \mathrm{~nm}$ pixel resolution. (g) Overlapping element maps superimposed over the area.

This section summarizes the techniques and processes developed for measuring the distribution of phases and underlying microstructure for two aluminum samples taken from long-term wet and dry stored ATR fuel. Defining the material chemistry, distributions, and methods for reporting these materials provides a basis for tracking changes that may occur in long-term dry storage. 


\section{CONCLUSIONS}

The irradiated samples analyzed in this task indicate that there is minimal change in the oxide and associated hydration of the surface of the aluminum ATR fuel elements that can be attributed to dry storage. The oxide layer ranges from 1 to 4 microns in thickness, which is consistent with the 2- to 6micron thickness of boehmite that was established by autoclave treatment prior to irradiation. The results from Thermogravimetric Analysis show the greatest percentage-level mass loss between 100 and $300^{\circ} \mathrm{C}$, which suggests that either the $\left(100^{\circ} \mathrm{C}\right)$ conditioning done when the fuel was moved to dry storage did not fully remove surface hydration, or that the surfaces had adsorbed water from the vapor in ambient air inside the storage canister in the intervening 22 years.

The XRD and TEM analyses indicate that the oxide phase present is primarily boehmite, which suggests that the passivation performed prior to irradiation has retained its protective effectiveness. Assuming comparable samples can be taken at a future time, using TEM or STEM-based imaging, diffraction, and spectroscopy, changes in underlying microstructure can be tracked in detail to determine if additional clusters, precipitates, and oxides have formed.

The fuel elements sampled here were stored in CPP-603 Basins for 12 years, in water with nominal chloride concentrations of $80 \mathrm{ppm}$. An unusual measure of adding calcium nitrate to maintain a nitratechloride balance was employed to minimize the chloride attack on aluminum. During the wet-to-dry transfer operations, there were indications of growth of some exceptional corrosion product, but they appeared to be localized to areas that may have had the initial boehmite layer damaged as a result of abrasion against fuel racks. This was manifested in the form of puffy white growths at exposed edges and points where the applied native oxide had been disturbed. Visual examination of the fuel elements sampled shows the same light-colored growths at points where friction tools were inserted and where the endboxes were cut off.

Future analysis of the potential changes in underlying microstructure may serve as an additional set of data for ultimately predicting the performance life of aging aluminum cladding in ATR spent fuel. Although no significant changes in the fuel characteristics were observed at this time, it would be prudent to revisit this system to confirm the stored fuel condition both of this specific sample set and a broader population to assure that no unexpected phenomena affect its integrity. Further inspection could be justified to ensure the safety of the system prior to final disposition. It may be possible that the non-native oxide growths have an undue water retention that could affect the potential for pressurization in a sealed dry canister system. These breaks in the boehmite layer may also represent locations with increased potential for corrosive attack in the event of storage system chemistry changes, with resulting conversion of metal to oxides or salts and hydrogen production. 


\section{ACKNOWLEDGEMENTS}

We acknowledge each of the co-authors contributed to the work equally. Alex Winston performed the SEM and optical sample preparation. Scott Middlemas performed the TGA analysis. Jatuporn Burns performed the FIB lamella sectioning. Jeff Agiuar analyzed all TEM data and drafted the TEM/STEM section of this report. Xiang Liu performed all high-resolution transmission electron microsopy. Kevin Tolman collected and did initial analysis of the XRD data. 


\section{References}

1. Sosa, J. M., Huber, D. E., Welk, B. \& Fraser, H. L. Development and application of MIPAR ${ }^{\mathrm{TM}}$ : a novel software package for two-and three-dimensional microstructural characterization. Integrating Materials and Manufacturing Innovation 3, 10 (2014).

2. MATLAB. version 7.10.0 (R2010a). (The Mathworks Inc., 2010).

3. Wefers, Karl. \& Misra, Chanakya. Oxides and hydroxides of aluminum. (Alcoa Research Laboratories, 1987).

4. Aguiar, J. A., Gong, Matthew L, Unocic, R. R., Tasdizen, T. \& Miller, B. D. Decoding Crystallography from High-Resolution Electron Imaging and Diffraction Datasets with Deep Learning. Science Advances aaw1949 (2019).

5. Aguiar, J. A., Gong, M. L. \& Tasdizen, T. Crystallographic prediction from diffraction and chemistry data for higher throughput classification using machine learning. Computational Materials Science 173, 109409 (2020).

6. Makenas, B.J. editor, Analysis of Internal Sludge and Cladding Coatings from N-Reactor Fuel Stored in Hanford K Basins, HNF-3589, June 1999 
